\title{
Extracting the social relevance of artefact distribution in Roman military forts
}

\section{Penelope M. Allison, Andrew S. Fairbairn, Steven J.R. Ellis and Christopher W. Blackall}

School of Archaeology and Anthropology, Australian National University, ACT 0200, Australia. tel: +61-2-61252942, fax: +61-2-612-52711, email: pim.allison@anu.edu.au

Cite this as: Allison, P.M., Fairbairn, A.S., Ellis, S.J.R. and Blackall, C.W. 2005 Extracting the social relevance of artefact distribution in Roman military forts, Internet Archaeology 17. https://doi.org/10.11141/ia.17.4

\section{Summary}

'Engendering Roman Spaces' is a research project concerned with using artefact assemblage analyses to better understand spatial and gender relationships in the early Roman Empire and to produce more engendered perspectives of Roman society.

This paper discusses the methodology and analyses being used in this project to investigate social behaviour within Roman military forts and fortresses of the 1st and 2nd centuries CE through analyses of the spatial distribution of artefacts at these sites. The processes involved include digitising previously published maps and artefact catalogues from Roman military sites to create searchable databases and GIS maps. They also include the classification of the artefacts according to a number of functional and gender-associated categories (e.g. combat equipment, male and female dress, toilet etc.) so that the spatial distributions of the relevant activities can be plotted. This data is then used to interpret the spatial relationships of these activities and the people involved in them.

The double legionary fortress of Vetera I, on the Lower Rhine, has been used to exemplify these processes. This fortress was excavated in the early 20th century and the artefacts were comprehensively published in 1995 (N. Hanel, Vetera I: Die Funde aus den römischen Lagern auf dem Fürstenberg bei Xanten. Rheinische Ausgrabungen 35, Rheinland-Verlag, Cologne and Dr Rudolf Halbert, Bonn, 1995). The paper includes descriptions of the methods and software employed in the digitisation of relevant material from these volumes, the formation of relational databases, and the importation of this data and of site maps into a GIS programme. To illustrate these processes and to 
present some of the results, the paper also includes a number of examples of the analyses carried out, together with the maps of these analyses.

\section{ENGENDERING ROMAN SPACES PROJECT}

Go to article Table of Contents

\section{Features}

- This article will particularly appeal to: those interested in Roman military forts, spatial analysis in archaeology.

- Key Features: Downloadable sample data

- Keywords: Roman; Military; Fort; Spatial relationship; gender; Vetera; GIS; Distribution

\section{NEXT CONTENTS HOME COMMENTS}

(c) Internet Archaeology URL: http://intarch.ac.uk/journal/issue17/allison index.html Last updated: Mon Jan 172005 


\section{Extracting the social relevance of artefact distribution in Roman military forts}

\section{Penelope M. Allison, Andrew S. Fairbairn, Steven J.R. Ellis and Christopher W. Blackall}

\section{Table of Contents}

- Summary.

- Table of Contents

- List of Illustrations

Section 1: Project Summary (by P.M. Allison)

Sections 2-4: Background and Approach

Section 2: Introduction to studies of social life in Roman military space (by P.M. Allison)

- 2.1 Introduction to archaeological research

- 2.2 Introduction to textual and epigraphical information

- 2.3 Artefact studies at Roman military sites

Section 3: Introduction to artefact assemblage studies in Roman archaeolog.y (by P.M. Allison)

- 3.1 Artefact assemblage studies in Roman domestic space

- 3.2 Categorising artefacts at Roman military sites

Section 4: The Roman fortress of Vetera (by P.M. Allison)

Sections 5-7: Methodology and Technical Procedures

Section 5: Re-appraising excavation data (by P.M. Allison)

Section 6: Digitising_published site plans (by C.W. Blackall and S.J.R. Ellis)

- 6.1 Introduction to procedures

- 6.2 Capturing the plans

- 6.3 Digitising the plans 
Section 7: Digitising_and formatting_artefact catalogues (by A.S. Fairbairn)

- 7.1 Capturing data from printed catalogues

- 7.2 Preparing_catalogue data for GIS

$\circ 7.3$ Creating distribution plots of people and their activities

Section 8: Analyses of the Distribution of People and Activities (by P.M. Allison)

- 8.1 Toilet activities

- 8.2 Dress

- 8.3 Cloth-production

- 8.4 Gaming

- 8.5 Writing

- 8.6 Gender and age

- 8.7 Overall interpretations (with statistical analyses by A.S. Fairbairn)

\section{Sections 9-12: Data, Reference Materials and Acknowledgements}

Section 9: Catalogues and GIS maps (by A.S. Fairbairn, S.J.R. Ellis, with assistance from P.A. Faulkner)

- 9.1: Sample from Vetera I artefact catalogue

- 9.1a Excel spreadsheet

- 9.1b Tab delimited files

- Vetera artefact data (tab delimited text file)

- Vetera trench XY coordinates (tab delimited text file)

- 9.2 Queried Access database formatted from Excel spreadsheet (Access database download may not work on some systems)

- 9.3 GIS project.

Following a review of legacy systems and in line with broader ADS practice, the interactive map element of this article has been decommissioned. The full underlying set of data is still available for download from the digital archive.

- 9.4 ArcIMS User Help File

Section 10: Glossary

Section 11: Bibliography

Section 12: Acknowledgements 


\section{back forward contents home}

\section{List of Illustrations}

Figure 1: Reconstructed entrance of the Roman fort at Saalburg (photo P. M. Allison)

Figure 2: Map of Rhine and Danube regions showing location of Vetera I (drawing P. A.

Faulkner)

Figure 3: Gerulata castellum in Slovakia (photo P. M. Allison)

Figure 4: Idealised plan of a fort, with basic buildings (drawing P. A. Faulkner)

Figure 5: Tombstone of Primus, cavalryman and orderly in the Ala Noricum, end 1st century CE. Xanten Regional Museum (photo P. M. Allison)

Figure 6: Aucissa fibula from Casa del Menandro in Pompeii (photo P. M. Allison)

Figure 7: Pendants and other objects (inv nos 4907-10) from a box in room 35, Casa del Menandro in Pompeii (photo P. M. Allison)

Figure 8: Pendant (inv. no. 4869) as part of harness from courtyard 34, Casa del Menandro in Pompeii (photo J. Agee)

Figure 9: Vetera bone stylus J1 (Hanel 1995, pl. 165)

Figure 10: Functional categories

Figure 11: Gender categories

Figure 12: Map showing Xanten, Colonia Ulpia Traiania and Vetera I (drawing P. A. Faulkner)

Figure 13: Vetera I, Neronian fortress, showing building numbers, kilns and fortifications of earlier fortresses (by P.A. Faulkner)

Figure 14: Workflows and software (drawing A. S. Fairbairn and C. W. Blackall)

Figure 15: Comparison of Bézier Curve and GIS Arc (drawing C. W. Blackall)

Figure 16: Screen dump of part of Excel spread sheet showing data from OCR translation of scanned original catalogue and added data for functional categories and their SQL abbreviations.

Figure 17: Access database relationships page exemplifying how the relational database was structured

Figure 18: Access query output showing the summaries by trench and gender categories with null values (i.e. empty cells)

Figure 19: .dbf table of the summary data with the null values in the gender categories filled with zeros

Figure 20: Sample of GIS view of long trench, Trench 750, through Buildings $\mathrm{P}$ and $\mathrm{F}$

Figure 21: Sample of GIS view of short trenches in Buildings $\mathrm{K}, \mathrm{J}$ and $\mathrm{M}$

Figure 22: Unguentaria (inv. nos 5080A-D) from House I, 10,2, Pompeii (photo J. Agee)

Figure 23: Spiral fibula B16 from Vetera (drawing Hanel 1995, pl. 28) 
Figure 24: Trumpet fibula B44 from Vetera (drawing Hanel 1995, pl. 30)

Figure 25: Kragenfibeln B45 from Vetera (drawing Hanel 1995, pl. 30)

Figure 26: Melon beads (inv. no. 4772), found with human skeleton in room 19 in the Casa del Menandro in Pompeii (photo P. M. Allison)

Figure 27: Gaming counters and die (inv. nos 4254 and 4258) from room 1 in the Casa del Menandro in Pompeii (photo P. Allison)

Figure 28: Correspondence analysis between buildings, with more than 10 artefacts, and gender categories (A. S. Fairbairn)

Figure 29: Correspondence analysis between groups of functionally related buildings and areas, and gender categories (A. S. Fairbairn)

\section{back forward contents home}

(c) Internet Archaeology URL: http://intarch.ac.uk/journal/issue17/4/tof.html Last updated: Mon Apr 42005 


\title{
Extracting the social relevance of artefact distribution in Roman military forts
}

\author{
Penelope M. Allison, Andrew S. Fairbairn, Steven J.R. Ellis and Christopher W. Blackall
}

\section{Section 1: Project Summary}

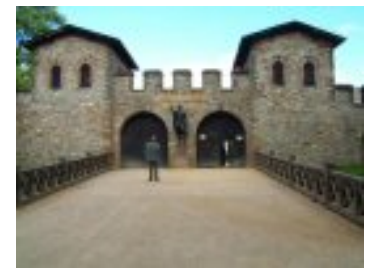

Figure 1: Reconstructed entrance of the Roman fort at Saalburg (photo P. M. Allison)

The objectives of the research project, 'Engendering Roman Spaces', are to contribute to a gendered history of the Roman world through the analysis of its material-cultural remains. This means using archaeological approaches to Roman material culture for a more holistic understanding of the nature and functioning of Roman society in its relationship to space. It also means a closer engagement for studies of Roman space with feminist scholarship, and more critical analyses of the use of ancient written sources to provide frameworks for contextualising gender roles within space. The particular areas with which the project is primarily concerned are domestic space and military space. This article presents a sample of the analyses being carried out for the latter.

The mapping of artefacts and artefact assemblages can facilitate analyses of the distribution of activities at Roman military sites and lead to greater insights into the range of activities which took place there, as well as into the range of people who inhabited these sites. The data from a number of Roman military forts and fortresses are being used to assess the similarities and differences in material-cultural patterning among the various architectural spaces of a site and between sites. That is, comparisons are being made between fort designs and their range of material culture (e.g. cooking pots and personal apparatus). Also, drawing on previous artefact analyses and relevant textual and iconographic material, gender and status markings of these activities are being assessed. Here, this project is taking a critical approach to relationships between artefacts and their contexts and the range of social activities and social actors with which they may have been associated. For example, an important issue is the relationship between the material-cultural patterning and the changing laws which allowed legal marriages for ordinary soldiers at the end of the 2nd century $\underline{\mathrm{CE}}$ (see Section 2.2.1b The marriage of ordinary soldiers).

This article, therefore, discusses approaches used in the 'Engendering Roman Spaces' project to identify artefact distribution and to analyse social behaviour within military fortifications of the 1 st and 2nd centuries $\mathrm{CE}$. It introduces processes for digitising previously published plans and catalogues of artefacts from Roman military sites and for then plotting and analysing the spatial distributions of artefact types according to personnel and functionrelated categories (e.g. male/female, toilet activities, combat equipment, horse equipment). It leads the reader through the processes involved in the digitisation of a published excavation report, the formation of relational databases from its artefact catalogues, and the importation of these data and of site plans into a GIS programme. 


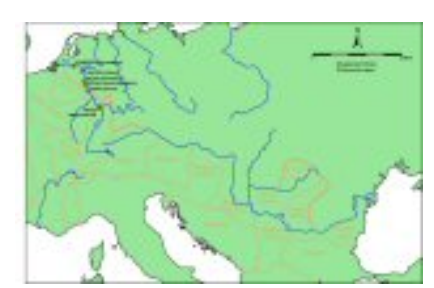

Figure 2: Map of Rhine and Danube regions showing location of Vetera I (drawing P. A. Faulkner)

To demonstrate the process, the Lower Rhine double legionary fortress of Vetera I has been used (Figure 2) (see Section 4). The fortress was excavated in the early 20th century but a catalogue of the excavated artefacts was not published until 1995 (Hanel 1995). A number of interactive examples from this site, in the form of graphically enhanced GIS maps and associated databases, are used to demonstrate the process and the types of analyses. The examples chosen for the purposes of this article focus on categories such as toilet activities, dress, cloth-production, gaming, writing, and gender (see Section 8). The activities discussed are not strictly of military concern but potentially highlight the presence and roles of women and children in the fortress and non-combatant activities of military personnel.

\section{ENGENDERRNG ROMAN SPACES PROJECT}

\section{back forward contents home}

(C) Internet Archaeology URL: http://intarch.ac.uk/journal/issue17/4/summary1.html Last updated: Mon Apr 42005 


\section{back detail forward contents home}

\section{Sections 2-4: Background and Approach}

In comparison with many branches of the archaeological discipline a surprising wealth of remains of settlement sites is available to Roman archaeology, not only from urban sites but also rural sites and, most notably, military sites. In addition, many of these sites can be identified as those discussed by ancient authors. Not only do these sites provide a wealth of structural remains but often they also have large quantities of artefacts, such as pottery and other small finds with relatively good contexts, which can add to our understanding of these sites and to their role in our understanding of social behaviour in the Roman world.

Roman military sites are well known and important strategic components in the expansion and maintenance of the Roman Empire. However, they also constitute the living spaces for a range of different people, not just soldiers and officers but also various service staff and combatants' families.

\section{Section 2: Introduction to studies of social life in Roman military space (by P.M.} Allison)

2.1 Introduction to archaeological research: Archaeological research into Roman military sites has been concerned with relationships of the fort occupants with those in settlements outside. Investigations of relationships within the fort, or fortress, have predominantly relied on the structural remains.

2.2 Introduction to textual and epigraphical information: Textual and epigraphical research has provided more information on the social life of Roman military sites than has the archaeological evidence and, in some recent studies, on the spatial arrangements of social relations.

2.3 Artefact studies at Roman military sites: The most studied classes of artefacts from Roman military installations are military equipment and pottery. More recent studies have highlighted the significance of artefacts such as fibulae (brooches), shoes and gaming items in camp life.

Section 3: Introduction to artefact assemblages studies in Roman archaeology (by P.M. Allison)

3.1 Artefact assemblage studies in Roman domestic space: My research into the distribution of artefacts in Pompeian houses provides the background for this investigation of artefact distribution within military fortifications.

3.2 Categorising artefacts at Roman military sites: Ascribing functional and gender categories to artefacts is problematic and this study attempts to deal with this.

\section{Section 4: The Roman Fortress of Vetera I (by P.M. Allison)}

The double legionary fortress of Vetera I was occupied from c. $13 \mathrm{BCE}$ to 69/70 CE. The final stone-built fortress was probably built only a few years before its demise. It was excavated in the early 20th century and its artefact catalogue published in 1995.

\section{back detail forward contents home}




\subsection{Introduction to archaeological research}

\subsubsection{A male domain}

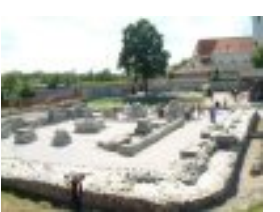

Figure 3: Gerulata castellum in Slovakia (photo P. M. Allison)

In the past, studies of Roman military bases have concentrated on these sites as part of a male domain, as combat units at the edge of the civilised world (e.g. Birley et al. 1974; Haupt and Horn 1977; Unz 1986). The Roman army has been viewed as a fighting machine (see Haynes 1999, 7; James 2002, 21), and the archaeology of Roman military forts has been concerned principally with the evidence these excavated sites provide for strategic military constructions and for Roman power. In this regard, Roman military archaeology, particularly that of the north-west frontier, has remained relatively segregated (see Gardner 2002, 325; James 2002, esp. 1-3), within the fragmented discipline of Roman archaeology (Woolf 2004). To a large extent, Roman military studies have been the domain of scholars who themselves have had military backgrounds (James 2002, esp. 10-11). Interest in the social life of the occupants of military sites has tended be at the more generalist level (e.g. Watson 1969), and to concentrate on 'laws, rules, customs and numbers' (James 2002, 24).

\subsubsection{Military and civilian populations}

In the last two decades there has been a marked shift in interest. There has been a growing concern for the relationships between military and civilian populations (e.g. Vetters and Kandler 1990; Maxfield and Dobson 1991, Groenman-van Waateringe et al. 1997; see also Jones 1997) from which has developed concern for the concept of a military/civilian dichotomy (Gardner 1999, 404). Thus, there has been a burgeoning interest in the settlements outside the fort proper, the vici and canabae (e.g. Sommers 1991; Groenmanvan Waateringe et al. 1997, section 3). Such settlements were often founded at the same time as the fort and are identified as accommodation for the many camp-followers and tradespeople who provided service for the soldiers within the fort walls. There has also been an increased interest in the interactions of the Roman army with local populations (e.g. Groenman-van Waateringe et al. 1997, section 4), including the impact of ethnic recruitment on these populations (e.g. van Driel Murray 2003). Roman military bases are now being viewed as communities, involving a range of military and non-military personnel (Goldsworthy and Haynes 1999). Michael Speidel (1999) has argued that legionary fortresses functioned like towns, involving families, slaves, craftspersons and businessmen.

\subsubsection{Use of space}

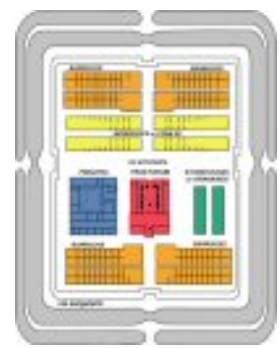

Figure 4: Idealised plan of a fort, with basic buildings (drawing P. A. Faulkner) 
These interests have tended to direct research away from the internal dynamics of Roman forts and fortresses and towards a broader examination of their place in the landscape. Essentially, the arrangements of the buildings and spaces within excavated forts follow a relatively consistent pattern (Figure 4). A formal structuralist approach, detailed study of the nomenclature used for these components in the texts (e.g. Polybius, Pseudo-Hyginus), and typological analyses of the components of actual excavated sites, have been employed to identify names and functions of the internal buildings, roads and open spaces within the walls of excavated Roman military bases. Sometimes the artefacts from a specific building have been used to verify the function of all buildings of the same form, although in a fairly anecdotal fashion.

Harald von Petrikovits' work $(\underline{1975})$ has been seminal in establishing the use of space within military forts. Since his study, the functions of the internal buildings in most excavated Roman sites are largely considered to be known. An understanding of the actual activities and internal relationships of the people who occupied these forts and fortresses has relied on this structuralist approach. For example, von Petrikovits' estimation of the amount of space each soldier required within a barracks $(\underline{1975}, 36)$ has been used to estimate how many soldiers an excavated barracks would have held and therefore the strength of the garrison housed there. However, such estimations are based on ground plans and do not consider that upper stories may have existed. Neither do they account for the possibility of the presence of non-military personnel within these barracks.

Von Petrikovits argued $(\underline{1975}, 37-67)$ that the personnel accommodated within the walls consisted principally of ordinary soldiers (milites gregarii), soldiers with special tasks (immunes); officers (centurions); staff officers (tribunes and praefecti) usually from equestrian or senatorial classes, and the commanders (legati legionis) of senatorial class. Inhabitants also included are cavalrymen, as well as grooms, stable-boys, drivers and guides associated with them and with the baggage train. This approach to the fort occupants and their use of space is based on the traditional belief that the fort was a segregated male military zone, and other non-military personnel, including women and children who were not members of an officers' family, would have resided and carried out their trade in the accompanying settlement, the vicus or canabae. This perspective has often been the premise on which interpretations of the use of space in Roman military forts and fortresses have been based. Gardner has argued $(\underline{2002}, 338)$, however, that this structuralist 'impression is counterbalanced by the complexity of the inhabitants' and this 'boundness' is 'blurred by the presence (indicated in the small finds data) of people within the walls who are not members [of the fort] in an organisational sense'.

\subsubsection{Social life}

Only in the last decade has greater interest been taken in the role of archaeological remains in informing on communities and social life within forts. For example, Birgitta Hoffmann (1995) has examined the layout and furbishing of centurions' quarters to gain a better understanding of the social backgrounds and statuses of these junior officers. Mark Hassall has surveyed much of the evidence for married quarters at military sites and stressed the large civilian element that would have been included within both forts and fortresses (Hassall 1999). At the 19th International Congress of Roman Frontier Studies in September 2003 (Limes congress - http://limesxix.btk.pte.hu/ a whole session was devoted to 'The material culture of the supply, preparation and consumption of food and drink' (chaired by Maureen Caroll). Simon James has also stressed the need for a 'soldiers-as-people' rather than a 'military-as-institution' approach and the role that archaeology can play in producing a better understanding of the internal dynamics of military communities (James 2002, esp. 42, 4648). Issues concerning the relationships between the populations of the military fort proper and of the vicus continue to be debated and are fundamental to our understanding of the use of space within the fort itself. While textual and epigraphic evidence play a major role in our understanding of social life in the military sphere (see Section 2.2), artefacts are also becoming increasingly important (see Sections $\underline{2.3}$ and $\underline{3.2}$ ). 


\subsection{Introduction to the textual and epigraphic information}

Investigations of textual evidence and the epigraphic remains have tended to produce more information on the social life of Roman military sites than have archaeological investigations. This type of evidence can be used to demonstrate that Roman military bases were both habitation and administrative places, involving a community that included non-military personnel such as officers' wives and families, concubines and 'camp-followers', tradespeople, artisans and slaves (James $\underline{1999}, 23$ ). What is not always clear from this type of evidence, however, is whether these non-military personnel inhabited the fort proper, the settlement outside, or both. Of particular concern for this article is the location and activities of women and families.

\subsubsection{Textual evidence}

Besides information on the construction of Roman military camps and the roles of military personnel, a number of ancient authors also give insights into the presence and roles of other individuals, particularly women and children, in the life of a Roman military base.

\subsection{1a Officers' families}

For example, several references, sometimes indirect, not only record the presence of officers' families within the camp but also the active participation of some officers' wives in military affairs.

Germanicus' wife, Agrippina, accompanied him on military duty in the northern provinces and, according to Tacitus (Annals 1.69), played a major role in commanding and supporting the troops against German forces at the bridge on the Rhine, at Vetera. During a mutiny on lower Rhine (Annals 1.41), however, Germanicus was persuaded to send her away from the camp, together with their baby son and the wives of staff officers. A number of Roman authors wrote about the inappropriateness of families in combat zones, and of women being involved in military affairs. Again Tacitus (Annals 2.55) informs us that Roman society was affronted when women such as Agrippina and Plaucina, the wife of the governor of Syria, Cn. Calpurnius Piso, interfered in military affairs. The senate debate of $21 \mathrm{CE}$ condemned this type of interference (Evans 1991, 27). Juvenal was sharply critical of 'those women who "with unflinching face and dry breasts" participated in male discussions of politics and military matters' (Juvenal Satires 6.398-405, quoted in Allason-Jones 1989, 52). Herodian also wrote (Histories: 3.8 .4 ) that soldier marriages and cohabitation with their wives were considered a hindrance to military discipline and readiness for action.

Such views, of ancient male authors, have been used to support the widely held perception, by modern scholars, that women and children were not usually to be found on the Roman frontier, and certainly not within the walls of a military base. On the contrary, such views would only need to be expressed if indeed their presence was overt in this sphere (for similar argument, see Dixon 2001, 16-25, 82-84). Cassius Dio commented that 'not a few women and children and a large retinue of servants' followed the marching column of Varus, and Caesar mentioned carts filled with female luggage at the back of his convoy (Cassius Dio LVI.20.2-5). These references are usually taken to refer to the inhabitants of the vici but this is not actually stated.

\subsection{1b The marriages of ordinary soldiers}

Most references to the presence of women in the military sphere, and particularly within the fort walls, concern the wives of commanders and senior officers. Legislation concerning the 
marriage of Roman soldiers is potentially important to the question of whether other women and families could have lived inside the walls of a Roman military base. In the mid-1st century $\underline{\mathrm{CE}}$, the Emperor Claudius 'gave the rights of married men to soldiers, since in accordance with the law, they were not permitted to marry' (Cassius Dio LX.24.3 - quoted from Allason-Jones $\underline{1989}$, 59). After $197 \underline{\mathrm{CE}}$, however, the emperor Septimius Severus allowed ordinary soldiers to 'live in wedlock with their wives' (Herodian Histories: $3.8 .4-5$ ). There has been much scholarship concerned with the impact of these laws on the state of marriage in the army (e.g. Garnsey 1970; Smith 1972; Campbell 1978). It has led many scholars to commence from the premise that a legal ban on the marriage of ordinary soldiers resulted in an absence of women from within fort walls, before the 3rd century, with the exception of officer's wives (Southern and Dixon 1996, 85). It has generally been assumed that only the families of officers could inhabit the fort proper, while concubines and 'campfollowers' would have been accommodated in the accompanying vicus (see Webster $\underline{1985}$, 209-10; Allason-Jones 1989, 60; Speidel 1999, esp. 78, 80).

\subsubsection{Epigraphic evidence}

Tombstones, papyri, military diplomas, and wooden tablets provide further information on the types of people associated with Roman military sites. Some of these even provide in situ evidence for the types of people who were accommodated, or at least employed, within the fort. Particularly important are the large quantities of inscribed wooden tablets, found in the very damp conditions at the fort at Vindolanda in Hadrian's Wall (Birley 1977, 133-57; Bowman 1994; Bowman and Thomas 1994) and on the rubbish dump of the 1st century $\underline{\mathrm{CE}}$ legionary fortress at Vindonissa in northern Switzerland (Speidel 1996).

\subsection{2a Wooden tablets}

Among the wooden tablets from Vindolanda are the famous letters concerning Sulpicia Lepidina, the wife of the prefect Flavius Cerialis, and Claudia Severa, the wife of fellow officer Aelius Brocchus. These belonged to Period III of the fort and can be dated c. 95-105 CE. One of these letters (Bowman and Thomas 1994, 256 no. 291) consists of an invitation by Severa to Lepidina to visit her for her birthday and so provides a glimpse of the social lives of these high-ranking women.

The tablets from Vindonissa, however, give us insights into other people and activities within a fortress. Speidel $(1996,15)$ has convincingly argued that this group of tablets originated from within the fortress and are dated between 30-101 CE. He has demonstrated that a number of the tablets refer to slaves, servants, secretaries, craftsmen and freeborn women and that some of these tablets also provide house numbers for buildings within the fortress. Some of these 'houses' seem to have been tabernae along the main axis roads (1996, 3856) and, in these wine shops and guest houses, some of the women mentioned in the tablets worked as barmaids or as innkeepers. This indicates that these people worked within the fortress and may well have been accommodated there, although Speidel follows the traditional view that they would have been the inhabitants of the settlements outside the fortress walls, presumably coming in to work each day. To my mind, however, this would be rather difficult for an innkeeper and is undoubtedly an anachronistic perspective on the spatial separation of living and working spheres projected onto the Roman world.

\subsection{2b Tombstones, diplomas and papyri}




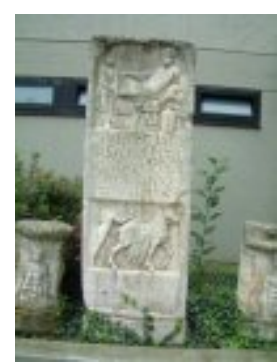

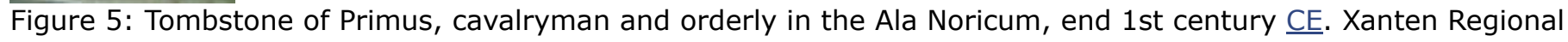
Museum (photo P. M. Allison)

Tombstones (Figure 5) also provide evidence for the presence of wives and families in the military arena, across all ranks. These were set up by families to commemorate the death of their soldier father or husband or, vice versa, tombstones were set up by a soldier to commemorate a member of his family (see Roxan 1991). In Roman Britain, for example, a tombstone near Hadrian's Wall records that an auxiliary soldier, Dagvalda, was mourned by his wife, Pusinna, and another soldier in the century of Obsequens, Aurelius Marcus, set up a tombstone to his wife (Collingwood and Wright 1965, nos 1667 and 1828; see Allason-Jones 1999a, 46). These wives undoubtedly accompanied their husbands into these combat zones but it is unclear whether they were domiciled within the fort walls or in the settlement outside. Such tombstones are believed by many to have been erected after the lifting of the ban on marriage for ordinary soldiers (e.g. Collingwood and Wright 1965: nos 11, 505) but there is actually no precise evidence to date them (Allason-Jones 1989,59 ).

There is much debate over the meaning of these legal rights and their relationship to the actuality of Roman military life. For example, it is not clear whether the centurions, as minor officers, were always permitted to marry (see Allason-Jones 1989, 58-59; Allason-Jones 1999a, 43), although there is evidence that centurions had children (Phang 2001, 79). Indeed, Sara Phang $(2001 ;$ 2002) has argued that, despite the ban on legal marriage for soldiers before $197 \mathrm{CE}$, there is ample evidence in military diplomas and papyri from Roman Egypt that soldiers 'married', at least in the de facto sense, and produced children while on active service. While their wives and children may not have existed within Roman law, this does not mean that they did not exist physically.

\subsubsection{Summary of the textual and epigraphic evidence}

The textual and epigraphic evidence indicates that, during the 1st and 2nd centuries $\mathrm{CE}$, numerous families and other non-military female personnel were present in the military arena, but it does not usually make explicit whether or not they resided inside the walls, even if some may have carried out their trade there. Von Petrikovits $(1975,62)$ had argued that women were not allowed to live within the fort. However, the references he cited (1975, $168 \mathrm{fn} 53)$ are not so definitive. For example, Liebenam $(\underline{1909}, 1676)$ stated that Augustus had set a strict law that ordinary active soldiers were not allowed to marry. However, he also concluded that, as dispensation, the lax handling of the discipline made it possible for a soldier to live together with a woman, through various arrangements. It has therefore traditionally been assumed that this meant that they lived in the area of the military base, but that they would not have come inside the fortification walls and caused a hindrance (see Debrunner Hall 1994, 221).

On the contrary, the combination of the textual and epigraphic remains, and more critical readings of this evidence, most notably the tablets from Vindonissa, gives the impression that life within the walls involved a range of inhabitants and interrelationships, which included a range of women and families. A closer examination of the structural remains and the artefacts from military sites shows that the community within the fort or fortress was much more complex than traditionally portrayed (see Sections $\underline{2.3}$ and $\underline{3.2}$ ). 


\section{back top forward contents home}

\subsection{Artefact studies at Roman military sites}

\subsubsection{Military equipment and ceramics}

Past studies of the artefacts from Roman military sites have essentially concentrated on the evidence they provide for military equipment. This is exemplified by the Journal of Roman Military Equipment and the Roman Military Equipment Conferences (e.g. Coulston 1988; van Driel-Murray 1989; see also Bishop and Coulston 1993; Southern and Dixon 1996, 89-126).

The large quantities of ceramics which have been found in Roman military sites have also meant that these contextualised assemblages have been useful in establishing dated ceramic typologies and in understanding the nature of the ceramic trade (e.g. Anderson and Anderson 1981; compare Willis 1997). Ceramics have also played an important part in providing dating information on various occupation phases of forts and fortresses.

As a consequence, the two classes of artefacts from Roman military sites that have received the most attention have been military equipment and ceramics, particularly the fine and imported ceramics. While studies of the former have often been concerned with function, this has not generally been the case for the latter. The most interesting work on the functional aspects of ceramics has rather been carried out on more utilitarian ceramics, most notably Vivien Swan's study of cooking wares (e.g. Swan 2003).

\subsubsection{Artefacts of social significance}

In more recent years, the other types of artefacts found at military sites have also received more detailed study. Increasingly, research is being carried out into the role of artefacts in developing a more critical approach to our understanding of Roman military life. Lindsay Allason-Jones, in particular, has carried out extensive research on various types of artefacts found in Roman forts in Britain (e.g. Allason-Jones and Miket 1984) and has stressed the need for a more critical approach to the concept of a 'military assemblage' (Allason-Jones $\underline{1999 b})$. She has also warned of the danger of ascribing specific artefacts to particular genders (Allason-Jones 1995). For example, she has noted that, while necklaces of beads were worn by women, beads could be worn as amulets by children of both sexes (AllasonJones 1995, 27). Horses could also wear melon beads (see Hoffmann 2002, 230; see Section 8.2.1e - beads). Allason-Jones has also argued $(\underline{1995}, 28)$ that the presence of needles in the presumably male-only turrets on Hadrian's Wall should warn us against simplistic engendering of activities (see Section 8.3.1).

\subsection{2a fibulae (brooches)}

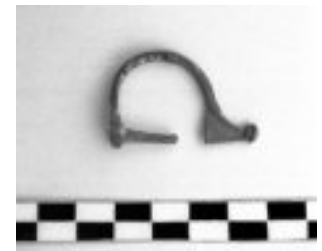

Figure 6: Aucissa fibula from Casa del Menandro in Pompeii (photo P. M. Allison)

A specific artefact class found on Roman military sites that can provide evidence on the nature of the community is that of fibulae, or brooches (Figure 6). While much research into brooches has consisted of classifying them according to technological aspects of their manufacture (e.g. Almgren 1923; Riha 1979; 1994), Astrid Böhme (1972; 1998a; 1998b) and Stefanie Martin-Kilcher (e.g. 1993) have considered them from the point of view of the 
wearer and the viewer. Allason-Jones has warned that assigning brooches to women or men, or to military or non-military personnel, is fraught with problems (Allason-Jones 1999b, 2). Böhme has cautiously argued that, while brooches classified as soldiers' brooches are the most frequent on Roman military sites, other types which could conceivably be women's brooches are also sometimes found at these sites (see also Gechter 1979, 77; see Section 8.2.1a).

\subsection{2b Leather shoes}

Artefact research which has produced results that render this present study necessary is that of Carol van Driel-Murray. Van Driel-Murray has studied leather shoes from Roman military sites (e.g. Van Driel-Murray 1986). Most recently, she has also investigated the spatial distribution of smaller-sized shoes at some of these forts (e.g. Van Driel-Murray, 1994; 1995; 1997). At Vindolanda, in particular, she found concentrations of what she identified as women's and children's shoes in the ordinary soldier's barracks in Period IV of the fort, dated c. 104-120 CE (van Driel-Murray 1995, fig. 1.8). Her findings, therefore, present a strong argument for the presence of ordinary soldiers' families within the fort itself, prior to the lifting of the ban on soldier marriage, and, therefore, provide a new premise from which to view the other artefacts found at these sites.

\subsection{2c Gaming items}

At Vindonissa, artefacts have been used to corroborate the epigraphic evidence for women within the fortress. For example, Speidel $(\underline{1996}, 55)$ identified Belica as a freeborn innkeeper or landlady. She is referred to in letter no. 44, as being 'opposite the baths' (Speidel 1996, $186-7 ; 1999,79-80)$. In the excavated area opposite the main baths within the fortress were found numerous gaming stones, dice and kitchen utensils, which Speidel felt confirmed this area's identification as an inn that was run by Belica (see Section $\underline{8.4}$ ).

\subsection{2d Surgical and toilet items}

Patricia Baker (2001) has studied instruments from military sites, identified as surgical or toilet items. She has stressed that medical practices are likely to have differed in the various parts of the Roman Empire because of local traditions. She has highlighted that instruments may also be used in different ways in different regions. She analysed the distribution patterns of medical instruments at four legionary fortresses and observed that the depositional patterns and quantities varied between these fortresses, although, notably, both Caerleon, in Wales, and Vindonissa, in Switzerland, seemed to have the highest numbers of such instruments in the baths.

\subsubsection{Summary}

As outlined, the general understanding, which has pervaded most thought on this subject, is that the 'camp-followers' were housed in settlements outside the military site, and not within the fortifications themselves. As Carol van Driel-Murray has commented (van Driel-Murray $1995,7)$, 'a typically 19 th century notion of segregated military communities pervades thought on Roman military life'. The work of scholars like Carol van Driel Murray and Lindsay Allason-Jones on artefacts from Roman military sites, and the discovery of artefacts such the wooden tablets from Vindolanda on Hadrian's Wall in Britain (e.g. Bowman and Thomas 1994) and from Vindonissa in Switzerland (e.g. Speidel 1996), have done much to show that it is time to take a closer look at the role of women within Roman military space.

To date, much artefact research has tended to investigate only one class of artefact at a time, lacking a more holistic approach to the complete archaeological record - the spatial arrangements, range of finds and finds assemblages and related activities - for its documentation of the complexity of army life and the interactions of the personnel. In other words, only limited attention has been paid to the distribution of artefact assemblages within 
these military bases or to the significance of these assemblages for our understanding of life within these spaces. There are exceptions, however (see Section 3.2).

\section{back top forward contents home}

(c) Internet Archaeology URL: http://intarch.ac.uk/journal/issue17/4/2.3.html Last updated: Mon Apr 42005 


\subsection{Artefact assemblage studies in Pompeian domestic space}

To best understand the role of artefacts in informing on social behaviour, one needs a good understanding of artefact function. Broadly speaking, much information on artefact function has been based on relatively anecdotal approaches to excavated Roman remains (see Allison 1999a; 2001, esp. 195-97).

The sites where artefacts and their contexts can be best used to inform on artefact functions are those at which the site formation processes have caused the least alteration to supposed normal living conditions at that site (see Schiffer 1987), and thus artefact assemblages are likely to be found in the context of their end use. The most suitable sites are those which are either short-lived, rapidly abandoned, or both. Although their depositional processes often do involve a whole range of discard processes (see e.g. Clarke 1994; Gardner 1999, 408; Baker 2001, 57-58), Roman military sites can be among some of the best types of site to fulfil these criteria. They are often short-lived, which means there is less chance than at most settlement sites of the reuse of spaces for different activities, and less chance of extensive redeposition, particularly of lost items. They are also frequently rapidly abandoned so there is a greater chance that artefact assemblages have been left at the location of their end use. Sometimes they are both short-lived and rapidly abandoned, in which case there is an even higher chance that the recorded artefact assemblages document the living conditions at that site. Also, because of the supposed single function of military sites, there is less likely to be a change of use for the various components of those forts that do not grow into civilian centres.

\subsubsection{Pompeian households}

The Roman site where rapid abandonment is most apparent is the town of Pompeii. This site has often been viewed as an eponymous site, providing the 'nearest thing to a time capsule' (Jongmann 1988,55 ), that can be used as a yardstick against which to measure less wellpreserved sites (Schiffer 1985). Thus, Pompeii ostensibly offers an ideal site for using artefact distribution to inform on social behaviour in the Roman world, particularly the use of domestic space. While Pompeian scholars are only too aware that the site does not offer the pristine conditions assumed by the New Archaeologists (compare Binford 1981 and Schiffer 1985 with Zanker 1988, 41; see also Allison 1992; Wallace-Hadrill 1994, 87-89; Fröhlich and Jacobelli 1995), it still provides an archaeological record which is unparalleled in terms of relationships between artefact distribution and spatial behaviour.

In addition, the actual study of social behaviour and the use of space at Pompeii is comparable to that of Roman military sites. The structuralist approach that scholars like von Petrikovits ( $\underline{1975}$ ) have taken to Roman military installations (see Section 2.1.3) has long been the approach used to identify the use of space in Roman houses (e.g. Becker 1876; Mau 1899; McKay 1977; Wallace-Hadrill 1994; cf. Leach 1997).

For the last seventeen years I have been studying artefact distribution in Pompeian domestic contexts, both to test the structural approach to room use and to reinvestigate the abandonment processes at this site (Allison esp. 1994; 2004). This study has included the compilation and analyses of databases of some 16,000 artefacts from thirty Pompeian houses (http://www.stoa.org/projects/ph/home). This database has been analysed, in combination with an assessment of household assemblages and a critical approach to the use of ancient written sources, to produce more informed perspectives to the use of Roman domestic space. This research has also involved detailed analyses of Roman artefacts and artefact assemblages with similarly critical approaches to their Latin nomenclature and its use in the written sources (e.g. Allison 1999a). I have also been concerned with archaeological approaches to the social category 'household', and to use the physical 
remains of houses and their contents for information on the people who occupied these spaces (Allison 1999b, 2001).

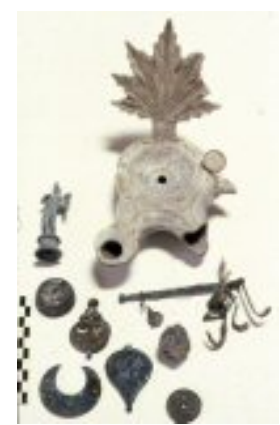

Figure 7: Pendants and other objects (inv nos 4907-10) from a box in room 35, Casa del Menandro in Pompeii (photo P. M. Allison)

My interest in artefact assemblages and artefact distribution led to my joining the British Pompeii Research Committee's project on the Insula del Menandro in Pompeii (Ling 1997; Painter 2001; http://www.stoa.org/projects/ph/home; the Casa del Menandro, the Casa del Fabbro, House I 10, 8, the Casa degli Amanti). This British project, commenced in the mid 1970s, is a reinvestigation of Amedeo Maiuri's 1930s excavation and publication of this insula (Maiuri 1933). My contribution comprises a catalogue and analyses of the excavated house contents from the insula, organised according to provenance, rather than typologically, and studied according to context and function (Allison n.d. 1) (Figure 7).

My Pompeian research has been concerned with the analysis of material from excavations carried out, in some instances, over 200 years ago. Thus, they have involved detailed investigations of the Pompeian excavation archives (See Section 5). Like many excavated Roman military sites, these excavations by no means provide perfect data from which to extract information on social behaviour but, given the considerable amount of data available, it was possible to produce meaningful information.

\subsubsection{Comparative artefact studies}

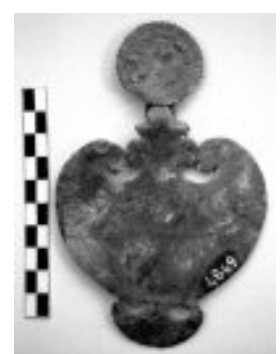

Figure 8: Pendant (inv. no. 4869) as part of harness from courtyard 34, Casa del Menandro in Pompeii (photo J. Agee)

This research has, therefore, included much detail on Roman artefacts which have received little press in the archaeology of Roman Italy, particularly the archaeology of Pompeii. My concentration on the functional aspects of these artefacts is also an approach that has tended to be employed only summarily in this region (cf. Carandini 1984; Berry 1997). For these reasons, to find comparable material with comprehensive publication, I found myself constantly turning to artefacts excavated in the Roman provinces, particularly in the western provinces and especially in Britain, Holland and Germany, (e.g. Ulbert 1969; Crummy 1983; Manning 1985). I also began to recognise the similarities with, and the differences between, the artefact assemblages from the 1st century $\mathrm{CE}$ urban site of Pompeii and the largely military sites of similar date in the western provinces or, more particularly, the similarities and differences between the functions ascribed by modern scholars to the artefacts from the different realms. Artefacts often considered to have a military function were turning up in Pompeian houses. For example, a horse pendant (Figure 8 ) found in the Casa del Menandro 
in Pompeii is of a type commonly identified as cavalry equipment (see Bishop 1988, esp. fig. 44.3c). Conversely, artefacts considered for female adornment or for female industries in Pompeian houses and other urban contexts were sometimes ascribed other functions, or passed over, when unearthed within Roman military sites (compare Crummy 1983, 19-25 with Hanel 1995, 285 and cat. no. J1, classified as a stylus - Figure 9). So, I decided that it would be interesting to apply the same approaches and principles that I had applied to Pompeian houses to these military sites.

Figure 9: Vetera bone stylus J1 (Hanel 1995, pl. 165)

\section{back top forward contents home}

(c) Internet Archaeology URL: http://intarch.ac.uk/journal/issue17/4/3.1.html

Last updated: Mon Apr 42005 


\subsection{Categorising artefacts at Roman military sites}

As outlined in Section 2.3, with the exception of specifically military equipment, there have been few comprehensive studies of artefact assemblages and artefact function in Roman military studies, although the number has been growing in more recent years. Twenty years ago Nina Crummy (1983) published a catalogue of the small finds from the excavations at Colchester, organised by a series of functional categories. Lindsay Allason-Jones has studied artefact assemblages from turrets on Hadrian's Wall (Allason-Jones 1988) and Simon Clarke (1994) also stressed the need to study complete artefact assemblages from Roman military sites. Hilary Cool and Michael Baxter (2002) recently demonstrated how artefacts from a number of different Romano-British sites - urban, rural and military - can be divided into a range of functional categories, and then multivariate analyses carried out to identify different types of sites as well as the varying functions of different spaces within a site. Patricia Baker (2001) has argued for a need to investigate the different depositional patterns for various types of artefacts within different military sites. Andrew Gardner (2001; 2002; 2004) has also recently stressed the need for a more contextualised approach to artefacts and social practices at Roman sites, using a consumer approach to classifying these artefacts. He has used GIS software to isolate distribution patterns of artefacts in the vicinity of the west gate of the fort of Birdoswald on Hadrian's Wall (Wilmott 1997; Gardner 2004), as well as at other British military sites (Gardner 2002).

\subsubsection{Ascribing functions and activities to artefacts}

Allason-Jones argued (1999a) that there are many pitfalls in identifying artefacts as being either military or civilian equipment (see also Gardner 2002, 331). For example, she posited that a lead candelabra and Minerva head couch decoration could be considered military equipment as these were the kinds of personal luxuries which soldiers, and especially officers, could bring with them during their posting, which might last at least three years. She has therefore argued for a separation of purely military equipment (e.g. swords, helmets, shields etc.) from non-military equipment.

These distinctive dichotomies are not important for a study that is concerned with extracting social relevance from artefacts and artefact assemblages. Given that all the activities within Roman forts and fortresses fall within the military sphere, as opposed to the urban or agricultural sphere, this study aims to highlight, through the artefact distribution, that life within a military site also embraced the 'domestic' sphere and, as such, included many activities which did not pertain to combat and defence and which could be carried out by both military and non-military personnel. In other words, the current study is not concerned with separating out the professional, community and personal activities. Rather it investigates how these are integrated together and what we can learn about relationships between these activities and the people who performed them. But, we need to be clear about levels of functional categories. For example, 'military' or 'domestic' are spheres of activities rather than actual activities, whereas 'combat', 'defence', 'food-preparation', 'eating' and 'drinking' are activities and functions, in terms of the specific function for which a person uses an item.

Cool and Baxter $(\underline{2002}, 366)$ cautioned that the current methods used by archaeologists to summarise finds according to functional categories are misleading, particularly concerning small finds which are not ceramic or bone and which are usually found in limited quantities. They argued that the ascription of these functions rarely include any formal analysis of the artefacts and involve only narrow functional interpretations. To map activities that provide a more nuanced understanding of how the components of each individual fort functioned we need to consider the range of activities for which each artefact can be used and also the range of people who could potentially have used it. 


\subsubsection{Ascribing categories}

\subsection{2a Functional categories [프물 10]}

To counter 'narrow functional interpretations', the functional categories in this study include alternative (or queried) functions that are intended to provide more flexibility to these ascriptions. They also include sub-categories that refine the ascribed function, although these sub-categories are not presented in this article. For example, 'jewellery' is a subcategory of 'dress'. Pendants belong to the sub-category 'jewellery', but some of them could have been either for the adornment of horse harness, armour or worn as pendants round the neck. They are therefore classified as the queried category 'dress?/combat equipment?/horse equipment?'. This means that, for example, one can collect all the material that can clearly be identified as 'dress' and the material that could conceivably have been dress ('dress?'), both together and separately (see Section $\underline{8.2}$ ).

\subsection{2b Age and gender categories [igure 11]}

Gender and status are more subjective categories. Most artefacts cannot be ascribed either a gender or a status category but in many cases it is possible to suggest these. For example, tools used for wood-, leather-, stone- and metal-working, and assault equipment, such as arrowheads, and remains of javelins, daggers and swords, as well as remains of armour, are more than likely to have been used by males. For items used for cloth-production this is less certain. Weaving could be carried out by men or women (Dixon 2001, 117-29) and sewing could be carried out by soldiers (Allason-Jones $\underline{1995}$, 28; see Section $\underline{8.3}$ ). Thus, many cloth-production artefacts have been classified as 'male?/female?'. However, those used for spinning have been classified as female as, to date, I have no evidence that men are involved in spinning in the Roman world (although cf. Nandris 1981, 251). Some items of dress can also be ascribed a gender category. For example, Böhme (esp. 1972) has argued that some fibulae (brooches) were most probably worn by women. On the basis of modern data for ring sizes and the knowledge that Romans wore rings on all fingers and all joints, Alex Furger (1990) has done a statistical study of the size-ranges of different types of rings from Augst and Kaiseraugst, in Switzerland and provided estimates for the range of ring sizes that would have been worn by men, women or children. Similarly, certain types of beads could have been worn by women, children or horses and so these are given queried gender and status categories (see Section $\underline{8.6}$ ).

\subsection{2c Status categories}

In the examples included in this article status does not really feature. For the project as a whole, many items are categorised as 'utilitarian' and some are either 'decent' or 'luxury'. These terms are based on those used for 19th century European middle classes where 'decency', or 'gentility', pertains to the items through which the middle classes aspire to imitate the upper classes (McKendrick et al. 1982, esp. 1-6; Young 2003). While this analogy is not quite appropriate for this study, 'decent' items are those which can be seen to be beyond 'utilitarian' because they are decorative (e.g. a harness pendant, or decorated belt plate) or have some level of decoration (e.g. a fibula with an incised pattern) or are a fine ceramic (e.g. thin-walled pottery or undecorated terra sigillata). 'Luxury' items include precious materials (e.g. a fibula with silver pearled wire) or fine workmanship (e.g. reliefdecorated terra sigillata vessels).

\subsubsection{Summary}

This article involves a network of interrelated functional and gender categories which can perhaps be seen as a closer approximation of reality than more narrowly assigned categories. It by no means includes the complete range of artefacts and activities at Vetera I, or all the permutations within those selected. Rather it uses a sample of the analyses to demonstrate the approach. At this point it is also important to state that these functions are 
invariably ascribed to fragments rather than to whole artefacts. Individual fragments are likely to be of little significance but the consistent distribution patterns of a number of fragments are likely to be more meaningful.

\section{back top forward contents home}

(C) Internet Archaeology URL: http://intarch.ac.uk/journal/issue17/4/3.2.html Last updated: Mon Apr 42005 


\section{back top forward contents home}

\section{The Roman fortress of Vetera I}

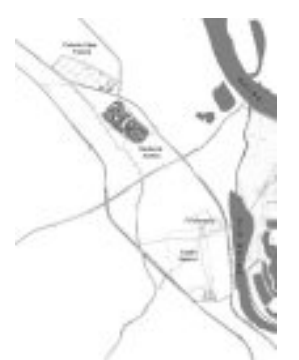

Figure 12: Map showing Xanten, Colonia Ulpia Traiania and Vetera I (drawing P. A. Faulkner)

The double legionary fortress of Vetera I is on the Fürstenberg, c. $1 \mathrm{~km}$ to the south-east of medieval and modern Xanten in the lower Rhine region, and is a useful site for an analysis of this type (Figure 12). It is predominantly a 1st century CE fortress, and relatively short-lived, lasting from C. $13 \mathrm{BCE}$ until c. $70 \mathrm{CE}$. It was excavated in the first decades of the 20th century and the finds were comprehensively published in 1995 (Hanel 1995).

\subsection{The history}

Tacitus is the main source for information on the history of the legionary fortress at Vetera I (e.g. Ann.1, 45, 1; Hist. 1, 67.2, 4, 21-23, 36, 57.1, 58; see Hanel 1995, 5-7, 315-25). Like many legionary fortresses in the region, the military base was established here, on the Rhine, during the early reign of the Emperor Augustus, probably in 13 or $9 \underline{\mathrm{BCE}}$. In $9 \underline{\mathrm{CE}}$, the Roman legions, under the command of Varus, were catastrophically defeated by the Germans, and the great Roman army annihilated. Tiberius, then the governor of the German provinces, called for the retreat and abandonment of the Augustan installations on the Lippe River, on the east side of the Rhine just to the south of Vetera I. Vetera became a refuge for 'dispersed military units, individual soldiers and also women and children ...' from these Lippe Valley sites (Hanel 1995, 322).

In $10 \underline{\mathrm{CE}}$, possibly as a consequence of the withdrawal from the Lippe Valley, Vetera became a double legionary camp and thus would have been home to some 12,000 men, and two legates. In $13 \mathrm{CE}$ a mutiny in Lower Germany was led by the garrison at Vetera. Vetera subsequently became a winter camp, probably to the summer camp at Novesium (modern Neuss) between Vetera and Colonia Claudia Ara Agrippinensium (modern Cologne). At this point, Vetera may have been manned by only a skeleton staff or completely abandoned. In 15-16 CE the two Roman legions, the Legio V Alaudae and the Legio XXI Rapax, were stationed here and were occupied with expeditions against tribes to the east of the Rhine.

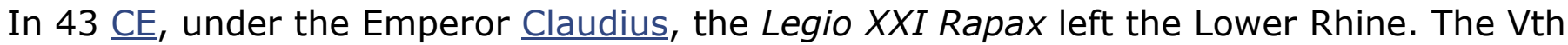
legion remained and XX1st legion was replaced by the Legio XV Primigenia. Following the death of Nero, in 68/69 $\mathrm{CE}$, there were a number of revolutionary upheavals in the Lower Rhine, particularly by Batavian mercenaries, and Vetera was besieged and destroyed. After the summer of $70 \mathrm{CE}$ there is no further mention of Vetera by Tacitus so this double legionary fortress was probably abandoned at this time. A successor fortress, Vetera II, was built during the Flavian period but at a different site, on the nearby Bischler Insel. In the 2nd century $\underline{\mathrm{CE}}$, the Roman colony Colonia Ulpia Traiania (CUT) was founded c. $2 \mathrm{~km}$ to the north-east and, subsequently, the medieval town of Xanten. The site of Vetera I was not occupied again.

\subsection{The excavations and their publication}


There had been some investigations at Fürstenberg in the late 19th century, but the fortification walls and the central area of the last fortress here were mainly excavated by Hans Lehner in 1905-1914, and again in 1925-1933/34 together with F. Oelmann (e.g. Lehner $1907 ; 1912 ; 1930)$. These excavations consisted of approximately one-third of the total fortress area of the latest, Claudian-Neronian, fortress. Further documentation and rescue excavation were also carried out at Fürstenberg in the 1960s and 1970s (Hanel 1995, 8-9).

Lehner also excavated outside the walls of the latest fortress at Vetera I and found traces of the fortifications of earlier fortresses (Lehner 1930 , pl. II). He published accounts of the process of his excavations, including plans of trenches and buildings. With the exception of a few noteworthy artefacts (e.g. a silvered harness: Jenkins 1985), the artefacts were not published until Norbert Hanel produced a comprehensive catalogue in $\underline{1995 .}$

\subsection{The construction phases of the fortress}

These excavations indicated that Vetera I had at least four building phases (Figure 13). Traces of the earlier fortresses were found to the north and east of the fortification walls, and within the north-central area of the last fortress.

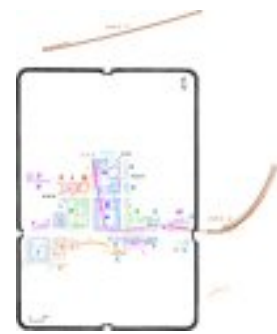

Figure 13: Vetera I, Neronian fort, showing building numbers, kilns and fortifications of earlier forts (by Pat Faulkner)

\subsubsection{Fortress B (Early Augustan)}

The earliest wood and earth fortifications ran through the centre of the last fortress, with which were associated some traces of internal buildings. Evidence from related pottery kilns has been used to date this construction prior to $9 \underline{\mathrm{CE}}$ (Hanel 1995, 287-93).

\subsubsection{Fortress A-C (Augustan-early Tiberian)}

The next building phase consisted of further wood and earth fortification walls to the north and east of the Claudian-Neronian fortress, commenced between 10-14 CE (Hanel 1995, 294-9).

\subsubsection{Fortress K (Tiberian)}

The Augustan-early Tiberian fortress (Fortress A-C) was burnt down and levelled, either at the end of the $20 \mathrm{~s}$ and in the $30 \mathrm{~s} \underline{\mathrm{CE}}$. It was replaced with a new installation, which was later abandoned and replaced with the final stone-built fortress (Hanel 1995, 300-2).

\subsubsection{Claudian fortress}

The change from the XXIst to the XVth legion, in $43 \underline{\mathrm{CE}}$, may have caused the abandonment of the Tiberian fortress (Fortress K) and the construction of a stone-built Claudian fortress. Little is known about this next fortress, however. The only definitive evidence is a stone building to the south of the south wall of Fortress $K$, Building $L$, overbuilt by Building $F$ of the later Neronian fortress (Lehner 1930, 21-3). This building is on a different alignment from the stone buildings of the later fortress and was identified by Lehner $(\underline{1930}, 23)$ as a 
hospital, because a number of surgical instruments were found here. However, Hanel argues that this functional identification is not necessarily substantiated (Hanel 1995, 304).

\subsubsection{Neronian fortress}

The Claudian fortress was replaced in the 60s $\mathrm{CE}$, during the reign of the Emperor Nero (Hanel 1995, 307-13). Stone was certainly used for the central buildings, which have been excavated and which are central to this study. This fortress did not last very long, however, and was most probably abandoned during the upheavals after Nero's death.

\subsection{Labels for buildings}

Through their parallels with other sites and the textual descriptions, and sometimes artefacts found there, Lehner (esp. 1930, 22-68), and others, have identified the functions of many of the buildings as follows:

- Buildings $A-B=$ principia

- Buildings C - D = possibly shops, tabernae (Hanel 1995, 311-12), later gravelled over for an open area, or possibly a market

- Building $\mathrm{E}=$ unidentified

- Building $F=$ probably officers' administrative building (Hanel $\underline{1995}, 100$ )

- Building $\mathrm{G}=$ praetorium

- Building $\mathrm{H}=$ legate's palace

- Building $\mathrm{J}=$ tribune's house

- Building $\mathrm{K}=$ tribune's house

- Building $L=$ utility building

- Pre-Neronian Building $L$ (under Building $F$ ) = valetudinarium according to Lehner but not according to Hanel (1995, 304).

- Building $M=$ tribune's house

- Building $\mathrm{N}=$ infantry barracks

- Building $\mathrm{O}=$ infantry barracks

- Building $P=$ legate's palace

- Building $\mathrm{Q}=$ probably tribune's house

- Building $\mathrm{R}=$ probably tribune's house

- Building $S=$ utility building; immunes barracks according to von Petrikovits ( $\underline{1975}$, pl. 4.10)

- Building $\mathrm{T}=$ unidentified

- Building $U=$ unidentified

- Building $\mathrm{V}=$ barracks (Hanel 1995, 132)

- Building $\mathrm{W}=$ unidentified, possibly barracks as Building $\mathrm{V}$

- Building $X=$ unidentified

- Building $Y=$ barracks (Hanel 1995: 309)

- Building $Z=$ valetudinarium

- Building $a=$ unidentified

- Building $b=$ unidentified

- Building $\mathrm{c}=$ unidentified

- Building $\mathrm{d}=$ unidentified

Lehner $(1930,39)$ identified the via principalis, running between the east and west gates, as a colonnaded street lined with shops on the north and south sides, more of which were at the east end than the west.

\section{back top forward contents home}




\section{back detail forward contents home}

\section{Sections 5-7: Methodology and Technical Procedures}

These sections summarise the methods for preparing printed excavation reports so that artefact assemblages can be used to study social behaviour at Roman sites. The processes involve: the selection of suitable sites, converting the printed site plans and artefact catalogues into digital formats so that the artefacts can be sorted according to provenances and activities, and then mapping these activities onto the new digital site plans using Geographical Information Systems (GIS).

We solved these challenges by developing an overall 'workflow' comprising discrete work tasks, skills and technology platforms. 


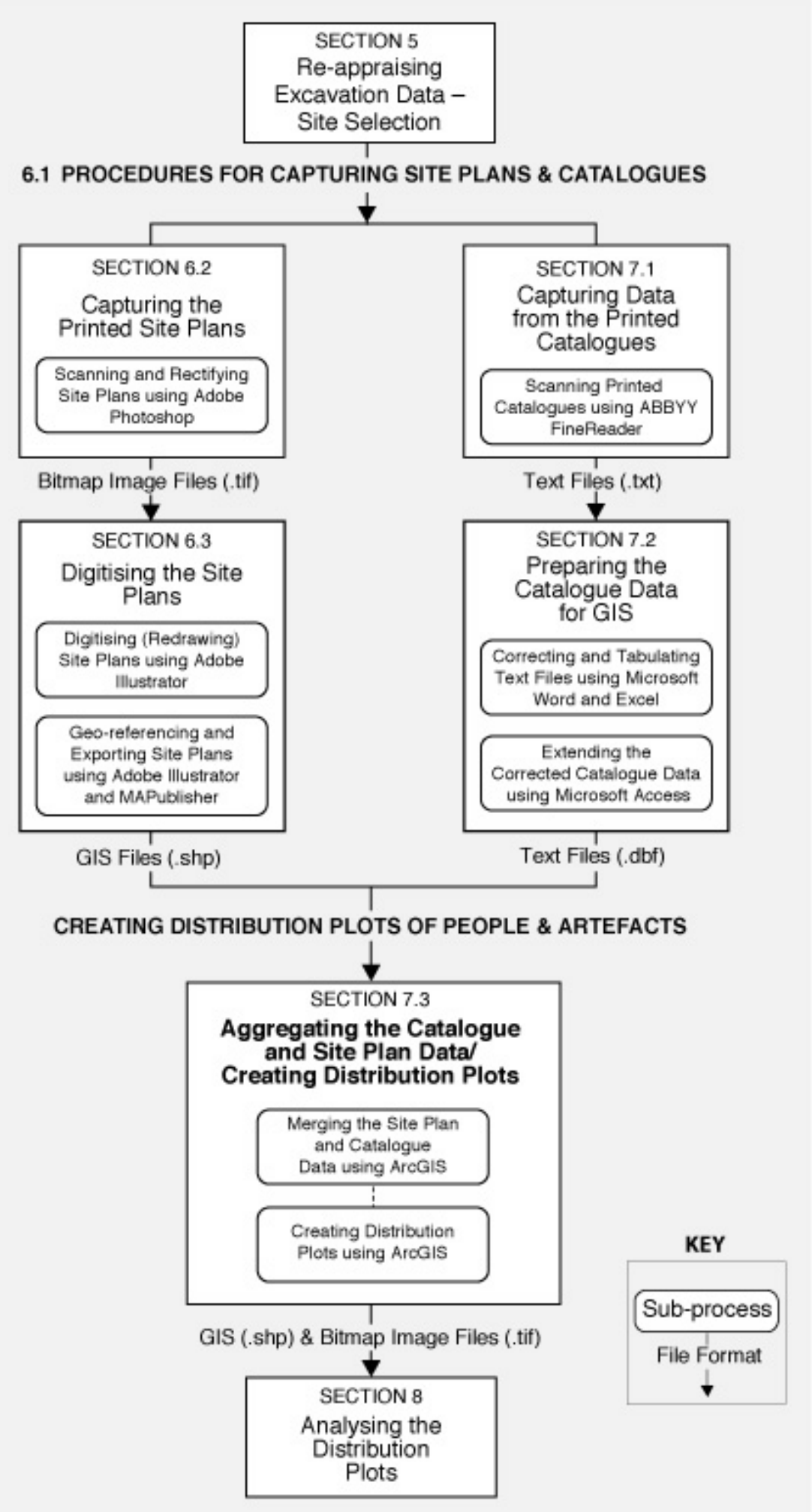

Figure 14: Workflows and software (drawing A. S. Fairbairn and C. W. Blackall)

\section{Section 5: Re-appraising excavation data (by P.M. Allison)}

Sites were selected for analysis, in the first instance, if their excavation reports had relevant characteristics. They had to have relatively comprehensive artefact catalogues, good site plans and each catalogue entry had to have a published findspot, which could be located on the plans. The fortress of Vetera I, in the lower Rhine region, was chosen as an example of an old excavation whose finds have recently been extensively published (Hanel 1995). 
6.1 Introduction to procedures - A number of procedures, and a range of software, were recommended for scanning and digitising the site plans.

6.2 Capturing the plans - The process involved scanning large format plans and preparing them for the next stage of digitisation.

6.3 Digitising the plans - The scanned site plans were imported into Adobe Illustrator and redrawn using its Bézier drawing tools. The finished drawings were then translated into georeferenced 'shape' (.shp) files using Avenza MAPublisher for export to ArcGIS 8.3.

\section{Section 7: Digitising and querying artefact catalogues (by A.S. Fairbairn)}

7.1 Capturing data from printed catalogues: The artefact catalogues were digitally scanned and converted into machine readable text files using Optical Character Recognition ( $\underline{O C R}$ ) software, Abbyy FineReader. The resulting data was manually disaggregated into descriptive, numeric and other categories using Microsoft Word and Excel.

7.2 Preparing catalogue data for GIS: The Excel spreadsheets were then imported into Microsoft Access and cross-tab queries created to summarise the data. The data was then exported as series of Dbase IV (.dbf) files, for importation into ArcGIS.

7.3 Creating distribution plots of people and their activities: The .dbf files were imported into ArcGIS and aggregated with tabular data from the 'shape' (.shp) files exported from Adobe Illustrator/MAPublisher. Distribution maps of various social activity and status categories were created using ArcMap, a component of ArcGIS.

\section{back detail forward contents home}

(c) Internet Archaeology URL: http://intarch.ac.uk/journal/issue17/4/summary5-7.html Last updated: Mon Apr 42005 


\subsection{Pompeian excavation archives}

My research into artefact assemblages in Pompeian households involved the collection and analysis of the information held in the Pompeian excavation archives. I used, in particular, the archives of excavations carried out between 1870 and 1970 (Allison 1994; 2004, 28-32). From these archives, I compiled electronic databases of the contents from thirty Pompeian houses, and studied their assemblages and spatial distribution for information on both the use of domestic space in Pompeii and the processes of abandonment at this site (see Section 3.1). These excavations by no means employed the rigorous data collection and recording methods that are used today (not even the 1970s excavations). Nevertheless, the wealth of data which they have provided, and the fact that the artefacts recorded are those which would have been part of the 79 CE 'house floor assemblages' (Schiffer 1985, 18; cf. Allison 1992), has meant that a considerable amount of information about spatial and artefact function can be gleaned from the resulting artefact assemblages. Although it was not the objectives of the original excavators to carry out artefact assemblage analyses, but rather to hunt out interesting art objects, their need to inventory most of their finds has meant that they have indeed recorded a considerable amount of contextualised information from which we can learn more about social behaviour in Pompeii. As Cool and Baxter have pointed out, 'even "poor quality" data can provide useful insights into past societies' $(\underline{2002}, 365)$.

\subsection{The excavation of Roman military sites in Germany}

Many of the larger Roman military sites in the Rhine and Danube region were also extensively excavated in the late 19 th and earlier 20th centuries (e.g. Saalburg - Jacobi 1897; Zugmantel - Jacobi 1937; Weissenberg - Kohl and Tröltsch 1914). Since the 1970s, such large-scale, open excavations have rarely been carried out. Rather, more recent excavations have consisted of more piecemeal excavation, often in the form of rescue archaeology within an urban centre, although there are exceptions (e.g. Ellingen - Zanier 1992).

1st and 2nd century CE military bases of the Rhine and Danube regions and their excavations have a number of characteristics that are comparable to Pompeii and its excavations, rendering them useful for a study of this nature. Firstly, they are similar in date and therefore offer comparable artefact types. More importantly, a number of these sites experienced rapid abandonment. This means that they have the potential to include considerable artefact assemblages with provenances that document their place of use, loss or immediate discard, rather than their relocation and redeposition. In addition, many of these military bases were short-lived and are therefore unlikely to show extensive reorganisation and reuse of space.

\subsection{Vetera I}

Like Pompeii, many of these military sites were excavated over a century ago, were fairly extensively excavated, and, like my work on Pompeian houses, some of these have also recently been reinvestigated and comprehensively published. An outstanding example in this respect is the double legionary fortress of Vetera I (Hanel 1995; see Section $\underline{4}$ ). For a site like Vetera I, I did not have to go back to painstaking archival research, as I had done for Pompeian houses. The data is already available in a systematic published form with good contextual information. In addition, while the first fort at Vetera dated to the Augustan period, the most extensive excavated remains within the stone fortifications can be dated to the Claudian-Neronian period. 
As was a common procedure in early 20th century excavations, the Vetera I excavations concentrated on exposing the ground plan of the latest fort, and location of the earlier ones. The bulk of the excavation trenches consist of long narrow trenches (c. $1 \mathrm{~m}$ wide and c. 1$1.5 \mathrm{~m}$ deep) following the walls of the Neronian buildings, particularly the buildings of the central section of the fort. These trenches were often dug to the foundations of the structures of the latest fort and also found traces from the earlier forts. Sometimes stratigraphical information is provided about the contexts of finds but it is not always clear at what level within these trenches the artefacts were found. A number of pits have also been identified within these trenches, sometimes dating to the pre-Claudian periods of the fort but not always. Hanel has done what he can to extract more precise stratigraphical information (see esp. Hanel 1995, 286-320) and his analyses and chronologies have been used in this study. Also, because the trenches were dug along building walls, for many of the outer walls it is not absolutely certain whether an artefact was found within a building or immediately outside. In addition, many artefacts are listed as being from the 'Oberfläche' (surface), and some for the 'heutige Oberfläche' (modern surface) but it is not clear if there is any distinction here between modern and ancient surface (cf. Zanier 1992, e.g. 85, 140, 151).

Hanel's artefact catalogues is organised typologically rather than spatially and are not created electronically. With the exception of certain bone items, currently part of another study, Hanel published the findspots for as many artefacts as possible and extensive plans for the excavation trenches. Thus, it seemed that all that was needed, to carry out my analysis of the spatial distribution of artefacts within the Vetera fortress, was to create electronic versions of Hanel's and Lehner's plans of the various phases of the fortress, and an electronic version of Hanel's catalogue, and then to combine these. However, the process was more complicated than it at first seemed and there were a number of problems that needed to be dealt with as we proceeded. This applied particularly to the concordance between the trench numbers in the artefact catalogues and the trenches that we were able to locate on the GIS plan. Hanel $(\underline{1995}, 341-52)$ provided a list of approximate locations for each trench number based on Lehner's plans. This was extremely helpful but there were still some problems. These problems took three main forms.

- Two trenches sometimes had the same number. This was because there was no systematic numbering system between the two main periods of the excavations (19051914 and 1925-1933/34) and, in an area covering about 60 hectares, some trench numbers were reused. The relevant trenches were usually identified by Hanel. For example, he has noted that Trenches 152 and 153 occur twice. However, he provided only one location for Trench 330 in his list of trench locations but there are two trenches labelled with this number in his trench plans. In such cases we have followed the location identified in Hanel's list.

- In some cases where two trenches have the same number, the location in Hanel's list is not specific enough to identify which is correct. In this sample, trenches which still have two locations are Trench 529, which was either in Building J or in the street to the west of this building, and Trench 325, which occurs in both Building $G$ and in the street between Buildings $G$ and $B$. For the purposes of this article, data recorded in Trench 529 has been plotted to Building $\mathrm{J}$ as both trenches are in the region of this tribune's house. Data from Trench 325 has been plotted to the street between Buildings $\mathrm{G}$ and $\mathrm{B}$. However, much of the material from this trench was found in pit 1 which is a preClaudian context and so is not relevant to this article.

- Some artefacts in Hanel's catalogue were provenanced to trenches which Hanel was unable to locate specifically for inclusion in his plans. For this particular sample, this applies to Trenches 115 (in the vicinity of east gate fortifications), 119 (in the area of Buildings $Y$ and a), 308 (location unknown), 582 (Building J), 754-755 (location unknown), 1067 (in the area of Buildings $\mathrm{P}, \mathrm{S}$ and F), 1294 (location unknown), 1323 (location unknown), 1332 (location unknown), 1512 (location unknown). Data from these trenches are therefore not included in the distribution plots, but are discussed in the analyses. 


\subsection{Using Vetera I data}

Using data such as that from Vetera I for spatial mapping thus has its problems. Given the quality and nature of the recording of this site it is not always possible to ascertain precisely whether the artefacts recorded in each building belong to it, belong to an earlier phase of the fortress, or were redeposited. It is also sometimes possible that they were found in the street outside the building, rather than in the building itself.

The plots in this analysis do not distinguish the pits within the trenches, as this study consists of a horizontal spatial mapping rather than a vertical one. Some pits are specifically identified as pre-Claudian contexts and these are discussed in the analyses and taken into account. Consequently, this study analyses broad patterns of artefact distribution. It is concerned with the distribution of material that is most likely to date to the final, ClaudianNeronian, period of the fort, and to have been used within the buildings, or in the streets, during that period and during the abandonment of the fortress. Hanel has dated many contexts by the coins or ceramics with which they are associated and a number are dated to the Claudian-Neronian period (Hanel 1995, 303-14). Many individual artefacts can also be dated to this final phase. Interpretations in this study are therefore based on general impressions of distribution patterns of the artefacts most easily datable to the ClaudianNeronian period of occupation, rather than on the specific location of each particular artefact (see also Allison 2004).

Further problems and their resolutions are discussed in Sections $\underline{6}$ and $\underline{7}$.

\section{back top forward contents home}

(c) Internet Archaeology URL: http://intarch.ac.uk/journal/issue17/4/5.html

Last updated: Mon Apr 42005 


\section{back top forward contents home}

\subsection{Introduction to procedures}

The following sections detail the methods for preparing printed excavation reports so that artefact assemblages can be used to study social behaviour at Roman sites. The processes involve: the selection of suitable sites, converting the printed site plans and artefact catalogues into digital formats so that the artefacts can be sorted according to provenances and activities, and then mapping these activities onto the new site plans using Geographical Information Systems ( $\underline{\text { GIS }}$ ).

Given the overall aims of the project, we assumed that GIS would help us to aggregate the data; to discern new patterns; to investigate relationships within and between sites and artefact groupings; and to represent the findings visually. The use of GIS in archaeology is of course widespread. However, we are using it somewhat atypically. Most archaeological practitioners use GIS to map or record new sites, whereas we are using it to aggregate, visualise and analyse data collected from heterogeneous printed reports. We acknowledge that the artefact data and site plans in these printed reports are of variable precision. We are not using GIS to enhance precision, but rather as a visualisation tool to help us answer our research questions. The utility of GIS for archaeological research is highly dependent on the availability of GIS data. GIS data is readily available nowadays for many countries and regions; however, it is rarely of a resolution helpful for site-specific archaeological research. Archaeologists typically solve this problem in two ways: by surveying sites using GIS and GPS technologies to produce new maps, or digitising existing printed maps and site plans.

For this study we needed to digitise existing printed site plans. This involved three major challenges: first, we needed a cost-effective method of capturing the numeric and textual data contained in a wide range of printed sources; second, we needed to redraw the site plans digitally so they could be imported in ArcGIS; and, finally, we needed to be able to 'merge' this data with the digitised catalogue data before importing it into ArcGIS so that the patterns and relationships between sites and artefacts could be visualised, and then analysed.

The methods with which we addressed these challenges could be applied in other contexts where archaeological data is only available in printed formats, or where the merging of 'born-GIS' data and legacy data is required.

\section{back top forward contents home}

(C) Internet Archaeology URL: http://intarch.ac.uk/journal/issue17/4/6.1.html

Last updated: Mon Apr 42005 


\section{back top forward contents home}

\subsection{Capturing the Vetera plans}

The first step in the process of transferring printed site plans into $\underline{\text { GIS }}$ drawings involves digitally scanning the site plans.

For this project, each plan, or set of plans, had limitations that needed to be overcome before they could be scanned and then digitised for use in GIS. For example, there was no single published plan of the entire Vetera I site. The twelve plans of the excavated areas of Vetera I were at various scales (Hanel 1995, plans 1-12), which meant that they had to be consolidated to a common scale before they could be digitised.

All of the Vetera I plans were scanned using a large-format digital scanner and were saved as TIFF (Tagged Image File Format) files. The different scales and alignments in the digitised Vetera I plans were rectified as far as possible using Adobe Photoshop. The results were adequate for digitisation, though some parts still required careful visual interpretation to decipher the detail of the original plans.

\section{back top forward contents home}

(C) Internet Archaeology URL: http://intarch.ac.uk/journal/issue17/4/6.2.html

Last updated: Mon Apr 42005 


\subsection{Digitising the site plans}

The exercise of creating GIS data from printed maps or plans is a technically demanding task. It typically involves redrawing the original map detail, either on a digitising table (referred to as 'head-down' digitisation), or on a computer screen ('head-up' digitisation). In 'head-down' digitisation, the operator uses a hand-held digitiser device, or puck, to capture the locations of geographic features by converting their position on a map to XY Cartesian coordinates that are stored as computer files for processing and analysis by GIS software. In 'head-up' digitisation, the map is scanned and imported into the GIS software where the operator redraws the map features using the tools provided by the software. There are a number of considerations that need to be taken into account in order to produce useful results in 'head-down' digitisation mode: accuracy and precision of the digitising table; size of the digitising table; and operator competence. Similar considerations apply to 'head-up' digitisation. Even when all goes well, manually digitising maps and plans is time consuming and error prone.

\subsubsection{Adobe Illustrator and MAPublisher}

With these limitations in mind, we decided not to digitise the Roman military site plans using standard GIS software and techniques. Instead we used Adobe Illustrator and Avenza MAPublisher (a software 'plug-in' adding GIS functions to Adobe Illustrator) to redraw the plans and then convert them into GIS data formats for ArcGIS. We chose this methodology because the digitisation process was quicker and easier than using ArcGIS in 'head-up' digitisation mode.

It will not come as news to most archaeologists that Adobe Illustrator is widely used for archaeological illustration. We are not partisan users of Adobe Illustrator - other popular 'vector graphics' applications, such as Macromedia Freehand for example, are just as capable. Less well known is the role Adobe Illustrator can play in providing a low-cost, highproductivity, environment for 'head-up' digitisation.

The key technology that transformed Adobe Illustrator into a digitisation environment is Avenza MAPublisher [see http://www.avenza.com]. Essentially, MAPublisher is a 'plug-in', or software extension, for Adobe Illustrator and Macromedia Freehand. It enables the users to import, edit and export GIS data, as well as several other useful cartographic functions. MAPublisher is widely used in cartography, but when compared to standard GIS or CAD software, its GIS functions are limited. But, to repeat, we were not using MAPublisher to compete directly with ArcGIS, but rather as a useful tool for getting complex, difficult to digitise, plans into ArcGIS.

The speed advantages of Adobe Illustrator over ArcGIS are clearest when digitising 'nonregular' graphic features, such as coastlines, waterways, topographic contours, buildings and excavation trenches. The speed improvements stem from the fundamental differences between the vector drawing technologies used by Adobe Illustrator and GIS software. These differences are illustrated in Figure 15.

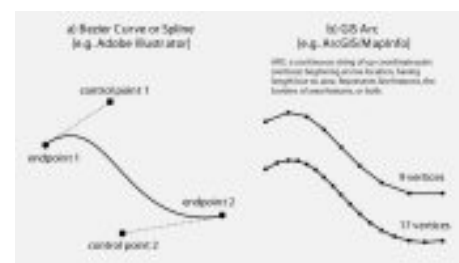

Figure 15: Comparison of Bézier Curve and GIS Arc (drawing C. W. Blackall) 
In Fig. 15 Adobe Illustrator uses Bézier 'splines' to produce continuous, mathematically precise, curves and lines using 'end points' and automatically generated 'control points'. Manipulating the Bézier control points changes the shape of the curve or line. By comparison, GIS software uses coordinate-based data structures to represent map features,

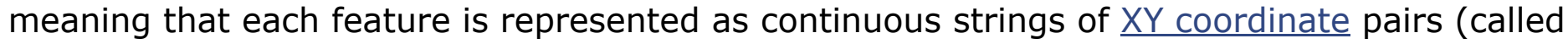
vertices).

Bézier splines are clearly a more efficient method of drawing curves and lines than

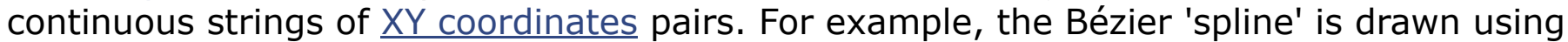
only two endpoints, whereas in Figure 15 above the same curve is drawn using 9 vertices, and a 'smooth' example using 17. But no matter how many vertices are created, an arc in GIS is never perfectly smooth. Importantly, the plans drawn with Adobe Illustrator retain their precision when viewed or printed at high magnifications, whereas the plans digitised with GIS software appear crude and 'blocky' in comparison.

Finally, an added advantage of using Adobe Illustrator for digitisation of plans is that it produces high-resolution files that can be used for print and web-based publications. GIS software also produces attractive output, but Adobe Illustrator is much better integrated with a wide range of industry-standard graphics, desktop publishing, and multimedia software, and has many more output options.

\subsubsection{Digitising Vetera I}

This section details the process of producing a digital plan of Vetera I from the published site plans (Lehner 1930, pl. II; Hanel 1995, pl. 169, plans. 1-12,) so that it was available for the spatial analysis of the artefacts and artefact assemblages from this site. As described, we needed to capture the various printed plans, to digitise them using Adobe Illustrator 10, import them into a GIS format with the aid of MAPublisher, and then create the final version of the digital plan using ArcGIS.

As noted in Section 6.2 , no single and precise published plan exists for the entire site of Vetera I, with all of its buildings, structures, trenches and pits. Hanel's publication included a plan of the fortress at 1:5000 (Hanel 1995, pl. 169), and twelve plans of the trenches excavated, at various different scales (Hanel 1995, plans 1-12). For example, Hanel had published plans of the 1629 trenches at scales of 1:2000 (1995, plan 1), 1:400 (plans 2-3, 5-12), and 1:350 (plan 4). Because these plans were drawn at different scales, considerable effort was required to consolidate them to a common scale. In addition, few of these plans could be precisely registered alongside their neighbours because of differences in scale and alignment, but also because of errors and inconsistencies in the original drawings that became apparent after scanning.

\subsubsection{Redrawing the plans in Adobe Illustrator}

After the site plans had been scanned and the problems identified had been resolved (using Adobe Photoshop), a consolidated TIFF file was imported into Adobe Illustrator and assigned its own 'layer' (the capacity to place graphics into virtual layers is common in graphics software). Separate layers were also created to isolate certain areas of the fortress, or particular construction phases. This made redrawing the plans easier to manage and helped with the staged transfer of data from Adobe Illustrator to ArcGIS when the new digital plan was completed.

The overall tasks of redrawing the plan consisted of activating the relevant layer of the Adobe Illustrator file, and redrawing the details of buildings and other major features using Illustrator's Bézier drawing tools. As discussed, drawing with Bézier drawing tools is quite unlike the vertex-by-vertex digitisation process in GIS. Straight lines are simple to draw in GIS but closed shapes, particularly the type of irregular 'polygons' common in archaeological 
plans, are not. Polygons are multi-sided figures that represent areas on maps or plans in GIS. Every polygon contains one label point within its boundary (for example a unique identifier) and has attributes that describe the geographic features they represent. It is not uncommon for digitisation errors to occur when creating polygons, such as 'gaps' in boundaries that result in their being processed as lines. These gaps need to be 'joined' in order to create true polygons. In the Vetera I plan, the most important polygons were the excavation trenches. The major problem here was the number of excavation trenches that either overlapped or had missing boundaries, which meant that they had to be redrawn as self-contained, gap-free, polygons. Because of the errors and inconsistencies in the original plans, we made the decision to redraw each of the 1629 trenches using Adobe Illustrator. Although time-consuming, this process was the only way of effectively dealing with these problems.

After redrawing the Vetera I plans in Adobe Illustrator we had a digital plan comprising separate layers for each phase of fortification, each building and structural feature, including pottery kilns, and a layer for the 1629 excavation trenches. This overall procedure was followed for other sites we have used in this project.

\subsubsection{Exporting the plan as GIS data}

In the next step, each layer of the Adobe Illustrator file was converted into 'shape files' using the MAPublisher software plug-in. Shape files (with the file name extension .shp) are one of the file formats used by ArcGIS.

Before the Adobe Illustrator layers were exported as shape files, a unique identifier (a number) was assigned to each of the 1629 excavation trenches. A new list of trench numbers was developed by Fairbairn and Ellis because the trench numbering in the Vetera I plans and catalogue was inconsistent, but also because a common list of unique identifiers was required to link the digitised features in the Adobe Illustrator layers with the artefact information in the Access database. Thus, in database terms, the trench numbers provided the common database 'key' that enabled the various data sources to be 'merged', thus allowing successful import into ArcGIS.

\section{back top forward contents home}

(C) Internet Archaeology URL: http://intarch.ac.uk/journal/issue17/4/6.3.html

Last updated: Mon Apr 42005 


\subsection{Capturing and formatting data from a printed catalogue}

This section describes how a printed artefact catalogue was converted into electronic data, which could then be used as a basis for plotting artefact distributions. This process involved the following four steps (see also Figure 14).

\subsubsection{Data capture}

The printed artefact catalogue of the Roman military fortress of Vetera I (Hanel $\underline{1995}$ ) provided the source data for this project, a sample of which is included in this paper. The catalogue was scanned at a resolution of 300 dpi into TIFF files using a scanner that allowed the compilation of multiple-page images. The TIFFs were then converted into digital text using ABBYY FineReader optical character recognition (OCR) software. Overall, the OCR software produced highly reliable data from the TIFF scan images, although OCR's reliability decreased significantly in scans of less than 300 dpi resolution. FineReader was also able to read and convert German characters into electronic form and check the spelling of the resulting text, speeding up verification of the OCR output. The capacity of FineReader to batch-process multiple TIFFs greatly improved the speed and efficiency of the OCR process. The OCR output was saved as Microsoft Word files.

\subsubsection{Correcting the data}

Although FineReader produced editable digital files of the printed text, the information they contained was not in the correct format for use in either the relational databases or GIS data tables. Information about each artefact in the printed catalogue was presented as a continuous block of text, arranged in groups following a typological classification. For this information to be useful, it had to be re-arranged into a data matrix, which could then be queried to provide a quantitative summary of the total number and range of artefacts found

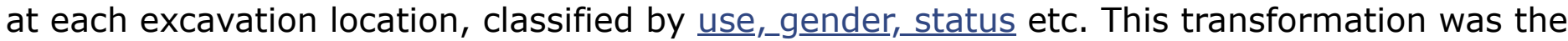
most time-consuming step in the data generation and manipulation process.

Although labour intensive, the most convenient and quickest way of re-formatting the catalogue was manually, using search and replace tools in Microscoft Word and Microsoft Excel. Basic formatting of the OCR text files was done in Word, with the formatting of the data matrix done in Excel. Macros could have been written to perform the task if each catalogue entry was identically formatted. However, this was not the case and in most cases printed catalogue entries were reduced to the bare minimum of descriptive information with empty descriptive categories simply left out.

The first step was to split the OCR text output into rows, one for each catalogue entry. This was largely done automatically by the OCR programme, but was also checked by eye. Each row was then split into a series of cells by inserting tab-stops in the Word documents at the point where cell boundaries were required. Information concerning artefact catalogue number, description, measurements, provenance or illustrations was put into a separate cell. Vetera's printed catalogue contained convenient abbreviations at the start of each subsection, signifying the type of information it contained. These abbreviations could be replaced at one stroke with tab-stops using the find and replace tool in Word. Once rows were arranged and cell boundaries defined, the text was simply copied and pasted into a new Excel worksheet. Excel automatically separated the data into cells and rows using the paragraph marks to signify row-endings and tab-stops to signify cell boundaries within those rows. As mentioned above, each catalogue entry contained a slightly different range of information. For example, some had long descriptions with measurements, illustration references and notes, while others contained only a basic description and provenance. This 
meant that each electronic catalogue entry initially contained a different number of cells when pasted into the Excel spreadsheet.

\subsubsection{Tabulating the data}

To enable the information to be queried in a database, the cells had to be arranged into single coherent fields, each containing only one type of information (e.g. description, provenance etc.). This was not the case when the data were first pasted into Excel, as the catalogue entries contained a varying number of cells (see above). Fields had to be correctly aligned by 'dragging and dropping' the cells for each catalogue entry into the appropriate field. While this process was time-consuming, it was not easily achieved by any other means and provided ample opportunity for eliminating mis-spellings and other errors generated during the OCR process.

Once the information derived from the OCR process was formatted correctly, additional information, such as typological group, material and the all-important interpretative categories (gender etc.) were added in new fields. Information about typological group and material was included in the printed catalogue only as section headings, so this information had to be added to each individual catalogue entry. The interpretative category data was new and was added in by Allison (see 3.2.). Another addition to the data table was the insertion of $\mathrm{SQ} \underline{\mathrm{L}}$-consistent abbreviations of the descriptive fields, used as field names in the summary artefact queries. These were necessary because, to run successfully, ArcGIS required $\underline{\mathrm{SQ}} \underline{\underline{L}}$ consistency for field names, whether data were added to the GIS project by a direct connection to Access using the OLE DB provider for ODBC driver, or by importing separate Dbase IV (.dbf) format tables. The abbreviations had to be a maximum of 8 characters long and to contain only alphanumeric characters or underscores. Clearly, some classification groups did not fit this format (e.g. tableware and serving?/food preparation?). A standard set of abbreviations was used (see Figures $\underline{10}$ and $\underline{11}$ ). (See Section $\underline{7.2}$ ).

Figure 16: Screen dump of part of Excel spread sheet showing data from OCR translation of scanned original catalogue and added data for categories and their SQL abbreviations.

The result of this process was a digital version of the artefact catalogue containing the descriptive information for each catalogue entry in a single row of data cells, arranged into fields, each of which contained a single type of information, such as provenance, use category or gender (Figure 16). The transformation from the printed page to data matrix, with the addition of interpretative categories, meant that rather than being simply an electronic translation of the original catalogue, the electronic version was a greatly transformed dataset.

Once the artefact catalogue spreadsheets were fully formatted (see section 9.1) and contained all the necessary data, the next step was to transfer them to a database programme where queries could be used to produce the summary quantitative data plotted in ArcGIS.

\section{back top forward contents home}

(C) Internet Archaeology URL: http://intarch.ac.uk/journal/issue17/4/7.1.html

Last updated: Mon Apr 42005 


\section{back top forward contents home}

\subsection{Preparing catalogue data for GIS}

Figure 17: Access database relationships page exemplifying how the relational database was structured

Data in the electronic catalogue produced using the process explained in Section 7.1 could not be used directly to plot artefact distributions in ArcGIS. This catalogue stored data by catalogue entry. ArcGIS, with its limited database capacity, was unable to generate quantitative summaries of the data by excavation provenance, in this case the excavation

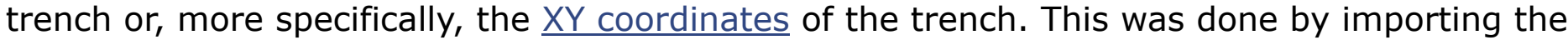
artefact catalogue into a relational database programme and using its query function. Microsoft Access was used in the project (Figure 17), but, in theory, any commonly available relational databases could be used.

\subsubsection{Summarising the data into output tables}

In the first instance, Access cross-tab queries were used to generate, from the main electronic catalogue file, a quantitative summary of the number of artefacts from any given interpretative category found in each excavation trench. The query counted the number of occurrences of each class (e.g. number of male, female artefacts) within each specified classification field (e.g. gender), within each trench (Figure 18).

Figure 18: Access query output showing the summaries by trench and gender categories with null values (i.e. empty cells).

\subsubsection{Adding XY coordinates}

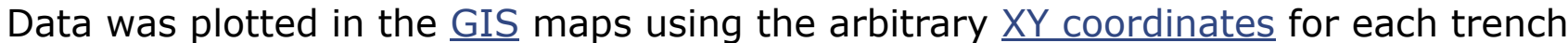
produced using an ArcGIS script (see section 6.2). Unprovenanced artefacts were given an arbitrary provenance code and $X Y$ coordinates so that they plotted outside the south-west

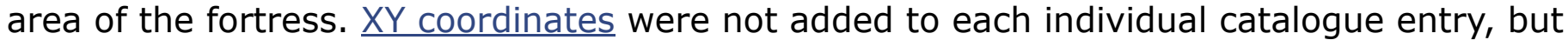
added to the summary data for each trench and data point from a separate data table in Access using a query. It should be noted that this process was necessary for Vetera I, whose site plan and artefact catalogues contained no $X Y$ coordinates, but was unnecessary for several artefact catalogues used in the Engendering Roman Spaces project which have their own XY coordinates systems (e.g. Ellingen - Zanier 1992).

\subsubsection{GIS data table production}

The queries summarising the quantity of each class of artefacts in any excavation trench formed the basis of the plots used in ArcGIS. Incorporating the tables into ArcGIS was, however, not a straightforward process.

Several options were tested, including linking directly to the queries in Access using the Microsoft OLE DB provider for ODBC driver in ArcGIS. This is potentially a useful means of adding tabular data to ArcGIS but was rejected in this case as much of the data became unplottable, especially in pie-charts, perhaps the most useful chart style in ArcGIS for this type of data. The reason was simple: the Access queries generated null values in the query tables when no occurrences of a specified artefact class were found in a data row. ArcGIS 8.3, which we used for the analysis of the Vetera data, would ignore any row, and thereby excavation trench, containing null values in its pie-chart plots, effectively excluding most of the data in many queries. The Access 'fix' for this problem (Nz function, which replaces null values with zeros) is not a standard $\underline{S Q} \underline{\underline{L}}$ command. It therefore could not be read by ArcGIS 
using the OLE DB for ODBC driver, and so would have rendered tables containing it largely useless.

A further problem was that directly linking to Access queries prevented the addition of calculated fields. Such fields are useful as a means of rapidly adding extra information to maps without going back to the original data. The solution to these problems was either to use Dbase IV files, exported from Access and separately imported to ArcGIS after replacing the nulls with zeros manually, or to use the ArcCatalog component of ArcGIS, which performed the operation automatically (Figure 19). An identical process was used to prepare data tables for Arcview 3.2, which also required SQL consistency.

Figure 19: . dbf table of the summary data with the null values in the gender categories filled with zeros

$\underline{\mathrm{SQ}} \underline{\underline{L}}$ consistency and the insertion of null values into Access queries caused major problems in the conversion of the electronic catalogue into a form that was readable and plottable in ArcGIS. The solution that has been used to date is robust and relatively simple, although suffers from the production of numerous tables in Dbase IV files. A well-structured file logging and storage system has minimised the potential confusion caused by production of multiple files. While use of the DBase IV files was not as elegant as direct connection to Access, it provided a flexible and rapid 'fix' to this technical problem. Another 'fix' to the null value problem would have been to totally re-design the catalogue database totally as a series of fully normalised related tables. While this was an elegant solution to the problem, the potential extra benefits of that course were not thought to be worth the considerable time investment it would have taken to reformat the Vetera catalogue of some 11,000 entries with 11 major category fields.

Since completing the analysis for Vetera I, however, we have been using ArcGIS 9 for other military sites and have found that this newer version can resolve some of these difficulties with null value translations.

\section{back top forward contents home}

(C) Internet Archaeology URL: http://intarch.ac.uk/journal/issue17/4/7.2.html

Last updated: Mon Apr 42005 


\section{back top forward contents home}

\subsection{Creating distribution plots of people and their activities}

Distribution maps of various activity and status categories were created using ArcMAP, a component of ArcGIS 8.0. Distribution plots of the quantities of artefacts, classified on the basis of the various applied interpretative categories (see tables, Figures 10 and 11), provide a means of showing where particular gender groups or activities may have been present in the past.

To create these distribution plots in ArcGIS, image files of the fortress buildings, excavation trenches etc were included as new layers in the map of the site. Tabular summary data from the DBase IV files were then added and the $X Y$ coordinates they contained were used to plot the quantitative summary of the desired functional and/or gender category. Plots were designed using the 'Symbology' menu in the 'Properties' dialogue box of ArcGIS. Several different plot types were used, but by far the most effective for pattern-searching were piecharts, the diameters of which were scaled to the sum of classificatory fields used in their calculation. Pie-charts allowed the distribution and relative quantity of artefacts in several interpretative categories to be visualised simultaneously. This was a useful means of searching for general distribution patterns, the details of which could then be investigated by generating individual category plots for any given artefact category.

The distribution of artefacts in specific buildings and rooms could also be investigated by zooming into desired parts of the GIS maps. However, it should be noted that the pie-charts plotted to the centre-point of each trench, using the arbitrary coordinates assigned to them as discussed above. Data plotted at a single point, therefore, summarised the artefacts found in a potentially large area of the site. Spatial accuracy of the artefact plots depended on the length of the excavation trench area and its location. Some of the trenches traversed large areas of the site and several buildings, while others were confined to specific rooms or buildings. Trench 750, for example, traverses the west side of Building $F$, the via principalis, and the whole west side of the palace. However, about two-thirds of it is located in palace P. Its artefacts, of which there were many, therefore plot to the palace $P$ but the potentially wider distribution must be borne in mind when analysing the distribution pattern (Figure 20). On the other hand, the trenches in Buildings A, B and G, and tribune houses K-M, are limited to these buildings and so provide a more reliable distribution pattern (Figure 21). So, while the GIS programme produced effective visualisation of the artefact data, its interpretation demanded careful consideration of the potential living spaces that the artefacts came from.

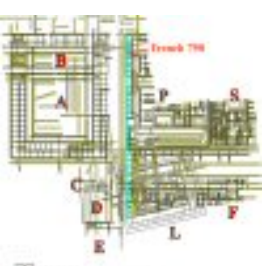

Figure 20: Sample of GIS view of long trench, Trench 750, through Buildings P and F

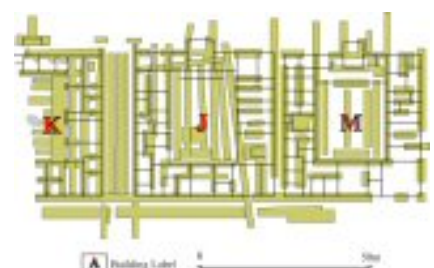

Figure 21: Sample of GIS view of short trenches in Buildings $\mathrm{K}, \mathrm{J}$ and $\mathrm{M}$ 


\section{back detail forward contents home}

\section{Section 8: Analyses of the Distribution of People and Activities}

\section{P.M. Allison, with a contribution from A. Fairbairn}

This article analyses the distribution patterns of a sample of functional and gendered categories within the fortress of Vetera which can be plotted by the reader (see 9.2 and 9.3). This group of categories has been selected because they are potentially concerned with personal activities and the presence and roles of women in this fortress. The distribution patterns for other categories (e.g. tableware and food preparation activities) at Vetera I have been explored elsewhere (Allison n.d. 3 ).

\section{Analyses}

8.1 Toilet activities: The few items related to toilet activities recorded at Vetera I were mainly concentrated in residential buildings, the main street and Building $\mathrm{T}$.

8.2 Dress: The distribution of dress-related items, including combat dress, showed a concentration of women' and children's items in the street and in the officers' residence but also in other less predictable areas.

8.3 Cloth-production: The poor representation of cloth-production at Vetera I may be related to traditional recording approaches to military sites but may throw light on the function of Building Z.

8.4 Gaming: Gaming items in good contexts are concentrated at the east end of the via principalis.

8.5 Writing: Artefacts associated with writing occur in concentrations which may help to identify the use of space in particular buildings and parts of buildings

8.6 Gender: Analysis of the distribution of gender-related activities and dress, can help better understanding of the areas frequented by women and children and the types of activities carried out in certain buildings.

8.7 Overall interpretations: These analyses, tested for robustness by using statistical analysis, demonstrated both predictable and unpredictable patterns of use of space at Vetera I and the place of women and children in this environment.

\section{back detail forward contents home}

(C) Internet Archaeology URL: http://intarch.ac.uk/journal/issue17/4/summary $8 . h t m l$

Last updated: Mon Apr 42005 


\section{back top forward contents home}

\subsection{Toilet activities}

\subsubsection{Toilet items}

Artefacts from Vetera I that have been classified as toilet items are those related to personal hygiene, health and possibly beauty. These include the remains of mirrors, strigils, probes and tweezers. Some of these may have been surgical instruments but no distinction is made here. The distribution of such items in the Insula del Menandro in Pompeii (Allison $\underline{\text { n.d. } 1}$ ) suggests that medical treatments, which today require specialised medical practitioners, might rather have been a type of first-aid in the 1 st century $\underline{C E}$. That is, minor surgery may have been practised as a more general household task than has occurred in more recent times. Thus, the distinction between personal or toilet activities and medical activities may have been more blurred than we tend to think. As Ralph Jackson has commented, the line between body care and medical healing in the Roman world is indistinct (Jackson, pers. comm.).

The situation within military installations may well have been different from that within domestic households, however. For example, in at least some forts and particularly large legionary fortresses like Vetera I, soldiers would no doubt have had better access to trained medical personnel than did Pompeian households. And, as argued by Baker (2001), the medical practices were likely to have varied across the Empire. Nevertheless, we should not discount that the types of objects listed above, and also found in Pompeian domestic contexts, would have been included among soldiers' personal hygiene equipment.

\subsubsection{Possible toilet items}

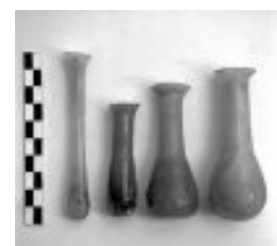

Figure 22: Unguentaria (inv. nos 5080A-D) from House I, 10,2, Pompeii (photo J. Agee)

Other artefacts from Vetera I have been categorised as possible toilet items, along with alternative classifications such as 'food preparation' or 'tableware and serving' where appropriate. Such items include small glass bottles, frequently referred to as unguentaria (for example, Isings 1957, 24; Kunina 1997, glossary; Fleming 1999, 4 pls 2-3; see de Tommaso 1990, esp. 19 n.1, 22) (Figure 22). While most evidence points to such vessels having been used for aromatic substances, cosmetics and medicaments, these may not have been their exclusive contents. There is also evidence, particularly from associations in Pompeian houses (Allison n.d. 1), which suggests that these vessels were used to hold food essences or condiments required in small quantities, or possibly paint. Small ceramic bottles and small glass bowls, cups and indeterminate fragments, have similarly been classified as 'toilet?'.

Glass bowls or dishes (with rim diameter mainly 100-200 mm), indeterminate glass vessel fragments, and bronze spoons, are categorised as 'tableware and serving?/toilet?'. While the larger of these vessels were probably used for tableware, this is by no means certain. In the assemblage above room 7 in the Casa del Fabbro in Pompeii, such bowls were found associated with personal items and artefacts that seem to have been for medical purposes (Allison n.d. 1). Other small glass cups and small glass bowls (with rim diameter $<100 \mathrm{~mm}$ ) are categorised as 'tableware and serving?/toilet?-drinking?'. 
Large bronze sub-hemispherical basins with horizontal handles have been found in Pompeii in association with jugs with one or two vertical handles and these have been identified by Tassinari as sets used in ablutions, such as washing feet $(\underline{1993}, \mathrm{I}, 232$; see also Allison, $\underline{\text { n.d. }}$ 1). A similar basin is also depicted in a relief from Ostia, in which a baby is about to be washed (Kampen 1981, fig. 1). Handles of such basins have been recorded at Vetera I and so have been categorised as possible toilet items. Similarly, remains of bronze buckets have been included among possible ablution or toilet items and categorised as 'foodpreparation?/toilet?'.

Remains of copper needles, of unidentified length, are categorised as 'cloth production?/toilet?' because large standard needles (length c. $150 \mathrm{~mm}$ ) were also used in surgery (see Jackson 1994a, 204-5 nos A14 and A15; see also Jackson 1994b, 176-77). Fragments which could be either needles or pins are categorised as 'dress?/cloth production?/toilet?'.

\subsubsection{Analysis and interpretation of the distribution patterns at Vetera}

The following queries were run to investigate the distribution of toilet activities. The first query mapped the distribution of remains of all artefacts unequivocally identified as toilet items and the second query mapped the distribution of all artefacts that could conceivably have been related to toilet activities.

\subsection{3a Artefacts categorised as certain toilet items (T1)}

Following a review of legacy systems and in line with broader ADS practice, the interactive map element of this article has been decommissioned. The full underlying set of data is still available for download from the digital archive.

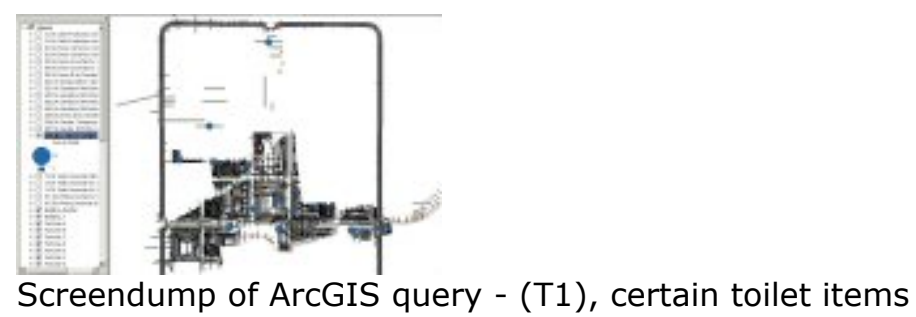

There are eighteen items in the catalogue identified as toilet items, but only sixteen of these could be plotted in known trenches. One probe was from the surface and unprovenanced and a strigil from Trench 308 (in a pit to the north of Building A) could not be plotted. Of the sixteen that could be plotted, two were outside the Neronian fortress. Those within the fortress are all single and dispersed finds. One was found in each of the north and east gateways, and another two were found in the main cross street, the via principalis. Of those found within the actual buildings, one probe was found in barracks $N$, two probes in the tribunes' houses $\mathrm{K}$ and $\mathrm{M}$, another two probes in Building $\mathrm{T}$, two mirror fragments in the central administrative building, Building $A$, and a mirror fragment in the legate's palace, Building P. Another mirror found in Trench 750 could conceivably also have been from palace P. One in Trench 64, in the north-east area of the fortress, and possibly the strigil in Trench 308 , were from pre-Claudian contexts. None of the items plotted within the buildings were found in pits.

Although the numbers are extremely limited, there is perhaps a predictable pattern, with toilet items in residences or lost in the street. The lack of any toilet items in palace $\mathrm{H}$ is not surprising given that there is a general lack of finds in this building (Allison n.d. 2, esp. fig. 10; see Section 8.7.6). More surprising are mirror fragments in Building $A$, although at least one of them is likely to have been from pre-Claudian contexts in the building's foundations. The lack of such items in Building $\mathbf{Z}$, identified as the hospital, but their apparent 
concentration in Building $\mathrm{T}$, are perhaps more noteworthy. While the quantities are essentially too insignificant to draw conclusions, one could perhaps be open to the possibility of habitation, or at least toilet activities, within Building $T$ and an incorrect identification of Building Z.

\subsection{3b Artefacts categorised as uncertain toilet items (T2) and (T3)}

There are many more of these types of items, adding more complications to the distribution pattern of possible toilet items (T2). They are therefore examined according to individual type.

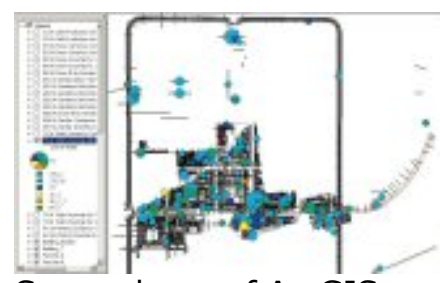

Screendump of ArcGIS query - (T2), all possible toilet items

The most prolific artefacts are remains of glass dishes or bowls (with rim diameters ranging from 80-200 mm), indeterminate glass fragments, and bronze spoons, which could alternatively have been tableware and serving items (ZTS_T). These have a fairly wide distribution but, within the area of the excavated central buildings, there are concentrations in: the front parts of Buildings $Z, Y$ and $a$, on either side of the via principalis near the west gate; tribune's house $M$; palace $P$ and Building $S$; the open area in front of Building $A$; and in the buildings fronting the south side of the via principalis, towards the east gate, notably Buildings $T$ and $U$. One in Building $a$, one near the east gate, and one in Building $M$ were in pre-Claudian contexts. Such items were present in the central administrative buildings, A-B and $\mathrm{G}$, but in comparatively limited numbers. At least one of the four found in Building $\mathrm{G}$, was from a pre-Claudian context. If these items were indeed toilet items then their concentrations in Buildings $M$ and $Z$ might be expected. Less expected is their presence in what were possibly more public buildings along the via principalis, identified by Lehner $(1930,39)$ as shops. It has been noted that these are also the locations for concentrations of ceramic tableware (Allison n.d. 2, figs 5-6), suggesting that these glass vessels were perhaps more usually tableware than toilet items. One item found in Trench 1512 and one in Trench 119 could not be plotted.

Also relatively prolific were small glass bowls and cups (rim diameter less than $100 \mathrm{~mm}$ ), which may equally have been tableware items, possibly drinking cups (ZTS_TD). The remains of these are likewise fairly widely distributed. In the central excavated area of the fortress, there were no real concentrations, but their presence is again noteworthy in: buildings opening onto the via principalis, particularly near the east gate; the open area in front of Building $\mathrm{A}$ (one in a pre-Claudian context); Building a; palace $\mathrm{H}$; and Building $\mathrm{F}$. There was also one such item in Building $N$, two in tribune house $M$ and one in the central administrative Building $A$. One of the three recorded in Building $G$ was from a pre-Claudian context, as was one from Buildings $C$ and $D$. One found in Trench 1332 could not be plotted. The general impression is that these bowls are not concentrated in particularly private areas, but rather in what would seem more public areas. They, again, may in fact be tableware rather than toilet items.

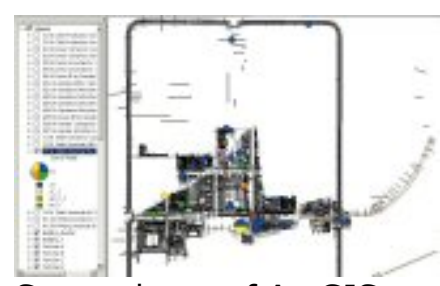

Screendump of ArcGIS query - (T3), possible toilet items (excluding glass bowls) 
By comparison only limited amounts of other possible toilet items were recorded (T3). The next most prolific are glass and ceramic unguentaria and bronze basins (ZT). There are twenty-three items of these types recorded at Vetera I, of which one in Trench 308 could not be plotted. Their distribution is, in some respects, comparable with that of the certain toilet items. They are from contexts predominantly identified as Claudian-Neronian and concentrated in tribunes' houses $\mathrm{J}$ and $\mathrm{M}$, the open area in front of Building $\mathrm{A}$, and Building $\mathrm{F}$. One from Trench 582, which could not be plotted, was also from Building J. These items are also present in the vicinity of the north and east gateways, in front of barracks $V$ and in palace $\mathrm{P}$, and four were found in the administrative buildings, Buildings $A$ and $\mathrm{G}$. One of the latter, and possibly the one in the east gateway were from pre-Claudian contexts. The concentration in Building $F$ is potentially the most interesting.

Only five needles and needle fragments (ZC_T) and (ZD_C_T), which could conceivably have been toilet items, were found: one in the portico in front of barracks $V$, two in the area in front of Building $A$; one in Building B (possibly pre-Claudian); and one north of barracks Y. The distribution of these limited and easily lost items is, on its own, probably not significant.

Bronze buckets may have been used in ablutions but also for carrying water for other purposes, such as food preparation (FP_T). Remains of two were found near the via principalis, in front of Building $F$ (dot hidden on screen dump) and barracks $Y$. One was in Building $a$ and another in the south-east area of Building $\mathrm{G}$. Given the distribution pattern of the glass bowls and ceramic tableware, the location of the former two might indicate their association with food preparation (see Allison n.d. 2, fig. 7). The location of the last one suggests that we might consider looking at the south-west area of Building $\mathrm{G}$ as either a potential food-preparation area or an area for personal hygiene activities. The lack of any other toilet items but the presence of other food-preparation items in this area, suggests that it was more probably a food-preparation area. However, this is by no means conclusive without further analysis.

In summary, the uncertain toilet items that are most likely to have been toilet items follow a similar distribution pattern to the more certain toilet items. That is, they are concentrated in the officers' residences, on the south side of the eastern end of the via principalis and near the east gate but also have a notable presence in the central administrative buildings.

\subsection{3c Gendered toilet items (T4)}

It is very difficult to ascribe gender convincingly to items used in toilet activities. The exception is perhaps razors but, interestingly, none were recorded here. Mirrors and tweezers were very probably used by men and women. Kampen commented that $(\underline{1996}, 22)$ mirrors have been 'symbolically associated with women' since Greek times. However, in practice, as Wyke has noted (1994, esp. 135-38), mirrors were also likely to have been used by males. Allason-Jones has also argued $(\underline{1995}, 28)$ that the presence of tweezers in the turrets on Hadrian's Wall indicates that they could have been male personal hygiene equipment. Likewise, from their presence in the turrets on Hadrian's Wall, Allason-Jones has argued $(\underline{1995}, 28)$ that needles were used by soldiers who would have needed to do their own mending. Thus, she has argued against a direct association between women and needles. The use of needles in surgical activities also argues against any direct association between women and needles. Therefore, most toilet items have been categorised as 'male?/female?'. Glass bowls, glass cups and indeterminate glass items (ZTS_T) and (ZTS_TD) have been excluded from this plot as many of these may well have been tableware and therefore have not been gendered. 


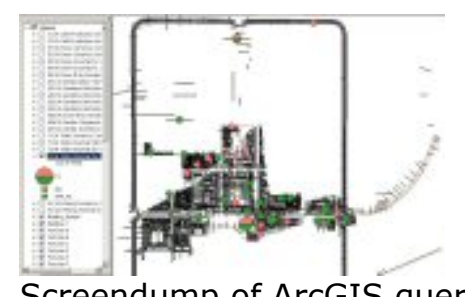

Screendump of ArcGIS query - (T4), gendered toilet items

If any of these toilet, or possible toilet, items could be categorised as women's items the most likely would be the unguentaria given their traditional association with aromatic substances and cosmetics, particularly glass unguentaria. Of the thirteen unguentaria from the central excavated area, five were found in the open area in front of Building $A$ and in Building $F$; three in Building $G$ (one in a pre-Claudian context), one in Building $A$; one in the east gateway; two in the tribunes' houses J and M; and one in Building L. Thus potentially female toilet items predominate in the vicinity of the tribune houses and of the central open area, which was possibly a market place (Lehner 1930,40$)$. This pattern should be borne in mind while investigating the distribution of items more convincingly associated with women (see Section $\underline{8.6}$ ).

\subsubsection{Conclusions}

The pattern for the distribution of personal hygiene items at Vetera I is perhaps disappointingly uninformative, not least because the quantity of artefacts is very low, with the exception of glass bowls and dishes which are dubious toilet items. Nevertheless, a number of toilet items were found in buildings identified as residential, and in Building $\mathrm{T}$, but notably not in the hospital, Building Z (see Section $\underline{8.7}$ ).

\section{back top forward contents home}

(C) Internet Archaeology URL: http://intarch.ac.uk/journal/issue17/4/8.1.html

Last updated: Mon Apr 42005 


\subsection{Dress}

\subsubsection{Items of dress}

Artefacts from Vetera I that are dress items include: fibulae, belts and belt attachments, jewellery, bronze and bone hairpins, and some textiles and leather remains. It is also possible, in some cases, to distinguish whether particular items were worn by men, women, or even children. The belt plates, which were part of armour, are most probably male dress and classified as 'dress-combat equipment'. Other particular items can be separated into male or female dress. As used here, male and female categories refer to adult male and adult female.

\subsection{1a Fibulae (brooches)}

The most common article of dress to be found in Roman military sites is the fibula (brooch). Most brooches found in these sites were worn by soldiers, both to fasten their coats and as an insignia. A number of brooches also occur in military sites that can be identified as women's, or possibly women's, brooches. Both men and women wore relatively high-bowed brooches which could fasten the thick cloth of overcoats. There were also certain types worn by women for lighter undergarments and as jewellery (see Martin-Kilcher 1993), although it has not been conclusively argued that these were exclusively women's brooches (AllasonJones 1995, 22-24).

\section{'Male' fibulae}

According to Gechter $(\underline{1979}, 77), 75 \%$ of the brooches within Roman military sites in the Rhine region had a high bow and were most probably worn by men. The more prolific types from these provenances have justifiably been identified as soldiers' brooches (e.g. Böhme 1972; form 20; Riha 1979, 1.6.2). Many fibulae that have been identified as men's brooches could conceivably have been worn by women to hold their thicker outer garments (e.g. the Aucissa fibulae: Riha 1979, 5.2) (see Figure 6). However, for the purposes of this study such brooches have all been categorised as 'male'. This is to guard against a too positivistic argument for the presence of women and may indeed mean that there were many more women's brooches at Vetera than are identified in this study.

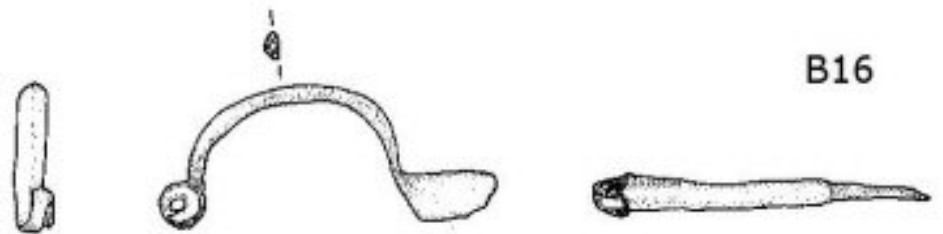

Figure 23: Spiral fibula B16 from Vetera (drawing Hanel 1995, pl. 28)

Böhme has argued that the spiral fibula, Almgren 16 (Böhme 1972, 14-15, Form 15 - Figure 23 ), can safely be attributed to women because this type frequently occurred in pairs in Belgic female graves, as did enamelled disc brooch (Böhme 1972, 36-37, Form 41). Likewise, Böhme has classified disc brooches decorated with silver or gold wire or coated with silver or gold as women's jewellery (Böhme 1972, 36-37, Form 44). Also, bowed brooches with a semi-circular headplate and a suspension eye for a chain (Böhme 1972, 17- 
18, Form 18) were worn by women. Only these types have been categorised as 'female' in this study (although cf. Allason-Jones 1995, 24).

'Female?' and 'Female/male?' fibulae
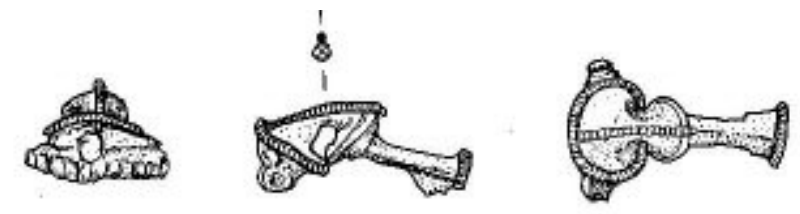

B44

Figure 24: Trumpet fibula B44 from Vetera (drawing Hanel 1995, pl. 30)

Because of its small size (c. 20-45 mm long), the trumpet fibula, Almgren 101 (Figure 24), was thought by Fischer $(\underline{1966})$ to have been a women's brooch type although Böhme ( $\underline{1970}$, 10-14) has argued that this type could be worn by both men and women. Their occurrence alone within forts is not, however, an argument for their having been worn by men.

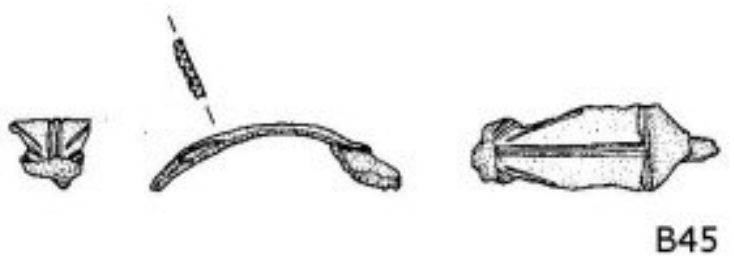

Figure 25: Kragenfibeln B45 from Vetera (drawing Hanel 1995, pl. 30)

Wild noted $(\underline{1968}, 202)$ that three Claudian Kragenfibeln were used for women's overtunics on stelae from Mainz-Wesenau and Ingleheim. Gechter commented $(\underline{1979}, 77)$ that Kragenfibeln represented under $5 \%$ of the brooches found inside military fortifications but that this number doubled in oppida. This suggested to him that they were probably civilian brooches and quite possibly women's brooches. According to Böhme (pers. comm.), Almgren 269 Kragenfibeln (e.g. Vetera B45, Figure 25) are a Late La Tène form, the more developed form of what was originally a women's brooch. However, she also warns (pers. comm. letter 15.04.04) that Kragenfibeln came in a great range of sizes and heights of bow, the higher bow being later, so it is no simple matter to identify whether a particular one is for male or female, or possibly children's, dress, without good contextual evidence.

Gechter also commented $(\underline{1979}, 77)$ that 'Langton-Down' and 'Distel' fibulae represented less than $5 \%$ of the brooches found within military fortifications, again with twice this number in oppida. Martin-Kilcher $(\underline{1993})$ has frequently noted 'Distel' fibulae in women's graves in the area of the Alps during the early Empire and smaller-sized brooches as fasteners for women's undergarments. Böhme argued (Böhme-Schönberger 1998a, 359-60) that 'Distel' fibulae (Almgren 239 and 240) are truly female brooches only in their indigenous milieu but that their military association is either evidence of women in Roman camps or of German soldiers. She also warns against classifying Langton-Down fibulae as 'completely female fibulae' (pers. comm. letter 15.04.04). A number of disc brooches in the form of animals (Böhme 1972, 40-41, Form 43) are also found in military sites, but in greater numbers in civilian sites. However, it is not possible to ascertain whether these were worn by men or women.

For the purposes of this study, these particular fibula types, which have been identified by some scholars as women's brooches, are categorised either as 'female?' or as 'female?/male?', depending on the relative likelihood of their being the size and specific type worn by women. 
Belts were required by Celtic, German and Noric-Pannonian civilian male and female dress and by Roman soldiers' dress (Böhme-Schönberger 1997, passim). It would seem possible to distinguish between at least some of the belts and belt attachments of the different gender and social groups. For example, metal belt plates and simple buckles with tongues seem to have belonged to Roman soldiers (see discussion below). Thus, for the purposes of this study, unless belt attachments have been definitively identified as women's dress they are categorised as 'male'.

\subsection{1c Hairpins}

A number of bronze and bone pins have been found at military sites, without an eye but with rounded and sometimes decorated heads. Pins of gold, silver, bronze, ivory, bone or gagat with plain or decorated heads, are common finds in settlement sites and burials and have been identified as women's hairpins (Böhme-Schönberger 1997, 83-84). The function of a hairpin was to hold the hair in a knot but they were also worn as jewellery (Riha 1990, 95). They became more common from mid 1st century $\underline{C}$, when women's hairstyles became more complex and ever higher, often following the styles of the women of the imperial family. For this reason hairpins are considered part of female dress.

At South Shields on Hadrian's Wall, a very large quantity of bone and bronze pins were recorded, both materials ranging in length 35-115 mm (Allason-Jones and Miket 1984, 6891, 178-184). Allason-Jones argued (Allason-Jones and Miket 1984, 68) that the well-made and neatly decorated bone pins were 'intended as hair-ornaments or possibly dress fasteners' while the coarser ones were possibly functional bag fasteners. To date, the evidence seems to suggest that decorated bone and bronze pins were used as hairpins in life but that bronze ones, at least, could be used in death to hold the shroud in the 3rd and 4th centuries (Allason-Jones 1995,28 ). For the purposes of this study, complete pins with shaped or decorated heads which fit within the size range of those at South Shields are identified as hairpins and categorised as 'dress' and 'female' (see Allason-Jones 1996, 19899).

\subsection{1d Shoes}

Remains of leather shoes are frequently found in Roman military sites, particularly the more waterlogged ones like Vindolanda on Hadrian's Wall and Valkenburg in Holland. An elegant sandal, stamped with the name of its maker and found within the Vindolanda fort is believed to have belonged to Sulpicia Lepidina, the commanding officer's wife, who had been writing to her friend, Claudia Severa (Birley 1977, 125; Van Driel-Murray, 1995, 9). While this definite attribution may be somewhat fanciful, it is certainly not the sort of footwear one would expect to find a soldier wearing. Finds of similarly elaborate footwear have been made at Saalburg, possibly from wells within the fortress complex (now on display in the Saalburg Museum). Other leather soles and wooden shoes, cannot be so easily 'sexed'. Carol van Driel-Murray $(1994 ; 1995 ; 1997)$ has studied the remains of shoes found at military sites and analysed the spatial distribution of smaller-sized shoes to argue for the presence of women and children within soldier's barracks prior to the end of the 2nd century $\underline{\mathrm{CE}}$.

\subsection{1e Jewellery}

Finger-rings

Bronze rings, which can be definitively identified as finger rings, and remains of ring inlays have been found within Roman military installations and identified as jewellery and therefore dress. A number of other rings are less certainly jewellery and are discussed below. 


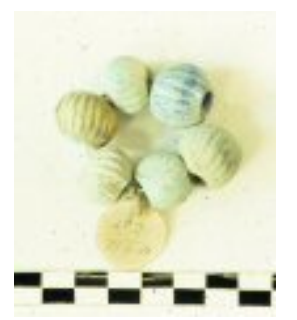

Figure 26: Melon beads (inv. no. 4772), found with human skeleton in room 19 in the Casa del Menandro in Pompeii (photo P. M. Allison)

Beads, particularly glass or bone beads, have been recorded at a number of Roman military sites. Allason-Jones has argued that, while necklaces of beads were worn by women ( $\underline{1996}$, 189-99), beads could be worn as amulets by children of both sexes $(\underline{1995}, 27)$. There is also evidence that the particular type of glass melon bead (Figure 26) was used to decorate horse harness and shield sheaths (Hoffmann 2002, 230). My study of artefacts from the Insula del Menandro in Pompeii (Allison n.d.1) indicated that bone discs with diameter 15-30 mm and a central hole of diameter 2-3.5 mm were most likely to have been worn as beads. Therefore, glass beads, which are not melon beads, and small bone beads are categorised as 'dress' and as 'female'. Glass medallions are also categorised as 'dress' here. These are sometimes considered to be military decoration although it is not necessarily proven that they were worn only by men.

Earrings, armlets and bracelets

Earrings and bracelets were not recorded at Vetera but they do occur at other military sites (see Allason-Jones 1995, 25-26). Allason-Jones noted that a number of Roman authors scorned the wearing of earrings by inhabitants of the East, but that some of these individuals would have served in the army in the western provinces. Therefore earrings from these military sites are not definitively female dress. However, such soldiers are unlikely to have worn the same types of earrings as Roman or native women from the western provinces although to prove this one would need to investigate the distribution of earring types across the Empire.

Roman authors were also disparaging about men wearing bracelets, but gold armlets were male accessories in the celtic world (Allason-Jones 1995,27 ) and armlets were worn by soldiers, at least in period of the tetrarchs, according to Bishop and Coulston $(\underline{1989}, 69)$.

\subsection{1f Armour}

There are a number of items found in military sites that can be identified as parts of armour, and therefore as military dress. These include some remains of helmets and of certain types of belts.

Belts

Soldiers usually wore belts with a metal buckle and made up of metal plates (Bishop and Coulton 1993, 96-98). These belts were sometimes worn as crossed pairs and carried swords and daggers (see Robinson 1975, pl. 242-5). Buckles, which appear to have been used specifically for 'lorica segmentata' armour, are hinged buckles (see Robinson 1975, pls 48593; Bishop and Coulston 1993, fig. 52). Therefore, this particular type of buckle and these metal belt plates have been categorised as 'dress-combat equipment' and 'male'.

Hinges

The reconstructed 1st century CE 'lorica segmentata' cuirass from Corbridge shows hinge types that have been identified as parts of armour (Allason-Jones and Bishop 1988 figs 2324). These types do occur in other contexts where such an identification is not so clear (e.g. 
in House I 10,8 in Pompeii: Allison n.d. 1, cat. no. 1646). Therefore, it should not be discounted that, even when they are found within military sites, these hinges may not always have been parts of armour. Nevertheless, for the purposes of this study they have also been classified as 'dress-combat equipment' and 'male'.

\subsubsection{Possible items of dress, jewellery and armour}

A number of other artefacts are likely to have been used for dress but this is by no means certain.

\subsection{2a Fasteners}

'Button-and-loop' fasteners are frequently found on military sites. Wild (1970b) has argued that they were associated with horse harness. However, their occurrence in domestic contexts (Wild 1970b, 143), in personal assemblages (Allison n.d. 1, in room 2 in the Casa del Fabbro), suggests that they could also have been used for human apparel, possibly male and female. They are therefore categorised as 'dress?/combat equipment?/horse equipment?' and 'male?/female?'. Bar-and-keyhole type fasteners have variously been identified as either for armour or for horse harness (see Bishop 1988, 103; Hanel 1995, 56). They are therefore categorised as 'dress?/combat equipment?/horse equipment?' and 'male'.

\subsection{2b Other bronze and bone pins}

As well as hairpins or dress pins, undecorated pins could have been used for a number of other purposes. Bronze or bone pins with a marked shoulder are identified as styli (see Deschler-Erb 1998, 143-4, 159-66, pls 22-23 and 31-36). Wild noted that spindles in the northern provinces were made of wood or bone and were up to $300 \mathrm{~mm}$ long (1970a, 32-33 and $\mathrm{pl}$. 3b), and that distaffs could also be made of bone and were 200-300 mm long (1970a, 31 and fig. 15). A spindle attached to a spindle-whorl discovered in the Casa del Fabbro in Pompeii had a squared head with a diagonal cut in the shaft, near the head, and a tapering shaft (Allison n.d. 1, cat. no. 1049).

Fragments of bone pins which have no evidence of a marked shoulder, decorated head, identifiable complete length, or evidence to indicate whether or not they had an eye, are categorised as 'dress?/cloth production?/writing?' and as 'male?/female?', although some could potentially have been bag fasteners. Bronze pins with no indication of whether or not they had a decorated head or eyes are categorised as 'dress?/cloth production?/toilet?' and also 'male?/female?'.

\subsection{2c Bronze rings}

Considerable numbers of bronze rings occur in Roman military sites and had a range of uses. Some, particularly those which are either decorated, or are of a particular size range with a flattened inside face, are categorised as 'jewellery?', as a subcategory of 'dress?'. It is also possible to suggest whether individual rings were worn by men, women or children.

On the basis of modern data for ring sizes and the knowledge that Romans wore rings on all fingers and all joints, Furger $(\underline{1990})$ has done a statistical study of the size-ranges of different types of rings from Augst and Kaiseraugst, in Switzerland. He has estimated that: children's rings had a general inner diameter c. $13 \mathrm{~mm}-14.3 \mathrm{~mm}$; the most common inner diameter for those worn by women was c. $17.5 \mathrm{~mm}$, with a range from $9-21 \mathrm{~mm}$; the smallest ring worn by an adult male had an inner diameter of $13 \mathrm{~mm}$; and rings worn by men most commonly had an inner diameter between c. 19-24 mm. He also found that keyshaped rings and polygonal rings were not generally worn by children; key-shaped and inlaid rings were worn by men and women, twisted wire rings and engraved rings were worn by men, rings with a flat plate were more commonly worn by children and men than by women, 
and open rings, plain bands, and rings with a rectangular section were women's rings. According to Allason-Jones $(\underline{1995}, 27)$ intaglio rings were worn by both sexes.

Most artefact catalogues do not indicate whether the diameter of rings given is the inner or the outer but the usual convention in archaeology is to measure the outer diameter of an object. Thus, the recorded ring-diameters tend to be somewhat larger than those discussed by Furger. For the rings discussed in this catalogue it is sometimes possible to measure the inner diameter but not always. Furger gave a maximum inner diameter of $24 \mathrm{~mm}$ for a male ring. Gold finger-rings from the treasure in the Casa del Menandro had an outer diameter of up to $30 \mathrm{~mm}$ (e.g. Allison n.d. 1, cat. no. 472) and a twisted ring from Vetera with an outer diameter of $30 \mathrm{~mm}$ (B505) was very probably a finger-ring.

On this basis, circular, as opposed to four-sided, rings whose internal diameter is not available but which have an outside diameter less than $30 \mathrm{~mm}$ and a relatively flattish inner profile have been tentatively identified as finger-rings. Depending on size, and allowing up to $4 \mathrm{~mm}$ difference between inner and outer diameter, they have been categorised variously as either men's, women's or children's rings. $4 \mathrm{~mm}$ is no doubt conservative for heavier rings, but possibly a bit optimistic for smaller and lighter rings. In balance, this means that a small percentage of the rings categorised as female?/child? could have belonged to small men, and some of those categorised as male? rings would conceivably have been female? rings. Thus, the gender categories tend to err on the conservative side.

\subsection{2d Glass and bone beads and discs}

As mentioned above, the particular type of glass melon bead was used to decorate horse harness and armour as well as for jewellery. It is therefore categorised as 'dress?/horse equipment?'. Discs similar in size to the bone ones discussed above but made of other materials (e.g. lead, stone) may also have been jewellery, so these have been categorised as 'dress?' and 'female?/children?

Many of the bone and glass discs with central holes from the Insula del Menandro in Pompeii could be shown to be either jewellery, spindle whorls or furniture fittings, depending on the size of the disc and of its central hole (Allison n.d. 1). Some may also have been reused as gaming counters, as identified by Hanel $(\underline{1995}, 285)$. Unfortunately the size of the central hole is seldom given in the finds catalogues of Roman military sites. Depending on the evidence for each one, they are therefore categorised as one or more of 'dress?/cloth production?/furniture?/gaming?'.

\subsection{2e Bells}

Large and small bronze bells occur in Roman military sites. Bells have a number of functions in the Roman world (see Allason-Jones 1999a, 2-3). Gusman suggested $(\underline{1900}, 127-28)$ that they were worn, or hung outside dwellings, for protection. Galliazzo (1976, 157 nos 2-5) identified bells for use in the domestic sphere (for example, as dinner bells). They could also be used in temples and shrines. Bells, often made of iron, were suspended from the collars or harness of horses, cows, sheep and goats (see Jacobi 1897, 534; Emery 1938, 262-71). Heavier ones were usually used for beasts of burden such as oxen or mules. In the Casa del Menandro in Pompeii, six bells (height c. $60 \mathrm{~mm}$ ) were associated with animal harness (Allison n.d. 1, cat. nos 603 and 622). Bells were also used as personal ornaments (for example, small light bells threaded onto an armlet) or as musical instruments (see Crummy $1992,186-87)$. Chavane suggested $(\underline{1975}, 147-8)$ that small examples were worn by children or used for chimes. In the Casa del Fabbro in Pompeii, two such bells (hts, $30 \mathrm{~mm}$ and $22 \mathrm{~mm}$ ) were found in association with personal items and jewellery (Allison n.d. 1, cat. nos 1442-3). In this study, bells with a height less than c. $30 \mathrm{~mm}$ are categorised as musical or jewellery items, probably for women or children. Those of c. $40 \mathrm{~mm}$ or more are classified as 'horse equipment?/music?/religion?'.

\subsection{2f Buckles}


The buckles of soldier's belts were sometimes hinged to one of the belt plates and were often D-shaped with a strap tongue (see Allason-Jones and Bishop 1988, figs 53-54). Buckles were also used on cuirasses (see Allason-Jones and Bishop 1988, figs 23-24). Wild observed $(1968,182)$ that '[b]elt-buckles are rarely found except in military contexts' (see also Manning 1985, 146-7), but this is not strictly true. A D-shaped buckle was found in a settlement context in Scole, although identified as military equipment (Bishop 1991, 24-25, fig. B1). D-shaped buckles are also found on horse harness (e.g. Palágyi 1986, figs 1-2) and occur in the domestic assemblages in Pompeii. Many of those found in the Insula del Menandro in Pompeii were thought to have been for horse equipment (Maiuri 1933, 452), but their distribution and associations suggest that this is improbable (Allison n.d. 1 , cat. nos $690,772-775$ ). Belts were also worn by civilians, both male and female. Varro (de. $\underline{L} . L$. $V$, 114 ) tells us that the cingillum was a belt, or girdle, worn by women (see also Bishop and Coulston 1993, 96). As well as the identifiable local types of belt attachments in the western provinces there also seems little reason to suppose that civilians, male and possibly female, never wore these D-shaped buckles, particularly given their provenances in Pompeii. They have, therefore, been categorised as 'dress?/combat equipment?/horse equipment?' and as 'male?'.

\subsection{2g Pendants}

Numerous bronze pendants, sometimes silvered or treated with niello have been found within military sites. The common types are pelta-shaped (Bishop 1988, Type 3); lunateshaped (Bishop 1988, Type 9); teardrop-shaped (Bishop 1988, Type 5); bird-headed (Bishop 1988 , Type 7); in the form of a phallus (Bishop 1988, Type 10); or the so-called 'trifid' pendant (Bishop 1988, Type 1).

There is no doubt that at least some of these pendants were parts of horse harness, being powerful magical symbols that were used to decorate it for apotropaic reasons (Bishop 1987; $\underline{1988})$. Bishop noted $(\underline{1988}, 96)$ that the 'trifid' pendant was the commonest form in the 1st century $\mathrm{CE}$ and linked to the simpler lunate type. This was the type that decorated the silvered horse trappings found at Vetera I (Jenkins 1985). According to Bishop, the peltashape pendants were rare, but seem to have occurred relatively frequently in the Vesuvian region in southern Italy, one at least of which is identifiably part of horse harness (Allison n.d. 1, cat. no. 624). Teardrop-shaped pendants were used, reputedly, for both horse harness and as terminals for the 'apron' straps worn as part of armour (Bishop 1988, 97-98; see Robinson 1975, pls 245 and 423). Bird-headed pendants were also popular in the preFlavian period and occur as horse harness decoration in the pre-Flavian period (Bishop 1988, 98). Bishop noted that lunate pendants were suspended from the brow band, breast strap and haunch straps in the reliefs of horses on a number of military tombstones $(\underline{1988}, 69-79$, esp. figs 1, 3-6, 8, 11 and 13), although the actual pendants on the tombstones seem more like bells or 'trifid' pendants than those classified by Bishop as lunate pendants. Bishop noted that phallic pendants are common in military contexts, but cannot be associated with the cavalry (Bishop 1988, 98). Bishop therefore suggested that they may have been used in vehicle harness or for beasts of burden.

In contrast, Jacobi had included leaf-shaped and lunate-shaped enamelled pendants from Saalburg in a collection of pieces for human adornment $(\underline{1897}, 500$ and pls 68-9, esp. pl. 69.10-11, 15). In Pompeii a number of bronze pendants have been found in domestic contexts and not associated with any military or horse equipment. Of particular note are three small pendants found in a box with other luxury items in the Casa del Menandro (Allison n.d. 1, cat. no. 671 - Figure 7). They include a teardrop and a bird-headed pendant and a lunate item which could also have been a part of a pendant. A phallic pendant (Allison n.d. 1, cat. no. 1724) was also found in a storeroom in House I 10,8, in the Insula del Menandro. This room had been used to store domestic equipment, including personal items such as two iron finger-rings.

The discovery of such pendants in domestic contexts, associated with luxury and personal items, suggests that they had wider use than purely military and predominantly for horse 
harness. While it is possible that these had been keepsakes from military relatives, it seem safest to suppose that such pendants could be worn by horses and men and women, military personnel and civilians. Thus, unless the pendants are found in direct association with other parts of horse harness (such as the silver trappings found at Vetera), or are particularly large (i.e. over $80 \mathrm{~mm}$ in length), the pendants here have been categorised as 'dress?/combat equipment?/horse equipment?' and 'male?/female?'.

\subsection{2h Drop handles}

Drop handles were used in helmets and on chests. Therefore these are classified as 'dresscombat equipment?/furniture?' and 'male?'.

\subsubsection{Analysis and interpretation of the distribution patterns at Vetera}

Similar types of queries were run for dress as those that were run for toilet activities. For all these items it was possible to separate them into gender and/or age categories.

\subsection{3a Artefacts categorised as certain dress items}

As one might expect from a double legionary camp that accommodated some 12,000 soldiers, there are a considerable number of items related to human apparel - 199 items of which fifty-seven are from armour (i.e. helmets and remains of armour and soldiers' belts).

Dress and combat dress (D1)

Following a review of legacy systems and in line with broader ADS practice, the interactive map element of this article has been decommissioned. The full underlying set of data is still available for download from the digital archive.

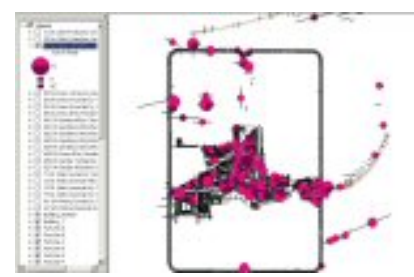

Screendump of ArcGIS query - (D1), certain dress items by category

141 items are classified as 'dress' (D). These items are distributed across most of the excavated areas of the site, although notably not Buildings b, $c$ and d, or, more strangely, in barracks $\mathrm{N}$ and $\mathrm{O}$, and most of palace $\mathrm{H}$ except the north-west corner. The main concentrations are in: the via principalis; the front parts of buildings facing this street; the open area in front of Building $A$; and in the gateways, especially the east gate. Dress-related items are also relatively prevalent in Building $Z$, Building $a$, palace $P$, and the administrative buildings, Buildings $A, B$ and $G$. The following items could not be plotted: one found in Trench 115 in the vicinity of east gate and classified as 'male?'; one found in Trench 308 (in a pre-Claudian context) and classified as 'male'; two found in Trench 1294, one classified as 'male' and the other as 'male?/female?'; one found in Trench 1512 and classified as 'male?'. Another four 'male?/female?', four 'female' and one 'male' items were predominantly from the surface and of unrecorded provenance.

Twelve of the certain dress items (D), which can be plotted, have pre-Claudian contexts, seven of which are found beneath the administrative buildings, Buildings $A-B$ and $G$ (in Building A - one 'male?/female?' item in Trench 375, pit 2, and one 'male?' in Trench 273, pit 22; in Building G - one 'male' item in Trench 327.1; and possibly one 'male' in the vicinity, in Trench 325, pit 2; in Building B - one 'male' and one 'male?' in Trench 424, pit 1). Two others 
were found outside the camp (a 'male' item in trench 229, and a 'male?' item in Trench 234), and three under Building F (two 'male?' and one 'male', in Trench 954, pit 2).

The items categorised as 'dress-combat equipment' (DE) are also concentrated in the central administrative buildings, particularly Buildings $A-B$, with some in the via principalis and the north gateway, four in the tribunes' houses $\mathrm{K}-\mathrm{M}$, three in palace $\mathrm{P}$, and two in Building $\mathrm{S}$. These are, obviously, all categorised as 'male'. One in Trench 308 could not be plotted and one is of unknown provenance. Of those that could be plotted, one in Building a (Trench 497, pit 2) is from a pre-Claudian context, as is one in Building $G$ (Trench 327.1), one in the east gateway (Trench 212, pit 33), and one outside the Neronian fortress (Trench 38).

In combination dress items, $(D)$ and $(D E)$, are distributed across the site but with a noted lack in barracks $\mathrm{N}$ and $\mathrm{O}$ and in palace $\mathrm{H}$, except in the north-west corner. While there is a noted concentration of dress items (D) in the east and west gateways and in the buildings immediately inside these gateways there is a relative dearth of combat dress in these areas.

Certain dress by gender (D2)

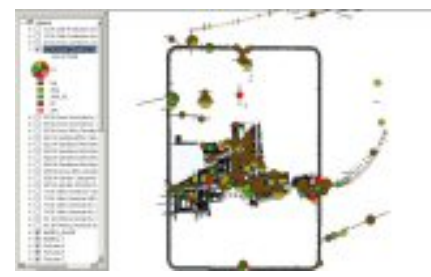

Screendump of ArcGIS query - (D2), certain dress by gender

Artefacts associated with dress $(D)$ and $(D E)$ can be separated into the following categories: 'male' (MA), 'male?' (ZMA), 'male?/female?' (ZMA_FE), 'female' (FE), and 'female?' (ZFE).

The items found in the administrative buildings, in the vicinity of the north gate are almost exclusively 'male', with only four 'male?' and one male?/female?. This includes the preClaudian items. 'Male' and 'male?' items predominated across the rest of the excavated areas of the fortress.

No dress items categorised as 'female' or 'female?' were recorded in the administrative buildings and none definitively from pre-Claudian contexts. Of the fifteen so-identified items, ten can be plotted within the fortress, four ('female') are of unknown provenance and one in trench 1294 could not be plotted. Of the nine within the central area of the fortress: four are in the vicinity of the east gate, three in residential Buildings $P, H$ and $M$, one in Building $Z$, and one in Building a. The concentration in the buildings near the east gateway, particularly in Buildings $T$ and $U$, is interesting, as is the item in Building a, which consisted of twentyone beads from a necklace (see Section 8.7). The latter assemblage included sixteen coins, two fibulae, a bronze bucket and tableware.

About half of the dress items from within the administrative buildings are actually from the earlier levels, including the one classified as male?/female?, somewhat reducing the apparent concentration of male dress items in these buildings. By contrast all the 'female' and 'female?' dress items are from contexts likely to be in the Claudian-Neronian period fortress, except probably a fibula of a Late La Tène/Augustan date found in Building $M$ but without a secure context. Their number is limited but their distribution shows perhaps an expected presence in the residences of officers and unexpected ones in the area of the east gate and in Buildings $a$ and $Z$. Considering that one of the three items in officers' residence might be in a pre-Claudian context, the higher proportion in the area of the via principalis is noteworthy. 
There are fewer uncertain than certain dress items (196 certain and 124 uncertain). At first glance, the latter appear to be fairly randomly distributed across most parts of the excavated areas. However, by separating them into the various types a pattern emerges.

Uncertain dress by category (D3)

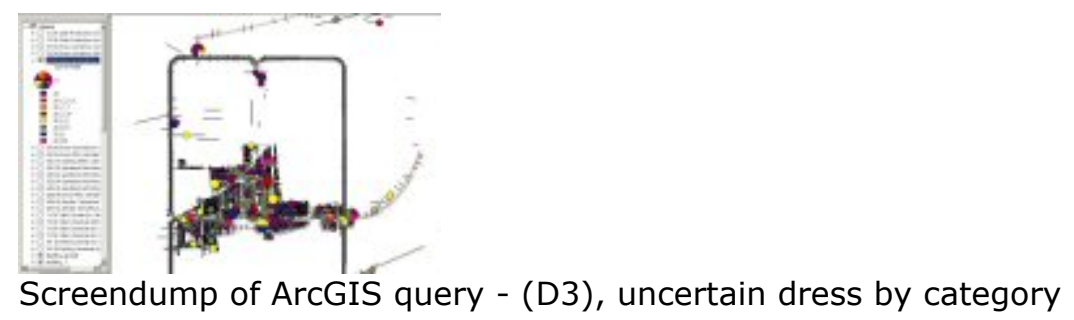

Forty-one items categorised as 'dress?' (ZD) consist of possible jewellery items (i.e. rings that may have been finger-rings and one bone disc that may have been a bead) and are fairly widely distributed. Five were found either outside the fortress, in the fortifications or were unprovenanced. At least one such item found in Building $G$ and one from Building $F$ (in Trench 954, pit 2) are from pre-Claudian contexts. Of the thirty-four remaining items, found within the fortress, three were near the north gate, and eight in the central and eastern part of the via principalis (mainly in front of Building F), two in Building Z, one in Building W, five in the tribunes' houses, four in palace $P$ (although two of these in Trench 750 and conceivably from street or Building $F$ ), two in palace $H$, four in Buildings $A-B$, and five in Building $\mathrm{G}$. This suggests that they were items that tended to be lost in the residential buildings or near the main street, a likely scenario for finger-rings and necklace beads. However, they also have a considerable presence in the central administrative buildings.

Of the thirty-nine buckles, fasteners and pendants classified 'dress?/combat equipment?/horse equipment?' (ZD_E_H), two were found outside the Neronian fortress and one was unprovenanced. Six were found in the main streets and gateways (although one in Trench 212 was possibly in a pre-Claudian context), fourteen in the administrative buildings (one in Trench 316.1 in a pre-Claudian context), four in tribune houses J-M, one in the street between palace $\mathrm{H}$ and Building $\mathrm{A}$, one from Trench 750 (possibly in palace $\mathrm{P}$ or Building $\mathrm{F}$ ), one in Building $a$, one to the north of barracks $Y$, and two in the front of barracks $V$.

Interestingly, two were found in Building $Z$ and one in Building $b$, the latter having very few finds. One in Trench 1323 could not be plotted. Thus, the main concentrations of these items are in the administrative buildings and perhaps in the gateways, with a notable presence in the tribunes' houses. Their presence in these residences might suggest that they were not horse equipment.

Eighteen glass beads are categorised as 'dress?/horse equipment?' (ZD_H), three of which are unprovenanced. One such item was found in the fortifications and another inside the north gate area, the latter in a pre-Claudian context. Of the remaining thirteen, six were found in the via principalis and open area in front of Building A, four were in tribune's house $\mathrm{J}$ and palace $\mathrm{P}$ (one of which was possibly in the street or Building $F$ ), and four in the administrative buildings $B$ and $G$. Two of the latter were probably in pre-Claudian contexts. This pattern intimates that they were perhaps items of dress rather than horse equipment, and had belonged to women.

Sixteen drop handles are classified as 'dress-combat equipment?/furniture?' (ZD_E_F), one of which is outside the Neronian fortress and two in trenches through the fortifications in the north-west area. Of the thirteen within the central excavated area: two were in the east gateway, two in the central open area in front of Building A, two in the street between Buildings $A$ and $P$, and one in the street in front of the west gateway; two were in barracks $Y$; one was in Building $Z$; one was in Building $d$; and two were in the north-east corner of Building $L$. This is a rather unusual distribution pattern which does not seem to reflect the patterns of other items in the possible dress category, except that about half were found in the street. This suggests concurrence with their role as a carrying mechanism for portable 
items like helmets and chests, perhaps dropped in the street during the final abandonment, but does not confirm either identification. The evidence is insubstantial but their discovery in more 'out-of-the-way' places like the southern end of Building $Z$, Building $d$ and Building $L$ suggests that these examples, at least, may have been in storage, and therefore possibly chest handles. A study of the distribution of other furniture items is needed to see if they have a similar distribution. However, furniture is not discussed in this article.

Five bells, classified as dress?/music? (ZD_MU), were found along the via principalis and in the east gateway. Another was found in Building G. Remains of five bone pins are classified as 'dress?/cloth production?/writing?' (ZD_C_W). One of these was from outside the Neronian fortress, in a pre-Claudian context. Two found in Trench 325, in the vicinity of Building G, may also have been in a pre-Claudian context. The other two were both found in the front western side of Building $A$, where other writing implements were also found (see Section $\underline{8.5}$ ). Two copper pins, classified as dress?/cloth production?/toilet? (ZD_C_T), were found in Building $A$ and in the east end of the via principalis. Another indeterminate bone disc, classified as 'dress?/cloth production?/furniture?/gaming? (ZD_C_F_G), was found at the front of Building $Z$. With the exception of the bone pin remains, which are likely to have been writing implements, most of these items appear to have been lost in the vicinity of the street.

Uncertain dress by gender and age (D4)

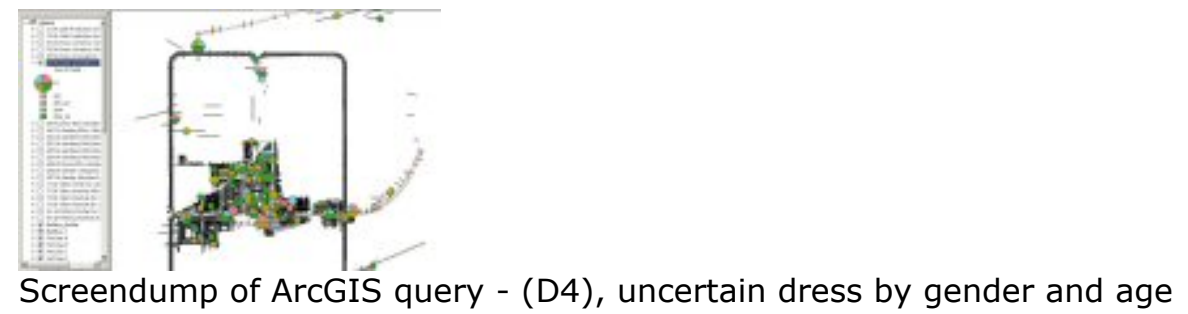

Some of the above items can be ascribed a possible gender. Items that are likely to be for male dress (ZMA) - i.e. buckles and some rings) or for either male or female dress (ZMA_FE) - i.e. pendants, other rings and remains of bone and copper pins) have the widest distribution. In the central excavated area, excluding those that may have been furniture handles, 'male?' items occur predominantly in the administrative buildings and surrounding streets, and in the central part of the via principalis and the east gateway. They are also present in Building $\mathrm{Z}$, in tribunes' houses $\mathrm{J}$ and $\mathrm{M}$, possibly palace $\mathrm{P}$ and barracks $\mathrm{Y}$ and $\mathrm{V}$.

The 'male?/female?' items are found in similar locations. They are relatively numerous in Building $G$, although one was in a pre-Claudian context. There are five in tribunes' houses J, $\mathrm{K}$ and $\mathrm{M}$, three in palace $\mathrm{H}$ and possibly one in palace $\mathrm{P}$. They are also present in Buildings $\mathrm{Z}$, $a, b, F, W$ and north of barracks $Y$.

More interesting is the distribution of possible female items (ZFE - i.e. rings, glass beads, bone and enamelled discs) and possible female or children's items (ZFE_CH - i.e. small rings and bells). These two groups are found in the similar locations: near the gateways; in the open area in front of Building $A$; in the tribune's houses $J$ and $M$; in palace $P$ and in Building $L$. There is a notable concentration of them in the areas where the possible male dress items are relatively rare, for example in palace $P$ and the open area in front of Building $A$. Their presence in the front parts of barracks $V$ and Building $Z$ and in Buildings $A$ and $G$ is noteworthy. None of these possibly female items have been definitively ascribed to preClaudian contexts. 


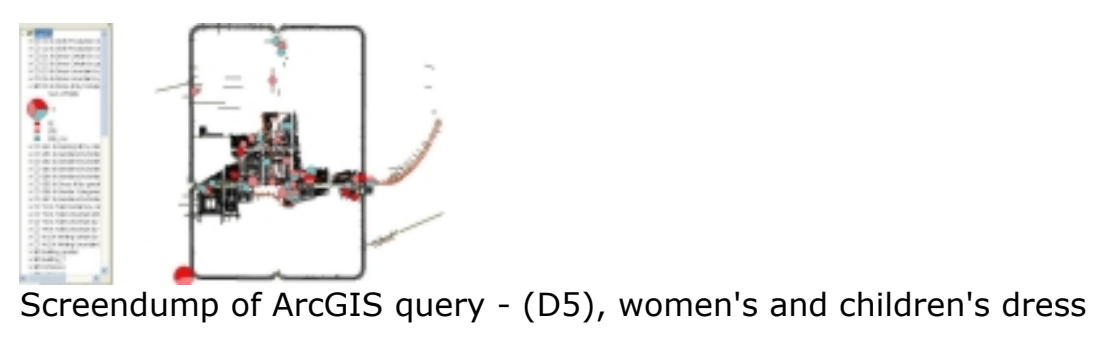

If we combine the possible dress items that could have been for women's and children's dress, with the certain dress items that were female or possibly female, the plot again shows concentrations: near the main gates, both in the street and in the fronts of buildings immediately inside the gates; in the market area in front of Building A; and in the officers' residences.

\subsubsection{Conclusions}

In summary, dress and possible dress items are scattered across the excavated buildings of this site. However, there is a noted lack of dress items in barracks $\mathrm{N}$ and $\mathrm{O}$ and in Buildings $\mathrm{b}$ and $\mathrm{c}$ (with the exception of a drop handle and a pendant). This is probably not significant for barracks $\mathrm{N}$ and $\mathrm{O}$, which were only very partially excavated. However, given that Buildings $b$ and $c$ were as extensively excavated as any other of the buildings in this central area, the comparative lack here may hint that these buildings were not being used for accommodation, or were not frequently entered by the fortress's occupants. Interestingly, there are twelve dress and possible dress-related items in Building $Z$ but no toilet items except glass bowls. This, again, seems to throw into question its identification as a hospital and renders it a more likely candidate for accommodation than barracks $\mathrm{O}$ and $\mathrm{N}$ (see Section 8.7).

Women's and children's dress items are found particularly in officers' residences, in the street, in the buildings opening onto the street, and in the main gates, with a noted concentration in the open, possibly market, area in front of Building A, and a presence in Building a (see Section $\underline{8.6}$ ).

\section{back top forward contents home}

(c) Internet Archaeology URL: http://intarch.ac.uk/journal/issue17/4/8.2.html

Last updated: Mon Apr 42005 


\section{back top forward contents home}

\subsection{Cloth production}

Cloth-production activities include spinning, weaving and sewing. As one might expect, few such items are found at Vetera I, although cloth-production items do exist at a number of military sites. Indeed, no items found at Vetera I can be definitively associated with clothworking but a handful is possibly associated. These include a pair of iron shears, clay weights, a bone disc and remains of bone pins, and bronze needles and/or pins.

The shears were most probably used for shearing sheep or cutting cloth (see Manning 1985, pl.14 D4-D6; see also White 1967, 119-120; Gaitzsch 1980, 213-16), although it has also been suggested that they could have been for other purposes such as trimming horse's coats or cutting the grass on the ramparts (Frere and Wilkes 1989,161 ; no. 128). The clay weights could have been used for weaving. K21 is not the usual pyramid-shape for a loomweight but has two holes which suggest that it could have been suspended as a loom-weight. The bone disc and some of the bone pins could have been the remains of spindles and spindle whorls. Wild's study of spindles from the northern provinces (1970a, 32-35), and my own observations on spindle whorls and bone discs from the Insula del Menandro in Pompeii (Allison n.d. 1), indicate that discs, with a diameter of c. 35-50 mm, a central hole of c. 6-9 $\mathrm{mm}$ in diameter and made of pottery, stone, lead or bone, were likely to have been spindle whorls. $\mathbf{J 8}$ is comparable, if a little on the small side. According to Wild (1970a, 32-33) spindles were made of bone or wood, thickened near the lower end to hold the spindle. They could be up to $300 \mathrm{~mm}$ in length but those in the northern provinces were commonly 120 $250 \mathrm{~mm}$, with bulbs c. $10 \mathrm{~mm}$ in diameter. The recorded remains of bone pins (J1-J2, J5-J7), could conceivably have been parts of such spindles. The complete and fragmentary bronze pins could have been used for sewing or toilet activities or were parts of hairpins.

\subsubsection{Who was involved in cloth production?}

Modern scholars generally view the processing of household cloth in the Roman world as a female activity, but when cloth production is identified as a commercial activity it is assumed to have been carried out by men (Dixon 2001, 117-29). However, as argued by Dixon (2001, 121-22), such a 'female/domestic and male/commercial' dichotomy relies heavily on analogies of post-industrial separations of public and private life (see also Dixon 2000-2001). Indeed, weaving seems to be a particularly androgynous activity in the Roman world, involving both male and female weavers in courtyard workshops, high-status houses and family businesses, although in general women seem to predominate in the working of wool (Treggiari 1976, 81-85). The procedures for weaving within a military context are not well understood. At Vindolanda there seems to be evidence for weaving, and possibly spinning, in that wool was purchased (Bowman 1994, 72, 118 no. 12, 120 no. 14; Bowman and Thomas 1994, nos 192 and 196). Weaving is, therefore, classified as 'male?/female?' here.

Spinning would seem to be more securely identified as a female activity (e.g. Deschler-Erb $\underline{1998}$, 136-37; Treggiari 1976, 82). Spinning implements are symbols often associated with women, and particularly brides (Dixon 2001, 117-18). They are therefore classified as 'female?' items here. However, as the remains of bone pins could alternatively have been parts of styli (see Section $\underline{8.5}$ ) or hairpins, these have been categorised as 'male?/female?'.

As noted in Section 8.1.2 needles may have been used for surgery as well as for sewing. Also, Allason-Jones has argued $(\underline{1995}, 28)$ from their presence in the turrets on Hadrian's Wall, that these items were used by men as well as by women, soldiers needing to do their own mending. Therefore needles and fragmentary remains of either bronze needles or pins are also categorised as 'male?/female?'. 
There are no items that are unequivocally categorised as cloth-working equipment from Vetera I. Besides the obvious explanation that cloth-working was not an activity expected to have been carried out within a military site, there are a number of other possible alternative explanations for this. One of the main reasons is likely to be because most of the bone items from Vetera I were not included in Hanel's artefact catalogue as these are currently being studied. Although Hanel could detect no hint of this (pers. comm.), there may also have been a process, whether conscious or unconscious, to pay less attention to items which provide little chronological information and which should not have been found with a military context, such as identifiable loom-weights. However, loom-weights, weaving hooks and spindle whorls have been found within other forts and fortresses (e.g. Ellingen - Zanier 1992, nos B150, D2-D3, EII1701-1705; Carnuntum - Grünewald 1981, esp. pl. 8 no 4, 1986, pl. 11 nos 1-4).

\subsection{2a Artefacts categorised as uncertain cloth production items (C1 and C2)}

Following a review of legacy systems and in line with broader ADS practice, the interactive map element of this article has been decommissioned. The full underlying set of data is still available for download from the digital archive.

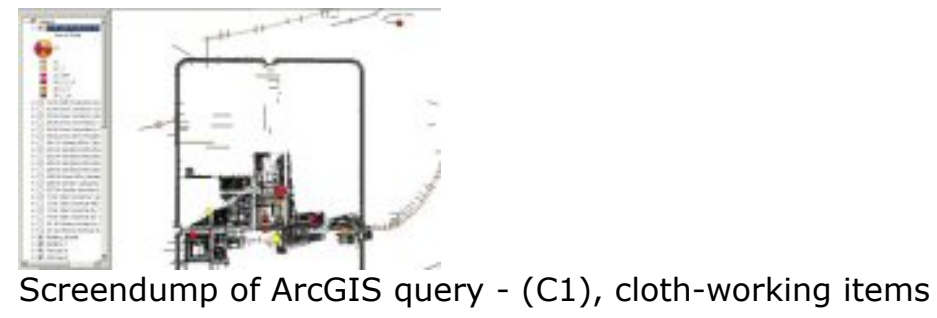

Only fourteen items could possibly have been used for cloth-working. These include remains of pair of shears (ZC), bronze needles (ZC_T), clay weights (ZC_WM), a bone disc (ZD_C_F_G), remains of bronze pins or needles (ZD_C_T), and remains of bone pins or needles (ZD_C_W). Two such items are from outside the Claudian-Neronian fortress and three, in the vicinity Building G, were probably in pre-Claudian contexts (Trench 325, pits 1and 2). Of the remaining nine items, three were found inside and immediately in front of Building $A$, two in the central open area, one in barracks $V$, one in Building $Z$, one to the north of barracks $Y$, and one in Building $S$. Two found within Building $A$ are likely to have been writing implements see Section 8.5. More interesting is the item found in Building $Z$, which was a dress, furniture or gaming item if it was not a cloth-working implement.

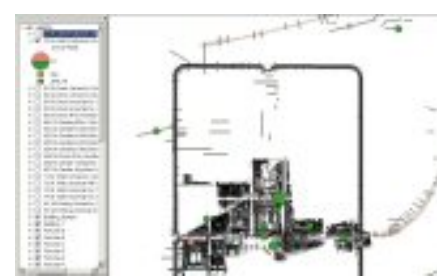

Screendump of ArcGIS query - (C2), cloth-working items - women?

Because most of these items have been gendered male?/female?, their distribution is uninformative about the presence of women. However, the bone disc found in Building $Z$ is gendered 'female?' and, again, presents an interesting perspective on the identification on this building.

\section{back top forward contents home}




\subsection{Gaming}

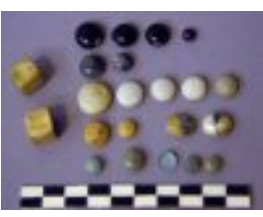

Figure 27: Gaming counters and die (inv. nos 4254 and 4258) from room 1 in the Casa del Menandro in Pompeii (photo P. Allison)

Numerous glass counters found at Vetera I have been considered by Hanel $(\underline{1995}, 249)$ to be gaming counters (Figure 27). Many of the bone discs with holes from the Insula del Menandro in Pompeii can be shown either to be jewellery, spindle whorls or furniture fittings, according to the size of the disc and of their central hole (Allison n.d. 1). Some of these may have been reused as gaming counters, however. A bone disc with a central hole (J8) was identified as such by Hanel $(\underline{1995}, 285)$.

\subsubsection{Analysis and interpretation of the distribution patterns at Vetera}

\subsection{1a Artefacts categorised as certain and uncertain gaming (GA1)}

Following a review of legacy systems and in line with broader ADS practice, the interactive map element of this article has been decommissioned. The full underlying set of data is still available for download from the digital archive.

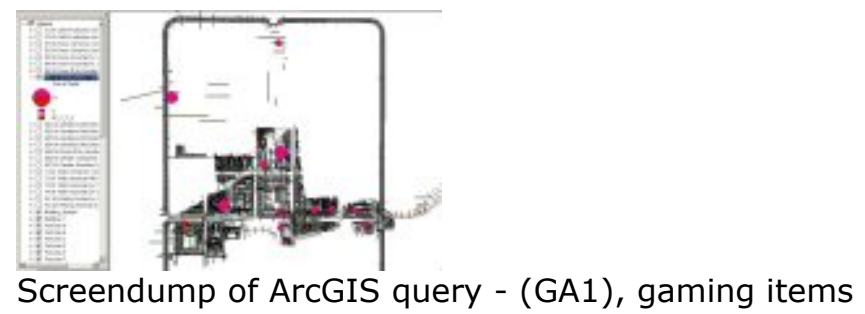

Of the forty-four glass gaming counters recorded, twenty-six were found on the surface, unprovenanced. Another three were found in a trench through the fortifications in the northwest part of the fortress and one near the north gate. Within the central excavated area, three in Building $a$, one in Building $A$ and all five in Building $G$ were from pre-Claudian contexts. This means that only five are actually from relatively good contexts and these are quite scattered, one in each of the garden of palace $P$, Building $S$, barracks $V$, Building $T$, and in the central open area in front of Building $A$. This is not a particularly significant pattern but it is perhaps notable that they occur mainly in the fronts of buildings off the eastern part of the via principalis.

Adding in possible gaming items to the above plot means the inclusion of only one bone disc found in Building $Z$.

In summary, it is notable that no such items were found in Claudian-Neronian contexts in the administrative buildings or the tribune's houses. The pattern is by no means substantial but it points to gaming activities being most likely to have taken place in the buildings bordering the eastern half of the via principalis. 


\section{back top forward contents home}

\subsection{Writing}

Artefacts from Vetera I which are considered to be for writing include: iron and bone styli, ceramic and bronze inkwells, and bronze seal boxes. Bone pins with a marked shoulder are identified as styli. Compasses have been categorised as 'weighing and measuring'.

A number of other artefacts may have been used for writing but this is by no means certain. Among these are incomplete bone pins or bone pins whose potential shoulder has not survived, and iron and lead implements that could also have been styli.

\subsubsection{Analysis and interpretation of the distribution patterns at Vetera}

\subsection{1a All artefacts categorised as certain writing equipment (W1)}

Following a review of legacy systems and in line with broader ADS practice, the interactive map element of this article has been decommissioned. The full underlying set of data is still available for download from the digital archive.

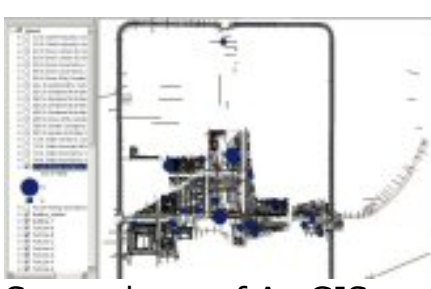

Screendump of ArcGIS query - (W1), certain writing equipment

There are thirty-eight items definitively identified as writing equipment (W). Five in Building $G$ and one near Buildings $C$ and $D$ were from pre-Claudian contexts. Of the remaining thirtytwo, predominantly of Neronian date, concentrations are observable in the following places: four in the courtyard of tribune house $\mathrm{K}$; five in front of the west side of Building $A$ and two on the west side of the courtyard of Building $A$; four just inside the east gate, in barracks $V$ and Buildings $U$ and $T$; and six in the west part of Building F. Two more were found on the via principalis sides of each of palace $\mathrm{H}$ and Building $\mathrm{b}$. Single finds were also made: near the north gate; in the suite of rooms in the north-east corner of tribune house $M$; in a trench between Buildings $B$ and $G$; in palace $P$ and possibly the street to the north of palace $P$; in Building $S$; and in the front part of Building $Z$.

The concentration in the area of Building $\mathrm{F}$ is the most significant, suggesting that this may have been an area where scribes worked. This is probably also the case for the parts of Building A where writing equipment was found - in one or more rooms on the west side off the courtyard and in one or more of the rooms along the front probably opening onto the street. The concentration in the courtyard of tribune house $\mathrm{K}$ perhaps reminds us that the 'home office' is nothing new! These concentrations were also noted by Hanel $(\underline{1995}, 132)$. 


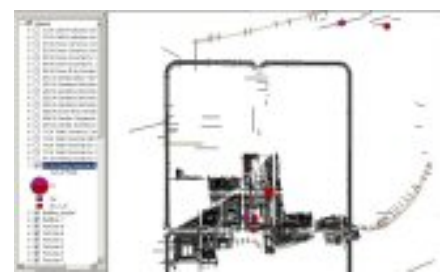

Screendump of ArcGIS query - (W2), possible writing equipment

Two of the seven possible writing implements were found outside the Claudian-Neronian fortifications and another two probably in a pre-Claudian context in the vicinity of Building $G$ (Trench 325, pit 2). The remaining three items - fragments of two bone pins and a possible iron stylus - were found in Building A, in similar locations to the more certain writing implements. These items potentially strengthen the identification of these areas as places where scribes worked, and the identification of these fragments as writing equipment rather of than hairpins or spindles.

\section{back top forward contents home}

(C) Internet Archaeology URL: http://intarch.ac.uk/journal/issue17/4/8.5.html

Last updated: Mon Apr 42005 


\subsection{Activities according to gender and age}

Ascribing gender or age categories to specific artefacts is fraught with problems. There are many Roman artefacts which might be considered female on the basis of modern analogy and which are often presented as female by modern scholars. However, this constitutes a simplistic approach to the engendering of artefacts (see Allason-Jones 1995). Items of dress which can potentially be ascribed either to men, women, or to children, have been discussed in Section 8.2. certain activities can also be ascribed to men, women or children. As used here, male and female categories refer to adult male and adult female and the expression 'gendered activities' consists of activities separated by age and by gender.

\subsubsection{Gendered activities}

\subsection{1a Combat}

The assumption has been made, for the purposes of this study, that combat was a male activity and that combat equipment is, therefore, all male. This includes javelins, swords and sheaths, arrowheads, daggers and other cut-and-thrust weapons, shields, and sling shots. Other possible combat equipment includes certain hinges, fasteners and nails as it is by no means clear that these were from military equipment. They are therefore categorised as 'male?'. Armour is included under dress.

\subsection{1b Wood-, leather-, stone-, metal-working, and agriculture}

Items associated with stone-, wood-, leather-, metal-working, agriculture and animalhusbandry are frequently found within Roman military camps. At least in this specific sphere, these are invariably considered male activities carried out by the troops themselves, or more particularly by the immunes. While this is no doubt true, in a large part, it cannot be exclusively concluded that such activities were never carried out by women, as women could be involved in such industries in civilian life (see Kampen 1981, 117-18, 123-27; Kampen 1982, 72-73). That said, however, such activities were probably even more infrequently practiced by women in the military sphere than in the civilian.

At Vetera, items associated with wood and leather-working include axes, saws, wood cleavers, planes, spoon-bits, scrapers, nail-pullers, points and certain types of hammers and chisels. Items associated with stone- and metal-working include smelting vessels, pliers, certain types of hammers and chisels, crow bars, trowels, and spatulas. Items probably used for agricultural purposes include sickles and scythes, choppers, pitchforks, mattocks, hoes, and shovels. These items are, therefore, categorised here as 'male'.

\subsection{1c Cutting and sharpening}

Knives and whetstones were categorised as cutting or sharpening implements. Again these activities, within the military sphere, are most likely to have been carried out by men although this is by no means conclusive. The potential involvement of women in foodpreparation, and hence the cutting of foodstuffs, within the military sphere is an area which has been little researched (see Van Driel-Murray 1997). For the purposes of this study, therefore, these items are categorised as 'male?'.

\subsection{1d Weighing and measuring, writing}

Items associated with weighing and measuring include scales, balances, and conical, oval and flat weights of bronze or lead, and also compasses. While some of the lead weights are 
pierced, they are too small to have been loom-weights. These weights ranged from c. 20-35 $\mathrm{mm}$ in length, while clay loom-weights listed by Wild (1970a, Table M) ranged from 90-180 $\mathrm{mm}$ in length. Lead weights, probably loom-weights, from House I 10,8 in Pompeii ranged from 59-94 mm. Items associated with writing consist of iron, lead and bone styli, ceramic and bronze inkwells, and bronze seal boxes. Although women were employed as clerks and secretaries in élite households in Rome (Treggiari 1976, 77-78), within the military sphere such activities were most probably carried out by men. Therefore these items are categorised as 'male?'

\subsection{1e Cloth-production}

As noted, weaving could be carried out by men or women in civilian contexts, sewing could be carried out by soldiers in military contexts and spinning was most probably a female activity. However, as one might expect of a military fortress, no definitive cloth-production items and few possible items associated with cloth-working are recorded at Vetera I. Therefore the possible cloth-working items are classified as male?/female?, with the exception of one bone disc which, if it can be gendered at all, would be either a piece of female jewellery or a spindle-whorl. It is therefore categorised as 'female?'

\subsection{1f Toilet}

There has been a tendency in the past studies of the classical world to classify a number of types of toilet items as women's equipment but this is not the case for many of these, as noted in Section 8.1.3c. Mirrors, probes, tweezers, which are personal items, are classified as 'male?/female?, and unguentaria as 'female?'.

\subsection{1g Food-preparation and consumption}

The preparation and consumption of food is a much more complex spatial and gender issue than widely believed (see also Foss 1994, esp. 47-50). One can probably assume that most food consumption within a military fort or fortress was carried out by men but this may not necessarily be the case for food preparation. Inscriptional evidence from Vindonissa (Speidel 1996, esp. 38 and 79), and preliminary analyses of the spatial distribution of tablewares and of food-preparation equipment at Vetera I (Allison n.d. 2), suggests that much more work needs to be carried out concerning the question of the spatial distribution of food preparation and consumption. Therefore, it will not be discussed here.

\subsection{1h Leisure}

The main evidence for leisure activities within the fortress at Vetera consists of gaming items, namely glass counters. Again one can assume that, within this sphere this was largely a male activity, but evidence from Vindonissa suggests that women were also involved in some capacity (Speidel 1996, esp. 80). The engendering of this activity, therefore, also requires more research so is not included in this analysis. For similar reasons other activities, such as religion and lighting, are not discussed here.

\subsubsection{Analysis and interpretation of the distribution patterns at Vetera}

\subsection{2a Gendered activities}

Certain activities by activity category (GE1)

Following a review of legacy systems and in line with broader ADS practice, the interactive map element of this article has been decommissioned. The full underlying set of data is still available for download from the digital archive. 


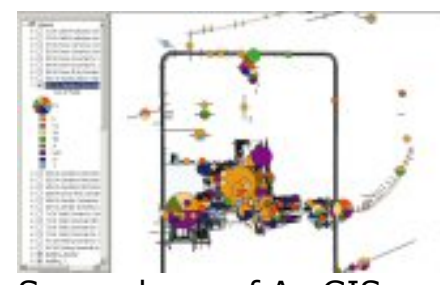

Screendump of ArcGIS query - (GE1), certain gendered activities by category

This first plot shows the distribution of the various activities, to which it is possible to ascribe a gender, by activity category.

It is immediately obvious, as might be expected, that the most prolific artefacts associated with such activities are combat weapons (E), gendered 'male' of which there are 136 items. Eight are unprovenanced and the rest are overwhelmingly concentrated in Buildings A-B. This concentration is largely because of a cache of 31 weapons was recorded by Lehner. These were recorded in Room VIII, the apsidal room at the west end of the courtyard in Building B, but Hanel (1995, 50-51) believes Lehner confused the sacellum (Room VIII) with armaments rooms (VI and VII), in the north-west corner of Building B. But even without including this hoard, most of the weapons are found in this administrative complex, leading Hanel to argue that many were hidden here from the invaders in C. $69 \mathrm{CE}$. Other more minor concentrations are found in the Building $F$ and near the west gateway. Two from Building $A$ and all three found in from Building $G$ are from pre-Claudian contexts. Given that many of these items were probably used in the final battle, these distributions may not be particularly significant for daily life in the fortress. A comparable concentration of items related to combat dress (DE) was also found in Buildings A-B (query D1), but these were more apparent in the officers' residence than were combat weapons.

Thirty-three cutting and sharpening items (CS) were recorded, gendered 'male?. The main concentration was, again, in Buildings A-B, although one in Trench 273, pit 6, and one in Trench 325, pit 2, were probably in pre-Claudian contexts. Otherwise, they were mainly scattered along the via principalis, and in the buildings bordering it, particularly on the north side. This distribution pattern suggests that this category includes both offensive weapons and utilitarian tools.

Twenty-seven wood and leatherworking items, also gendered 'male', were recorded (WL). There was a notable concentration in front of barracks $Y$, along with other tools and weapons (see below). They were also particularly prominent in front of barracks $\mathrm{V}$ and in the east gateway (although one in Trench 212 was possibly in a pre-Claudian context).

Seventeen items were identified as for stone and metal-working (SM). Four of these were smelting vessels, possibly of Augustan date, found in the north gateway. Of the ten in the central excavation area: one was found in front of barracks $\mathrm{Y}$; one in palace $\mathrm{H}$; one in Building $A$ and one in front; four in the area of Building $F$; two in barracks $V$; and one in the east gateway. This is not a particularly significant pattern but seems to reflects the pattern for the previous tool types, associated with male activities, particularly in barracks $\mathrm{Y}$ and $\mathrm{V}$.

Nineteen recorded items can be associated with agriculture $(A)$. These are prominent in front of barracks $Y$ and $V$. They also appear to be relatively prolific in the north-east area of Building B, although one in Trench 325, pit 2, and one in Trench 317, pit 2, were probably in pre-Claudian contexts.

Thus, 'male' activities appear to be concentrated in Buildings A-B, Building $F$ and barracks $Y$ and $\mathrm{V}$. From the evident prominence of such tools in barracks $Y$ and $V$ it is tempting to suggest that immunes were housed there. Interestingly, such items were absent from the Claudian-Neronian contexts in Building G.

Forty-seven weighing and measuring items (WM) were recorded and gendered 'male?'. In the central excavation area these were concentrated in the buildings facing the west end of 
the via principalis (notably with other tools in front of barracks $Y$ ) and on the west side of Building $\mathrm{G}$. They are also scattered among the buildings along the eastern part of the via principalis. Another in the vicinity of Buildings $\mathrm{P}, \mathrm{S}$ and $\mathrm{F}$ could not be precisely plotted. The finds of 13 lead weights, of Neronian date, in front of barracks $Y$ suggest that, as well as crafts being carried out in here, there may also have been commerce.

As discussed in section $\underline{8.5}$, writing equipment (W), gendered 'male?', was concentrated in the west side of Building $A$, in Building $F$, and in tribune house $K$.

The distribution pattern of the few certain toilet items ( $T$ ), gendered 'male?/female?', as discussed in section 8.1 , showed their presence in the via principalis, the officers' residences, and Buildings $A$ and $T$.

Certain activities by gender (male and variations of male) (GE2)

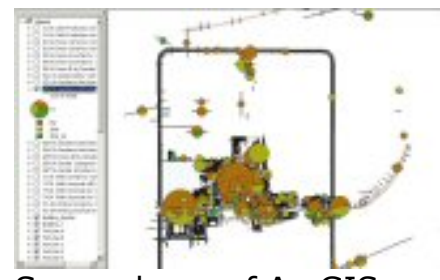

Screendump of ArcGIS query - (GE2), certain activities by gender

To simplify the visualisation of the distribution pattern discussed above, a query was run on the same data, but separated into 'male' (MA), 'male?' (ZMA), and 'male?/female?' (ZMA_FE). This plot shows that, in the central excavated area, the main male activities were: in Buildings $A-B$; in barracks $Y$ and $V$ near the west and east gateways, respectively; in the north gateway; and in Building F. Some of the possibly male activities (ZMA) are in the same locations but also more widespread, in building $b$, the tribunes' houses; palace $P$; Building S and Building G. Items categorised 'male?/female?', all toilet items, tend to be found in similar areas to the possible male items. This again draws our attention to the prominence of male activities in Buildings $A-B$, as the central administrative buildings. Building $\mathrm{F}$ may well have had an important administrative role, given its concentration of writing equipment and other tools and weapons.

From this distribution pattern it seem likely that, even if the immunes were accommodated in Building $S$, they carried out their crafts and possibly distributed their products in front parts of barracks $\mathrm{Y}$ and $\mathrm{V}$. However, the assemblage in Building $\mathrm{S}$ has more in common with those in palace $P$ and the tribune houses so this may rather have been an officer's residence. While Building $\mathrm{G}$ did have certain male activities present these items were comparatively few compared with those in the other administrative Buildings A-B.

\section{Go to Interactive GIS map (ArcIMS).}

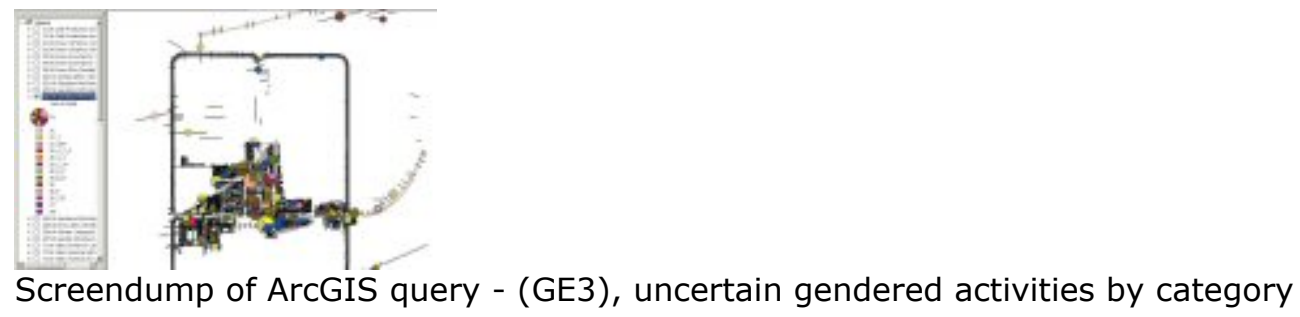

Items possibly associated with the above activity categories were also plotted, including items which could have been dress items. As with certain combat equipment, possible combat equipment (ZE), (ZD_E_H), (ZE_F) and (ZD_E_F), found in the central excavation 
area, was concentrated in the central administrative buildings but also in the tribunes' houses, $K, J$ and $M$. It was also present in Building $Z$, barracks $Y$, Building $L$, Buildings $a, b$ and $d$, palaces $H$ and $P$, Building $S$ and barracks $V$. It was notably lacking in Buildings $T$ and $F$ and the central open area in front of Building $A$, with the exception of two drop handles.

As discussed in Section $\underline{8.3}$, possible cloth-production items (ZC), (ZC_T), (ZC_WM), (ZD_C_T), (ZD_C_F_G) and (ZD_C_W) in the central excavation area were mainly found in the central open area in front of Building $A$, in Building $Z$ and in barracks $V$. Exceptions were items that were also possible writing or weighing items, some of which were in a probable pre-Claudian context (in Trench 325, pit 2). Other possible writing equipment (ZW) and (ZD_C_W) was all in the south-western part of Building A.

Possibly toilet equipment $(Z T),\left(Z C \_T\right)$ and (ZD_C_T) was present in Building $L_{\text {, tribune }}$ houses $\mathrm{J}$ and $\mathrm{M}$, Building $\mathrm{G}$ (one in a pre-Claudian context), Building $A$, palace $P$, barracks $V$ and the east gate, with a notable concentration in the central open area (two in a cellar) and in Building $\mathrm{F}$.

An interesting fragment is the head of a spouted vessel in the form of a hen's head (C8242). Hanel (1995: 221) suggested that the hen was a symbol of a Mercury cult and of state religion and so dismissed any identification of this fragment as the spout of a feeding vessel (cf. Hilgers 1969, 80-82). Both possibilities have been considered here, however, so it has been categorised as 'religion?/tableware and serving?' (ZR_ZTS) and as 'child?' (ZCH). It was found in the front part of Building $Z$.

Uncertain activities by gender (GE4)

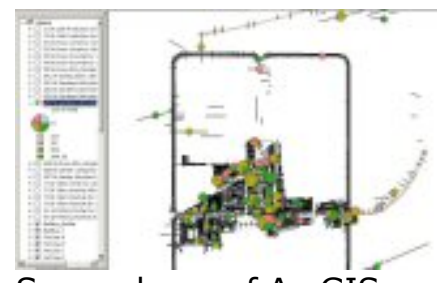

Screendump of ArcGIS query - (GE4), uncertain activities by gender

This plot includes the possible activity categories in (GE3), which are all assigned possible gender categories. The plot shows a similar distribution pattern to certain activities according to gender (GE2). That is, 'male?' and 'male?/female?' activities dominate the main administrative buildings, while possible female activities are most prominent in the tribune houses and Building $L$, and in the central open area and Building F. Interestingly, however, possible female activities are also present in Buildings $G$ and $A$, although one in Building $G$ was in a pre-Claudian context.

\subsection{2b Gendered Dress (GE5)}

Dress related items were discussed in Section 8.2. This plot combines queries (D2) and (D4).

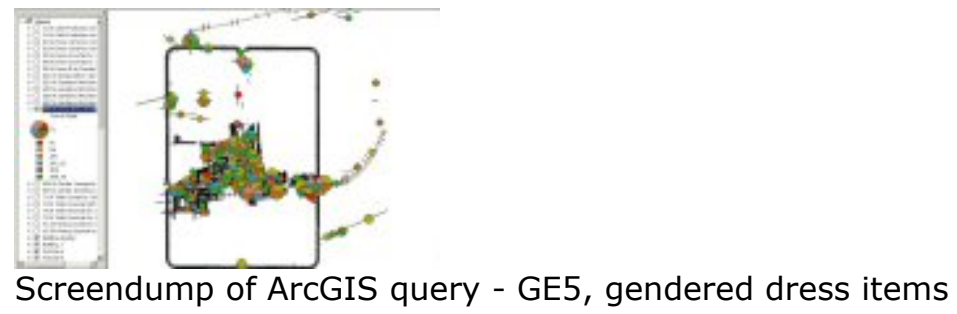

As noted in Section $\underline{8.2}$, this plot shows that certain and uncertain dress items within the central administrative buildings, and near the north gate, were almost exclusively 'male', 'male?' or 'male?/female?'. Items classified as 'female', 'female?' or 'female?/child?' were 
concentrated in the officers' residences, in the central open area, but they were also present in Building $Z$, Building $a$, and near the east gate.

\subsection{2c Combined gendered dress and gendered activities (GE6)}

This query consists of combining the following plots (GE2), (GE4), (D2) and (D4) to investigate the overall pattern of all gendered items, dress and activities.

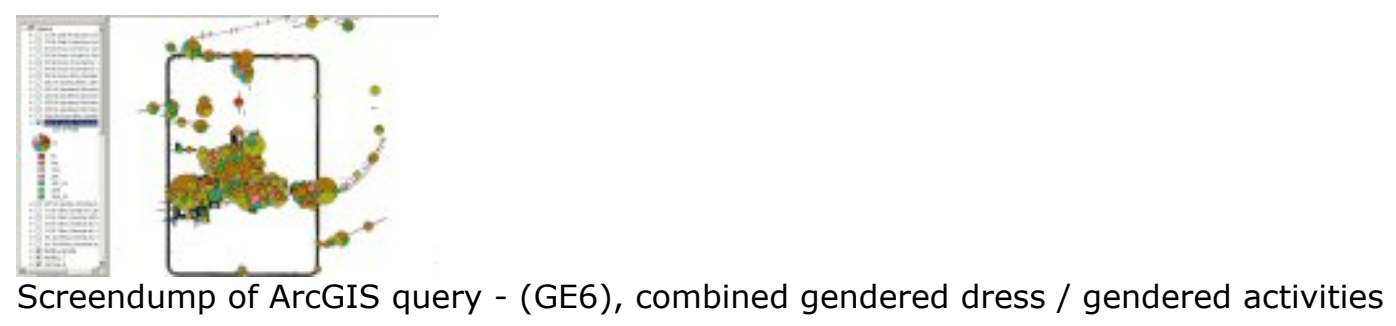

There are no certain activities documented at Vetera I that can be classified as 'female' or 'female?', and only some that classified 'female?/male?'. There are a number of reasons for this. One is that there are few activities potentially carried out by women that leave a material record, with the exception of cloth production and possibly food preparation.

As is to be expected, the number of items categorised male is the most extensive - 329 as 'male', 199 as 'male?', and 105 as 'male?/female?'. Also, as might be expected, the major concentration of certain male items, within the central excavated area, is in Buildings $A$ and $B$. Other concentrations are found in front of barracks $Y$ and $V$, in the east gateway, and in the area of Building $\mathrm{F}$. There are also notable amounts in Buildings $\mathrm{G}, \mathrm{Z}$ and $\mathrm{a}$, but at least five of those in or near Building $G$ were from pre-Claudian contexts. Interestingly, certain male items are less prolific in the tribunes' houses, $K, J$ and $M$, and in Buildings $S$ and $b$, compared with other buildings and other categories.

Items categorised as 'male?' or 'male?/female?' are relatively common in the same buildings as certain male items, but are more prolific in the tribunes' houses, in palace $\mathrm{P}$ and Building $\mathrm{S}$, and in Building $\mathrm{b}$. For the officers' residences this is probably explicable because items classified as certain male items include combat equipment and more industrial types of artefacts concerned with crafts. Items categorised as 'male?' or 'male?/female?' activities are related to lighter weight activities, such as weighing, measuring and cutting, and personal activities, such as toilet. However, this does not explain the distribution in Building $b$.

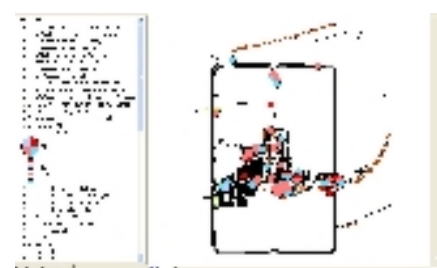

Screendump of ArcGIS query - (GE7), women's and children's items

Seventy-one artefacts are categorised as 'female', 'female?', 'female?/child?' or 'child?', nine of which are either outside the fortress or unprovenanced. Twelve are categorised as 'female' (i.e. bronze hairpins, glass beads, one fibula and one belt attachment), four of which have provenances inside the fortress. Another seventeen are categorised as 'female?/child?' (i.e. bronze rings and small bells), one of which is outside the camp. This means that a total of twenty-four items inside the fortress were very probably associated with women and children. Another forty-one 'female?' items were also recorded. Eighteen of these were melon beads, which could have been horse equipment, but this category also included bone discs, bone pins, a fibula and a belt hook. Remains of a possible child's drinking vessel were 
also recorded. The distribution pattern of these artefacts shows a predominance of women's and/or children's artefacts in the streets and gateways (although two of these were possibly from pre-Claudian contexts), in the open area in front of Building $A$, in palace $P$ and in the front of Building $Z$. Three of the definitively female items (two bronze hairpins and a fibula) were associated with the buildings immediately inside the east gate, Buildings $\mathrm{T}, \mathrm{U}$ and $\mathrm{X}$. Possibly female items are also relatively prominent in the tribunes' houses, $\mathrm{K}, \mathrm{J}$ and $\mathrm{M}$, and in palace $P$, but are also present in the administrative buildings $A-B$ and $G$. This distribution patterns suggest that women's and children's presence was most notable in the main street and in the officers' residence, as is perhaps to be expected. The numbers are extremely limited but it is interesting that the more definitively female and children's items are found in the buildings near the main gates, and Building a, rather than in the street itself or in the officers' residences. This distribution may throw light on the functions of these buildings and the wider role of women within the fortress.

\section{back top forward contents home}

(c) Internet Archaeology URL: http://intarch.ac.uk/journal/issue17/4/8.6.html

Last updated: Mon Apr 42005 


\section{back top forward contents home}

\subsection{Overall Interpretations}

\subsubsection{Problems of stratigraphy, percentage of site excavated and category assignment}

There are three important aspects of this project which are fundamental to its validity. The first, in the case of an old excavation like Vetera I, is the difficulty of identifying artefacts which indeed relate to activities that took place during the occupation of the final Neronian fortress, and were not from earlier occupations or part of any redeposition process; the second is the representativeness of the excavated area, and the third is the difficulty of correctly assigning functional categories to these artefacts.

While trench provenances are provided for most of the artefacts in Hanel's catalogue, very little stratigraphical information is available. For example, a trench that was dug to investigate the wall foundations of one of the Neronian buildings can include a combination of undifferentiated contexts from the modern surface through to, in some cases, Augustan levels. As discussed, the stratigraphical contexts have been indicated where possible, and any items from identifiable pre-Claudian contexts have not been included in the analyses. However, there are many other items that may also have been from pre-Claudian contexts but this cannot be verified, most notably those from the excavations to explore the foundations of Building A. Identifying whether material has been redeposited is also difficult, although the short life, rapid abandonment, and nature of the area excavated at Vetera I suggest that the likelihood of this is minimal. Only through the consistency of any distribution pattern can it be argued that these assemblages do not constitute residual material from earlier phases or redeposition.

A second potential problem relevant to this analysis is whether the same percentage of each building was excavated. Visual analysis of the overall plan of the trenches indicates a fairly comparable coverage of most buildings although, as already noted, some buildings were only partially excavated. This applies particularly to palace $P$, Building $T$, Building $F$, barracks $O$ and $\mathrm{N}$, and Buildings $\mathrm{R}$ and $\mathrm{Q}$. The latter two do not really feature in this analysis and, despite the small percentages of palace $P$ and Building $F$ that have been excavated, these buildings each contained a considerable range of finds. Building $T$ also demonstrates a tantalising assemblage in the small area excavated. Thus, when their artefact distribution patterns are examined alongside the completely excavated buildings, these few fall within observed patterns. The lack of excavation of barracks $\mathrm{O}$ and $\mathrm{N}$ and of about two-thirds of the fortress is more significant for a study interested in distribution of activities across the fortress. It, therefore, has little to say on the distribution of activities within most of the accommodation of ordinary soldiers and probably that of storerooms, workshops, granaries and stables. That said, however, substantially more of this site has been excavated than many Roman fortress sites.

The assignment of functional and gender categories to certain items in this study may also seem, at times, rather positivist. However, the aim is not to prove that these items had such categories. Rather it is to explore the kinds of activities which took place at Vetera and the spatial distributions of these activities if these categories are indeed correctly assigned.

To demonstrate that the data and distribution patterns in this study are relatively robust it needs first to be shown that these patterns conform to what might be expected at such a site.

\subsubsection{Traditional building function and gender distribution}

This study can assess the relationships between artefact distribution patterns and their related functional categories, and the functions ascribed to the buildings at Vetera I by 
Lehner, and Hanel, and indirectly by von Petrikovits (see Section 4.4). It can also investigate the spatial distribution of gendered activities in relation to the various components of the fortress.

In many ways the study supports expectations of the distribution of activities and people within a 1st century $\mathrm{CE}$ Roman military fortress. The central administrative buildings, particularly Buildings $A$ and $B$, contained a wealth of items related to male activities, especially combat activities, but also to administrative activities such as writing. In contrast, personal activities, such as dress (excluding combat dress), toilet activities, and leisure activities (i.e. gaming), were comparatively less well represented in these buildings than they were in the officers' residences, and interestingly, in the buildings along the east end of the via principalis. Similarly, items which are likely to have been associated with women were only sparsely represented in these central buildings but relatively predominant in the officers' residences. These distribution patterns suggest that the functional and gender categories ascribed in this study are likely to have some validity.

In addition, there is no clearly distinguishable pattern between these items with good Neronian contexts and those with less secure contexts. Thus, the overall pattern seems to be robust and valid. The errors that are no doubt present from the incorrect assignment of functional and gender categories, or from the imprecise stratigraphy, have little impact.

If these distribution patterns can, therefore, be accepted as valid, then it is interesting to investigate what distribution patterns at Vetera do not conform to the traditional functional ascriptions of its buildings or to the expected positions of women and children within a 1st century $\underline{\mathrm{CE}}$ legionary fortress such as this.

\subsubsection{Re-asssessing the functions of buildings}

\subsection{3a The barracks}

In the first instance the lack of personal items, such as toilet and dress items, in the buildings identified, on architectural grounds, as barracks is perhaps noteworthy. This applies to infantry barracks $\mathrm{N}$ and $\mathrm{O}$, although one toilet item was found in barracks $\mathrm{N}$ and generally very little was recorded from these buildings. There is also a relative lack of personal items in barracks $Y, V$, and $W$. In contrast, barracks $Y$ in particular, but also barracks $\mathrm{V}$, had a wealth of tools and items related to commerce. These were most evident in the row of rooms along the front of each of the barracks. It is interesting to postulate that these buildings fronting the street, and identified by Lehner $(1930,39)$ as shops, were indeed workshops for the craftsmen, the immunes, who may have resided in the barracks behind. They were well positioned to deal with the needs of both the fortress and any settlements outside. No comparable finds were made in Building $S$, identified by von Petrikovits ( $\underline{1975}$, pl. 4.10) as an immunes barracks. The activities documented in Building $S$ had more in common with the officers' houses, although notably no items potentially related to women or children were found here.

It is also interesting to note that both these areas, barracks $Y$ and barracks $V$ and $W$, had items that were possibly associated with women and children. A small, silver decorated trumpet fibula, dated Claudian-Trajanic, was found in or near barracks $W$ and two small bronze bells, possibly belonging to children, were found in the front parts of both barracks $Y$ and barracks $\mathrm{V}$. These are not particularly significant but the trumpet fibula is of interest in debates concerning the presence of women within the barracks.

\subsection{3b Valetudinarium Z}

It has been noted on several occasions in the preceding analyses that the finds in Building $Z$ do nothing to substantiate its identification as a hospital. There was a lack of toilet items here, with the exception of glass bowls. Remains of three larger glass bowls or dishes were found in the rooms on the street front of the building and one just inside the central 
courtyard. Two more glass bowls, one small and one large, were found along the outer west side of the building. In contrast, thirteen possible dress items were found here, including at least one female item, a belt attachment. There were also a number of combat items in the rooms along the front. Although the recorded finds from within this building were minimal, the lack of toilet-related items compared to, for example, Building $T$ would suggest that the function ascribed to Building $Z$ is improbable, or else that military hospitals functioned without the usual equipment found in the toolkit of medical practitioners (see Jackson esp. 1994b; compare Baker 2001). However, it is not possible to ascribe any other function to this building through the distribution of the particular artefact types selected in this sample.

\subsection{3c Buildings $b, c$ and $d$}

There was a relative dearth of finds in Buildings b, c and d. Finds from Building b, investigated in this study, consisted of a bronze pendant, a lead weight, two inkwells and a hinge. Finds in Building $d$ consisted of a drop handle only and nothing was recorded in Building c. However, over 400 artefacts were recorded from Building b, being predominantly tableware, food-preparation and storage items, and some thirty artefacts from the small part of Building $d$ which has been excavated, also predominantly tableware and food preparation items. While more investigation of other activity patterns is needed, this distribution pattern suggests that Building $b$ was not used for any of the personal or gendered activities discussed here. That would tend to suggest that it was not a workshop and probably not a residence.

\subsection{3d Building a}

Finds in Building a included a number of dress-related items, one being the remains of a women's necklace. They also included a number of glass bowls and finds related to either toilet or eating and drinking. The finds from this building, but not included in this gender study, also consisted of a considerable amount of tableware and serving items, foodpreparation items and coins (Allison n.d. 2). It is by no means conclusive but it is tempting to see this as an inn or guest house, like the one run by Belica at Vindonissa (see Section 2.3.2c).

\subsection{3e Building F}

Lehner $(\underline{1930}, 23)$ identified a pre-Neronian hospital beneath this building but Hanel $(\underline{1995}$, 304 ) felt that this identification was unsubstantiated. In this study no certain toilet items were documented here but the remains of a number of glass unguentaria and bronze basins were recorded, all from Claudian-Neronian contexts. Other finds from this building, and from the street immediately in front of it, included a number of dress-related items, excluding three from a pre-Claudian context, and numerous tools and craft implements, notably six writing implements. Food preparation, tableware and serving items were also relatively prolific here (Allison n.d. 2). It is difficult to interpret this assemblage which seems to cover a wide range of activities. Given that Building $F$ is only partially excavated and many of these artefacts were found along the street front, this assemblage may rather document a range of services and wares sold in shops along the via principalis. Three of these items may have been associated with women and children. With the possible exception of the comparative wealth of writing items, this assemblage would not seem to confirm Hanel's identification of Building $\mathrm{F}(\underline{1995}, 100)$ as an officers' administrative building.

\subsubsection{Re-assessing the place of women and children within the fortress}

While it is noted above that a large proportion of items related to women and children were found in officers' residences, an equal, or perhaps even greater, proportion of such items was not. A scattering was found across the central administrative buildings, Buildings A, B and G, but it is difficult to assess the significance of these, not least because none of these 
particular items are definitively women's and children's items. Though, perhaps they warn us that these were not exclusively male zones.

\subsection{4a The gateways, the street, the shops and the central market area}

There is, however, a relative concentration of women's and children's material in the open area in front of Building $A$, particularly immediately above Buildings $C$ and $D$. This material was mainly from Trench 288 , pit 6 , which also contained many complete utilitarian ceramics and glass artefacts and which Hanel (1995, 311-312) dated to 69/70 CE. Lehner suggested $(1930,40)$ that this open area was a market area. Pseudo-Hyginus $(12)$ had referred to the area on the via principalis, in front of the praetorium, as the place where the crowd gathered. The high proportion of possibly female and children's items here, as well as in the via principalis and in the buildings opening on to it, and in the east gateway, may point to the equal, or greater, numbers of women and children frequenting these public and relatively commercial areas as the officers' private residences (see James 2002, 43).

There is a significant concentration of such items, mostly dress-related, in buildings in front of Building $Z$ that open onto the street. The numbers are extremely small but, if the quantity of women's and children's items in the tribunes' houses documents their habitation there, then the quantity here might also document habitation.

\subsection{4b Buildings $T$ and $U$}

Three definitively female items were found in the vicinity of the east gateway, including two bronze hairpins in Buildings $T$ and $U$. Other items found in the relatively small excavated area of these two buildings, and included in this study, were: six 'male' and 'male or female' dress items, two probes, remains of eight glass bowls, two writing implements, one small lead weight, one knife, and one gaming counter. With the exception of one mattock, which seems to have been in the courtyard, no definitely male activities were recorded here, most notably no combat equipment and no combat dress. Among the other items recorded here but not included in this gender study were quantities of tableware, food-preparation and storage items, and some coins. Painted wall plaster, with vertical stripes and fields, was also recorded in these two buildings. It is difficult to interpret this pattern. The apsidal buildings may suggest that they had a religious purpose but the artefacts do not support this identification. The lack of combat equipment is interesting, as is the preponderance of dressand toilet-related items. Is it possible that these buildings could have been part of a bath complex within the fortress, as was recorded at Vindonissa (see e.g. Unz and Deschler-Erb 1997, fig. 2)?

\subsubsection{Statistical analyses}

The data and distribution patterns in this study can also be tested for robustness by assessing whether the patterns portrayed by spatial analysis are also repeated using statistical analyses.

\subsection{5a Multivariate Analyses}

Correspondence analysis (CA), a multivariate statistical technique, was used to explore the pattern of variation in the gender data and especially to see if statistical analysis repeated some of the patterns identified visually on the GIS plots. CA is an ordination method, which summarises many numerical descriptive variables, in this case gender attributes, into a smaller number of axes of variation along which the statistical cases they describe (excavation trenches, buildings etc.) can be plotted. In this way, groups of buildings or excavation trenches, formed on the basis of these numerical variables, can be identified and displayed. CA has the added advantage of producing plots in which the position of the variables is also displayed, allowing the numerical relationship between all cases, all 
variables, and between cases and variables to be analysed and seen (Shennan 1988; Baxter 1994).

Bi-plots showing the first two axes of variation were prepared for two sets of data derived from the gender classification. Data from individual trenches were not used as they represented arbitrary divisions of space. Rather, gender data was grouped by building or area, with cases excluded in which the sum of gendered artefacts was less than 10 . This was done to reduce the effect of cases with small sample sizes. It was sometimes difficult to map precisely where individual artefacts came from and some were excluded if they derived from trenches that crossed building boundaries. CANOCO (Ter Braak 1999), was used to perform correspondence analysis after standard reductions and transformations of the data were applied to minimise the influence of rare artefact occurrences. Variables occurring in less than $10 \%$ of the cases were removed and, because of positive skewing, all data were subject to a square-root transformation.

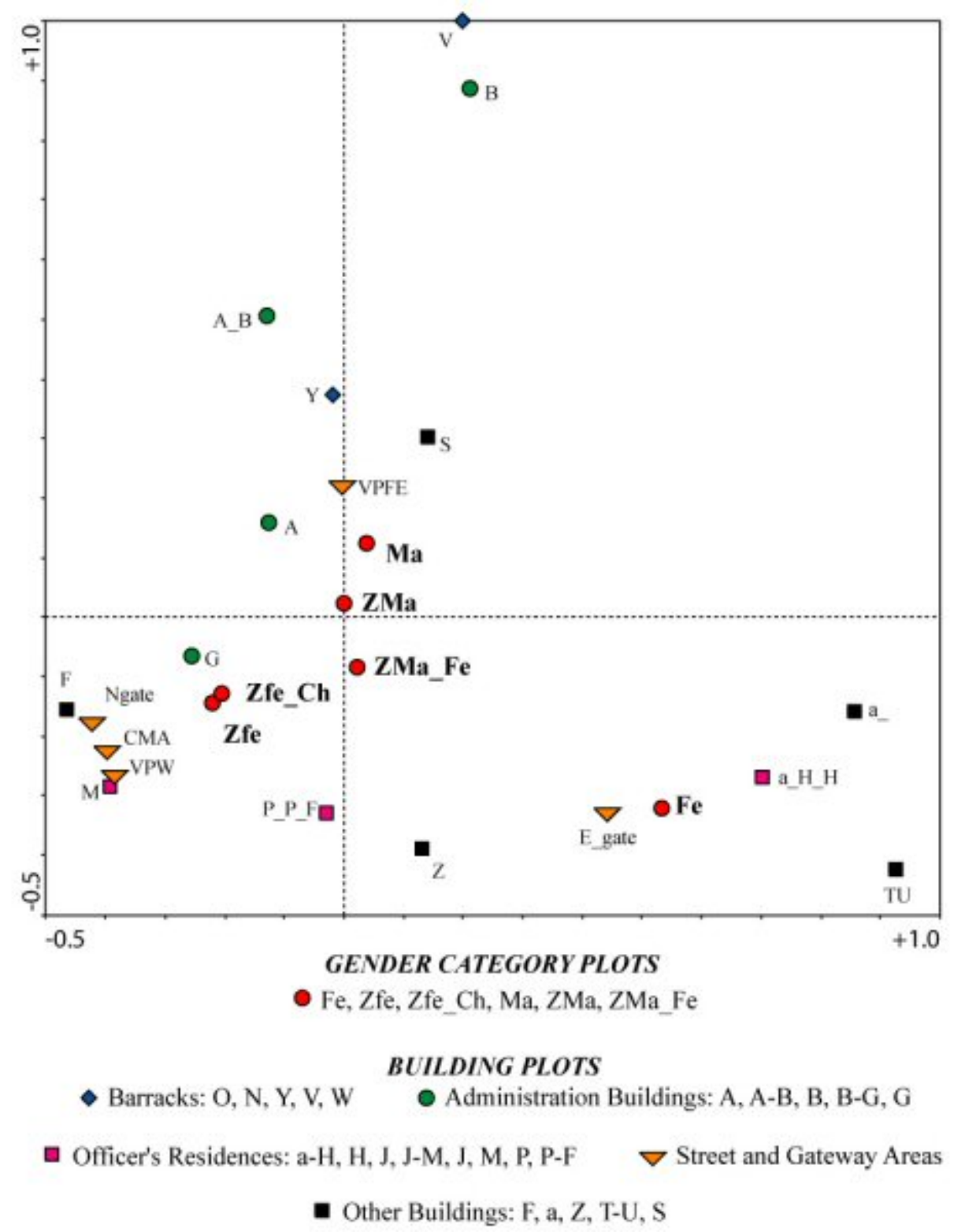

Figure 28: Correspondence analysis between buildings, with more than 10 artefacts, and gender categories (A. S. Fairbairn)

The first data set was derived from all buildings and excavation areas in which there were more than ten gendered artefacts (Figure 28). This included 513 artefacts (of the 704 gendered artefacts) from trenches in Buildings, A, a, B, A-B (i.e. includes trenches that cut through both buildings), $\mathrm{F}, \mathrm{G}$, trenches from $\mathrm{a}-\mathrm{H}$ and $\mathrm{H}$ combined, $\mathrm{M}, \mathrm{P}$ and $\mathrm{P}-\mathrm{F}$ combined, $\mathrm{S}$, $T$ and $U$ combined, $V, Y, Z$, finds from the central market area, the gates and the via principalis. 


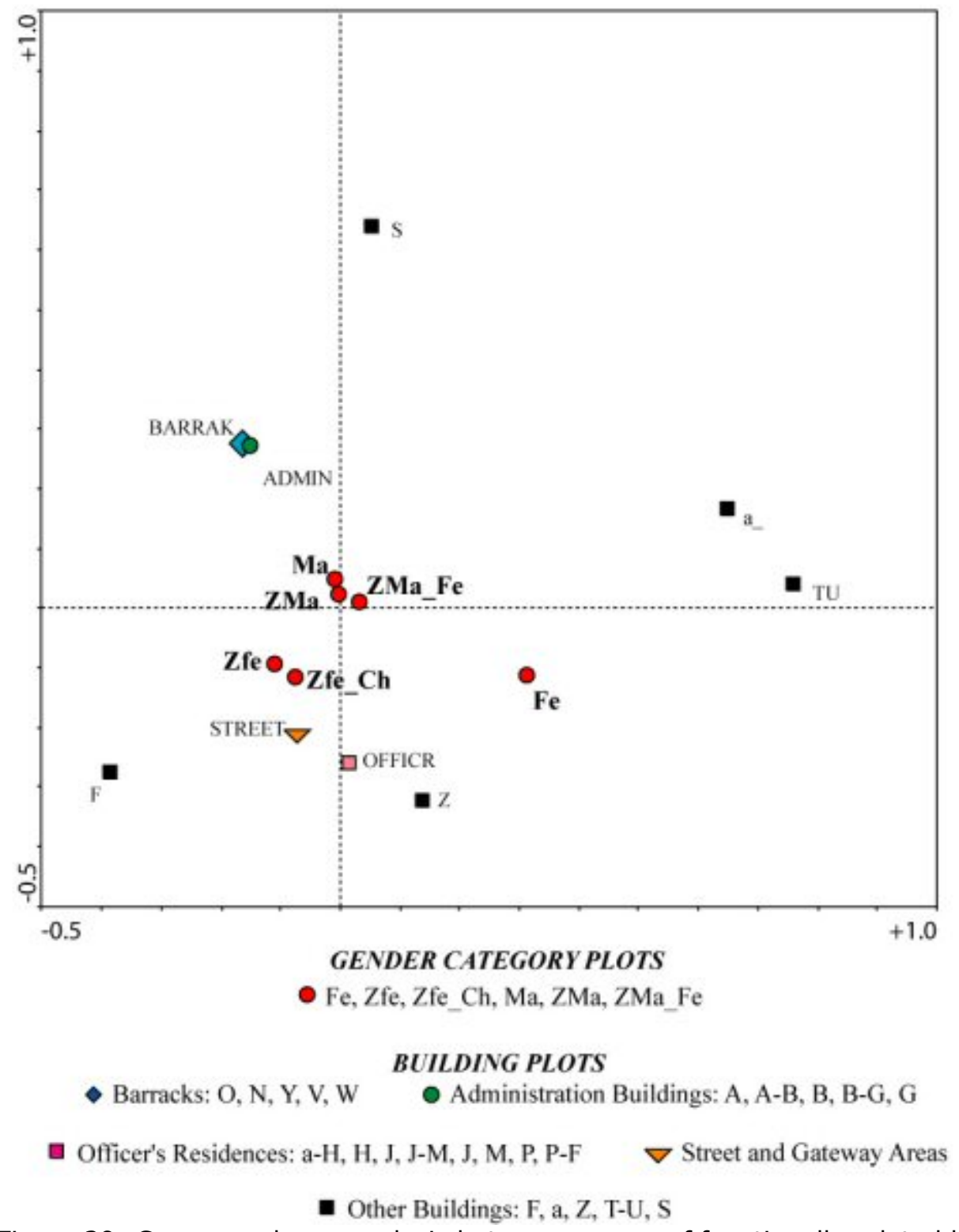

Figure 29: Correspondence analysis between groups of functionally related buildings and areas, and gender categories (A. S. Fairbairn)

A second analysis was carried out which grouped the buildings according to their overall functions (Figure 29). This was done to simplify the data further and had the added advantage of including artefacts from several important buildings that were excluded in the first, taking a sample size to 546. The remaining artefacts in the total sample for this study were either outside the Neronian fortress or unprovenanced. Buildings $K, J, M, H, P, Q$ and $R$ were grouped as officers' residences (OFFICR on plot), A,B and $G$ as administrative buildings (ADMIN on plot), Buildings $O, N, Y, V$ and $W$ as the barracks (BARRAK on plot), the gates, central market area and via principalis were grouped as open spaces (STREET on plot). In addition, a, F, S, Z and a merged TU group were also plotted.

The results show a similar pattern of variation in both plots, with the female and child artefacts causing the main variance along the first axis (horizontal) and the male and uncertain male/female objects causing little. Male and female categories were distinguished more along the second axis of variation, with male categories plotting to the positive side of the axis and female to the negative side. In short, the officers' quarters and public spaces, with the possible exception of the via principalis area in front of Building $F$, showed a tendency for containing more non-male artefacts. This tendency was shared by Buildings $\mathrm{H}$ (a_H_H on plot), a, Z, F and a combination of Buildings $T$ and $U$ (TU on plot). The barracks and the administration blocks showed a tendency to contain fewer non-male artefacts, as did Building $\mathrm{S}$. 
This analysis broadly supports the assessment of the GIS artefact distribution plots, even though sample sizes from many of the buildings were small.

\subsubsection{Occupancy of the fortress}

Given that only a small proportion of the fortress has actually been excavated it is difficult to use this portion to assess the state of occupancy immediately before its abandonment. It has already been noted that no finds were made in Building $c$. Does this mean that this building had been empty before the final destruction of the fortress? Does this emptiness reflect its habitual use and state of cleanliness?

\subsection{6a Palace H}

Perhaps a more interesting observation is that palace $\mathrm{H}$ was largely bereft of domestic finds from the Claudian and Neronian periods, compared both with the tribunes' houses and also, notably, with the relatively limited excavated area of palace P. In this study were recorded: two writing implements at the front of the palace, facing the via principalis; a few fragments of glass bowls, at the front, on the east side, and in the courtyard; and a small scatter of other items. The main concentration of artefacts was found in the north-west corner and consisted of dress-related items, including one bronze hairpin, a lead slingshot and a lead weight. Given the area covered by this building, it was also relatively bereft of other finds (see Allison n.d. 2, esp. fig. 10).

The trenches across palace $\mathrm{H}$ indicate that it was as extensively excavated as any other excavated area within the central part of the fortress. If the pattern does not relate to some anomaly in the excavation process, this lack of finds suggests that this palace may well have been empty at the time the fortress was besieged. It is tempting to suggest that this might mean that only one legate had been in residence in 69/70 $\underline{\mathrm{CE}}$, and possibly only one legion.

\subsubsection{The ban on soldier marriages in the 1 st century $\mathrm{CE}$}

The double legionary fortress at Vetera I was destroyed in 69/70 $\underline{C E}$, over a century before Septimius Severus had allowed ordinary soldiers to live in wedlock with their wives (Herodian, Histories: 3.8.4-5). Thus, the study examines the traces of women and children within the fortress at a time when only officers' families, and perhaps their domestic servants, were supposed to have lived within Roman military fortifications.

Unfortunately, this study throws little light on the issue of whether or not, despite the legal ban, soldiers lived with their wives and families within the fortress at Vetera. This is largely because very little of the soldiers' accommodation has been excavated. What the study does show, however, is that women and children were as present in the more public areas of the fortress - the central market place, the shops lining the street and other buildings immediately off it - as they were within the officers' residences. One can perhaps postulate their role in these places. For example, is not difficult to imagine that local women, or women from the canabae came into the central market area to sell merchandise or that they provided services in the shops along the street. If indeed Buildings $T$ and $U$ were part of a bath complex, however, does the presence of women's hairpins here document one or more of those services and is it necessary to assume that such women lived outside the fortress? Given the lack of finds in barracks W why was a trumpet fibula found here? Why is there such a concentration of women's and children's items in front of Building Z. These traces are admittedly extremely meagre but they can be seen to support the epigraphical material from Vindonissa (see Section 2.2.2) and the findings of Carol van Driel Murray (see 2.3.2b and $\underline{8.2 .1 c)}$.

\subsubsection{Concluding comments}


The observations presented in this study demonstrate how such an approach, if applied to a series of military sites, can start to tell us more about the life within a Roman military base, about the roles of non-military personnel, particularly women and children, and about the non-military activities in this community.

With the exception of male dress and male activities, this article has concentrated on a number of activities that are not normally documented by large numbers of artefacts within an excavated military installation. Consequently the analyses produce maps of only a small number of items and are, therefore, suitable for a methodological article such as this. However, much more work is needed, particularly more inter-site analyses, before the suggestions made in this article can be given more weight.

Also, the analyses of other activities, such as cooking, eating and drinking, which are represented by larger amounts of material and which produce more complex maps, are as important to our understanding of fort life. A preliminary exploration of this material has been carried out for Vetera I and showed interesting patterns (Allison n.d. 2).

One of the main reasons why it is possible for me to carry out research of this type, using previously published excavation reports, is that the questions in which I am interested are different from those of the original investigators. Until recently, as outlined in Section 2.1 , most investigators of Roman military sites have been more concerned with the fort as a fighting unit and as an element in the expansionist machine of the Roman Empire, or with the evidence the excavated artefacts provided for the dating of pottery typologies. The applications of new theoretical frameworks to answer questions concerning social behaviour and of new technologies to already published data from old excavation reports demonstrate that much useful information can still be gathered by revisiting past research.

\section{back top forward contents home}

(c) Internet Archaeology URL: http://intarch.ac.uk/journal/issue17/4/8.7.html

Last updated: Mon Apr 42005 


\section{back forward contents home}

\section{Sections 9-12: Data, Reference Materials and Acknowledgements}

Section 9: Catalogues and GIS maps (by A.S. Fairbairn and S.J. Ellis, with assistance from P.A. Faulkner)

9.1: Sample from Vetera I artefact catalogue

- 9.1a Excel spreadsheet

- 9.1b Tab delimited files

- Vetera artefact data (tab delimited text file)

- Vetera trench XY coordinates (tab delimited text file)

9.2: Queried Access database formatted from Excel spreadsheet (Access database download may not work on some systems)

9.3: GIS project (Following a review of legacy systems and in line with broader ADS practice, the interactive map element of this article has been decommissioned. The full underlying set of data is still available for download from the digital archive.)

Section 10: Glossary

Section 11: Bibliography

Section 12: Acknowledgements

\section{back forward contents home}

(c) Internet Archaeology URL: http://intarch.ac.uk/journal/issue17/4/summary9-12.html

Last updated: Mon Apr 42005 


\section{back contents home}

\section{Section 12: Acknowledgements}

The project 'Engendering Roman Spaces' is funded by an Australian Research Council QE II Fellowship. I am grateful to the Australian Research Council and to the Australian National University for providing me with the opportunity to carry out this research.

I particularly wish to thank the research team who have worked so enthusiastically on this project. Dr Andrew Fairbairn was appointed in 2001 to translate published excavation catalogues into a digital format and the success of this project owes much to his creativity and enthusiasm. Steven Ellis was appointed to digitise the site maps and plans and has been committed to producing excellent maps. They have both been great assets to the project. Pat Faulkner took over from Andy in 2004 and I thank him for his dedication to bringing this article to fruition, not least his excellent computer drafting skills. I am also grateful to Christopher Blackall (Centre for Cross Cultural Research, Australian National University), who, from the early stages in the development of the technical side of the project, has given freely of his time and expertise, advising on the best procedures to follow, and recommending the appropriate software and the overall methodology for merging the textual and cartographic information in ArcGIS. In addition I wish to acknowledge the technical support of Karl Nissen (Department of Geography, Australian National University), who has not shied away from the weird things that archaeologists want to do with GIS.

Without Norbert Hanel's careful and dedicated study of Hans Lehner's excavations of Vetera I, it would not have been possible to use this important site as a sample for this study. I thank him for his permission to use his work in this manner and to reproduce some of his drawings and for his comments on this paper. Last, but not least, I am also grateful to Carol van Driel Murray, Astrid Böhme and Lindsay Allason-Jones for their support and for sharing with me their expertise in engendering Roman artefacts and to the anonymous referees for their comments and amendments. However, they are not responsible for the views in this article.

Penelope M. Allison

\section{back contents home}

(C) Internet Archaeology URL: http://intarch.ac.uk/journal/issue17/4/ack.html

Last updated: Mon Apr 42005 


\section{back forward contents home}

\section{Section 11: Bibliography}

Allason-Jones, L. 1988 'Small finds from the turrets on Hadrians Wall' in J. C. Coulton (ed.), Military equipment and the identity of Roman soldiers: Proceedings of the fourth Roman military equipment conference. BAR International Series 394, 197-233. Oxford.

Allason-Jones, L. 1989 Women in Roman Britain. British Museum, London.

Allason-Jones, L. 1995 '"Sexing" small finds' in P. Rush (ed.), Theoretical Roman archaeology: Second conference proceedings. Worldwide Archaeology Series, no. 14, 22-32. Avebury.

Allason-Jones, L. 1996 'Museum note 1996: Roman military and domestic artefacts from Great Chesters'. Archaeologia Aeliana, 5th series, vol. XXIV, 187-214.

Allason-Jones, L. 1999a 'Woman and the Roman army in Britain' in A. Goldsworthy and I. Haynes (eds), The Roman army as community. Journal of Roman Archaeology Supplement 34, 41-51. Portsmouth, Rhode Island.

Allason-Jones, L. 1999b 'What is a military assemblage?'. Journal of Roman Military Equipment Studies 10, 1-4.

Allason-Jones, L. and Bishop, M.C. 1988 Excavations at Roman Corbridge: The hoard. English Heritage Archaeological Reports 7. English Heritage, London.

Allason-Jones, L. and Miket, R. 1984 The catalogue of small finds from South Shields Roman fort. The Society of Antiquaries of Newcastle upon Tyne monograph series. Newcastle upon Tyne.

Allison, P.M. 1992 'Artefact assemblages: Not the Pompeii premise' in E. Herring, R. Whitehouse and J. Wilkins (eds), Papers of the fourth conference of Italian archaeology, London 1990 3, pt I, 49-56. Accordia Research Centre, London.

Allison, P.M. 1994 The distribution of Pompeian house contents and its significance (Ph.D. thesis, Univ. of Sydney). UMI Dissertation Services (no. 9400463). Ann Arbor, Michigan.

Allison, P.M. 1999a 'Labels for ladles: Interpreting the material culture of Roman households' in P. M. Allison (ed.), The archaeology of household activities, 57-77. Routledge, London and New York.

Allison, P.M. (ed.) 1999b The archaeology of household activities. Routledge, London and New York.

Allison, P.M. 2001 'Using the material and the written sources: Turn of the millennium approaches to Roman domestic space'. American Journal of Archaeology 105, 181-208.

Allison, P.M. 2004 Pompeii households: Analysis of the material culture. Cotsen Institute of Archaeology, UCLA, Monograph 42. Cotsen Institute of Archaeology, UCLA, Los Angeles. (See also online companion: www.stoa.org/pompeianhouseholds/).

Allison, P.M. n.d.1 The Insula of the Menander in Pompeii III: The finds in context. Oxford University Press, Oxford.

Allison, P.M., n.d.2 'Mapping artefacts and activities within Roman military forts'. Proceedings of the XIXth international congress of Roman frontier studies (Pécs Sept. 2003, conference details online at http://limesxix.btk.pte.hu/). 
Almgren, O. 1923 Studien über nordeuropäische Fibelformen der ersten nachchristlichen Jahrhunderte mit Berücksichtigung der provinzialrömischen und südrussischen Formen. Mannus Bibliothek 32. C. Kabitzsch, Würzburg.

Anderson, A.C. and Anderson, A.S. (eds) 1981 Roman pottery research in Britain and Northwest Europe: papers presented to Graham Webster. BAR International Series 123. Oxford.

Baker, P.A. 2001 'Medicine, culture and military identity' in G. Davies, A. Gardner and K. Lockyear (eds), TRAC 2000: Proceedings of the tenth annual theoretical Roman archaeology conference, 48-68. Oxbow Books, Oxford.

Baxter, M.J. 1994 Exploratory multivariate analysis in archaeology. Edinburgh University Press, Edinburgh.

Becker, W.A. 1876 'Excursus I, scene I, the Roman house' in Roman Scenes at the time of Augustus (5th edition), 231-80. Longmans, Green and Co., London.

Berry, J. 1997 'Household artefacts: Towards a re-interpretation of Roman domestic space' in R. Laurence and A. F. Wallace-Hadrill (eds), 'Domestic space in the Roman world: Pompeii and beyond', Journal of Roman Archaeology, supplement 22, 183-96. Portsmouth, Rhode Island.

Binford, L.R. 1981 'Behavioral archaeology and the "Pompeii premise"', Journal of Anthropological Research 37, 195-208.

Birley, E., Dobson, B. and Jarrett, M. (eds) 1974 Roman frontier studies: 8th congress of Limesforschungen. University of Wales, Cardiff.

Birley, R. 1977 Vindolanda: A Roman frontier post on Hadrian's Wall. Thames and Hudson, London.

Bishop, M.C. 1987 'The evolution of certain features' in M. Dawson (ed.), Roman military equipment: The accoutrements of war, Proceedings of the third Roman military equipment seminar, 109-39. BAR International Series 394. Oxford.

Bishop, M.C. 1988 'Cavalry equipment of the Roman army in the first century A.D.' in J. C. Coulston (ed.), Military equipment and the identity of Roman soldiers: Proceedings of the fourth Roman military equipment conference. BAR International Series 394, 67-196. Oxford.

Bishop, M.C. 1991 'Soldiers and military equipment in the towns of Roman Britain' in V. A. Maxfield and M. J. Dobson (eds), Roman frontier studies 1989, Proceedings of the XVth international congress of Roman studies, 21-27. University of Exeter Press, Exeter.

Bishop, M.C. and Coulston, J. 1989 Roman military equipment. Shire Archaeology, Aylesbury.

Bishop, M.C. and Coulston, J. 1993 Roman military equipment: From the Punic Wars to the fall of Rome. Batsford, London.

Böhme, A. 1970 'Englische Fibeln der Kastelle Saalburg und Zugmantel'. Saalburg Jahrbuch 27, 5-20.

Böhme, A. 1972 Der Fibeln der Kastelle Saalburg und Zugmantel. Saalburg Jahrbuch 29.

Böhme-Schönberger, A. 1997 'Kleidung und Schmuck in Rom und den Provinzen'. Schriften des Limesmuseum Aalen 50. Zweigmuseum des Württembergischen Landesmuseum, Stuttgart.

Böhme-Schönberger, A. 1998a 'Die Fibeln Almgren 101' in 100 Jahre Fibelformen nach Oscar Almgren, Internationale Arbeitstagung 25-28 Mai 1997 in Kleinmachnow, Land Brandenburg, 175-85. Forschungen zur Archäologie im Land Brandenburg 5, Wünsdorf. 
Böhme-Schönberger, A. 1998b 'Die provinzialrömischen Fibeln bei Almgren' in 100 Jahre Fibelformen nach Oscar Almgren, Internationale Arbeitstagung 25-28 Mai 1997 in Kleinmachnow, Land Brandenburg, 351-66. Forschungen zur Archäologie im Land Brandenburg 5, Wünsdorf.

Bowman, A.K. 1994 Life and letters on the Roman frontier: Vindolanda and its people. British Museum Press, London.

Bowman, A.K. and Thomas, J.D. 1994 The Vindolanda writing-tablets (tabulae Vindolandenses II). British Museum Press, London.

Campbell, J.B. 1978 'The marriage of soldiers under the empire'. Journal of Roman Studies 68, 153-66.

Carandini, A. 1984 Settefinestre: Una villa schiavista nell'Etruria romana I-III. Panini, Milan.

Cassius Dio, Roman history (transl. by E. Cary, 1968). Loeb Classical Library. Harvard University Press and William Heinemann, Cambridge, Mass. and London.

Chavane, M.-J. 1975 Salamine de Chypre: Les petits objets. De Boccard, Paris.

Clarke, S. 1994 'A quantitative analysis of the finds from the Roman fort of Newstead' in S. Cottam, D. Dungworth, S. Scott and J. Taylor (eds), TRAC 94: Proceedings of the fourth annual theoretical Roman archaeology conference, Durham 1994, 72-82. Oxbow Books, Oxford.

Collingwood, R.G. and Wright, R.P. 1965 The Roman inscriptions of Britain 1: Inscriptions on stone. Clarendon Press, Oxford.

Cool, H.E.M. and Baxter, M.J. 2002 'Exploring Romano-British finds assemblages'. Oxford Journal of Archaeology 21.4, 365-80.

Coulston, J.C. 1988 Roman military equipment and the identity of soldiers. Proceedings of the fourth Roman military equipment conference. BAR International Series 394. Oxford.

Crummy, N. 1983 Colchester archaeological reports 2: The Roman small finds from excavations in Colchester 1971-9. Colchester Archaeological Trust and Council for British Archaeology, London.

Crummy, P. 1992 Colchester archaeological reports 6: Excavations at Culver street, the Gilberd school and other sites in Colchester. Colchester Archaeological Trust and Council for British Archaeology, London.

de Tommaso, G. 1990 Ampullae vitrese: Contenitori in vetro di unguenti e sostanze aromatiche dell'Italia romana. G. Bretschneider, Rome.

Debrunner Hall, M. 1994 'Eine reine Männerwelt?: Frauen und das römische Heer' in M. H. Dettenhofer (ed.), Reine Männersache?: Frauen in Männerdomänen der antiken Welt, 20728. Böhlau, Cologne.

Deschler-Erb, S. 1998 Römische Beinartefakte aus Augusta Raurica: Rohmaterial, Technologie, Typologie und Chronologie. Forschungen in Augst Band 27/1. Römerstadt Augst, Augst.

Dixon, S. 2000-2001 'How do you count them if they're not there?'. Opuscula Romana 2526, 7-17.

Dixon, S. 2001 Reading Roman women. Duckworth, London.

Emery, W.B. 1938 The royal tombs of Ballana and Qustul. Government Publishers, Cairo. 
Evans, J.K. 1991 War, women and children in ancient Rome. Routledge, London and New York.

Fischer, U. 1966 'Zu Fibeln Almgren 101'. Jahresschr. Halle 50, 229-62.

Fleming, S.J. 1999 Roman glass: Reflections on cultural change. Univ. of Pennsylvania, Philadelphia.

Foss, P. 1994 Kitchens and dining rooms at Pompeii: The spatial and social relationship of cooking to eating in the Roman household (Ph.D. thesis, Univ. of Michigan). UMI Dissertation Services (no. 9513356). Ann Arbor, Michigan.

Frere, S.S. and Wilkes, J. 1989 Strageath: Excavations within the Roman fort 1973-86. Britannia monograph series no. 9. London.

Fröhlich, T. and Jacobelli, L. (eds) 1995 Archäologie und Seismologie: La regione vesuviana dal 62 al 79 d.C.: problemi archeologici e sismologici. (Deutsches Archäologisches Institut Rom, Soprintendenza Archeologica di Pompei, Osservatorio). Biering and Brinkman, Munich.

Furger, A. 1990 'Exkurs 3: Ringgrössen' in E. Riha (ed.), Der römische Schmuck aus Augst und Kaiser Augst. Forschung in Augst Band 10, 49-51. Römermuseum Augst, Augst.

Gaitzsch, W. 1980 Eiserne römische Werkzeuge: Studien zur römischen Werkzeugkunde in Italien und den nördlichen provinzen des Imperiums Romanum. BAR International Series 78. Oxford.

Galliazzo, V. 1976 Bronzi romani del Museo Civico di Treviso. G. Bretschneider, Rome.

Gardner, A. 1999 'Military identities in late Roman Britain'. Oxford Journal of Archaeology 18.4, 403-18.

Gardner, A. 2001 'Identities in the late Roman army: Material and textual perspectives' in. G. Davies, A. Gardner and K. Lockyear (eds), TRAC 2000: Proceedings of the tenth annual theoretical Roman archaeology conference, 35-47. Oxbow Books, Oxford.

Gardner, A. 2002 'Social identity and the duality of structure in late Roman-period Britain'. Journal of Social Archaeology 2:3, 323-51.

Gardner, A. 2004 'Artefacts, contexts and archaeology of social practices' in R. Hingley and S. Willis (eds), Promoting Roman finds: Context and theory. Oxbow Books, Oxford.

Garnsey, P. 1970 'Septimius Severus and the marriage of soldiers'. Californian Studies of Classical Antiquity 3, 45-53.

Gechter, M. 1979 'Die Anfänge des Niedergermanischen Limes'. Bonner Jahrbücher 179, 1138.

Goldworthy, A. and Haynes, I. (eds) 1999 'The Roman army as a community'. Journal of Roman Archaeology, supplement 34. Portsmouth.

Groenman-van Waateringe, W., van Beek, B.L., Willems, W.J.H. and Wynia, S.L. (eds) 1997 Roman frontier studies 1995: Proceedings of the XVIth international congress of Roman frontier studies. Oxbow, Oxford.

Grünewald, M. 1981 Die Kleinfunde des Legionslagers von Carnuntum mit Ausnahme der Gefäßkeramik (Grabungen 1968-1974). Der römische Limes in Österreich Heft 31. Österreichische Akademie der Wissenschaften, Vienna.

Grünewald, M. 1986 Ausgrabungen im Legionslager von Carnuntum: Keramik und Kleinfunde 1976-1977. Der römische Limes in Österreich Heft 34. Österreichische Akademie der 
Wissenschaften, Vienna.

Gusman, P. 1900 Pompei: The city, its life and art (transl. F. Simmonds and M. Jourdain). William Heinemann, London.

Hanel, N. 1995 Vetera I: Die Funde aus den römischen Lagern auf dem Fürstenberg bei Xanten. Rheinische Ausgrabungen 35. Rheinland-Verlag and Dr Rudolf Halbert, Cologne and Bonn.

Hassall, M. 1999 'Homes for heroes: married quarters for soldiers and veterans' in A. Goldsworthy and I. Haynes (eds), The Roman army as community. Journal of Roman Archaeology supplement 34, 35-40. Portsmouth, Rhode Island.

Haupt, D. and Horn, H.G. (eds) 1977 Studien zu den Militärgrenzen Roms II: Vorträge des 10. Internationalen Limeskongress in Germania Inferior. Beihefte der Bonner Jahrbücher Band 38, Cologne and Bonn.

Haynes, I. 1999 'Introduction: the Roman army as a community' in A. Goldsworthy and I. Haynes (eds), The Roman army as community. Journal of Roman Archaeology supplement 34, 7-14. Portsmouth, Rhode Island.

Herodian Histories (transl. by C.R. Whittaker 1969). Loeb Classical Library. Harvard University Press and William Heinemann, London, Cambridge, Mass.

Hilgers, W. 1969 Lateinische Gefässnamen: Bezeichungen, Function und Form römischer Gefässe nach den antiken Schriftquellen, Beihefte der Bonner Jahrbücher vol. $\mathbf{3 1}$. Landschaftsverband Rheinland Rheinisches Landesmuseum Bonn und Verein von Altertumsfreunden in Rheinlande Düsseldorf.

Hoffmann, B. 1995 'The quarters of legionary centurions of the Principate'. Britannia 26, 107-51.

Hoffmann, B. 2002 Römisches Glas im Baden-Württemberg: Archäologie und Geschichte. Freiburger Forschungen zum ersten Jahrtausend in Südwestdeutschland 11. Stuttgart.

Isings C. 1957 Roman glass from datable finds. J.B. Wolters, Groningen.

Jackson, R. 1994a 'Medical instruments in the "Antiquarium" at Pompeii' in L. Bliquez, Roman surgical instruments and other minor objects in the National Archaeological Museum of Naples. Philipp von Zabern, Mainz.

Jackson, R. 1994b 'The surgical instruments, appliances and equipment in Celsus' De medicina' in G. Sabbah and P. Mudry (eds). La médecine de Celse. Aspects historique, scientifiques et littéraires. Centre Jean-Palerne, Mémoires XIIII. Saint-Étienne.

Jacobi, L. 1897 Das Römerkastell Saalburg bei Homburg von der Höhe. Self-published, Homburg.

Jacobi, L. 1937 Das Kastell Zugmantel (1909). Der Obergermanisch-Raetische Limes des Roemerreiches B II1 no. 8. Otto Petters, Berlin and Leipzig.

James, S. 1999 'The community of soldiers: a major identity and centre of power in the Roman empire' in P. Baker, C. Forcey, S. Jundi and R. Witcher (eds), TRAC 98: Proceedings of the eighth annual theoretical Roman archaeology conference, Leicester 1998, 14-25. Oxbow Books, Oxford.

James S. 2002 'Writing the legions: The development and future of Roman military studies in Britain'. Archaeological Journal 159, 1-58. 
Jenkins, I. 1985 'A group of silvered-bronze horse-trappings from Xanten (Castra Vetera)'. Britannia 16, 141-59.

Jones, G.D. 1997 'From Brittunculi to Wounded Knee: A study of the development of ideas' in D. Mattingly (ed.), Dialogues in Roman imperialism, 185-200. Journal of Roman Archaeology supplement 23. Portsmouth, Rhode Island.

Jongman, W.M. 1988 The economy and society of Pompeii. Gieben, Amsterdam.

Juvenal Satires (transl. by G. G. Ramsay, 1918). Loeb Classical Library. Harvard University Press and William Heinemann, Cambridge, Mass. and London.

Kampen, N.B. 1981 Image and status: Roman working women in Ostia. Mann, Berlin.

Kampen, N.B. 1982 'Social status and gender in Roman art' in N. Broude and M. D. Garrard (eds), Feminism and art history: Questioning the litany, 60-77. Harper and Row, New York.

Kampen, N.B. 1996 Sexuality in ancient art: Near East, Greece and Italy. Cambridge University Press, Cambridge.

Kohl, W. and Tröltsch, J. 1914 'Das Kastell Weissenberg'. Der obergermanisch-rätische Limes des Römerreiches B VII no. 72, 1-59.

Kunina, N. 1997 Ancient glass in the Hermitage Collection. The State Hermitage ARS Publishers, St Petersburg.

Leach, E. 1997 'Oecus on Ibycus: Investigating the vocabulary of the Roman house' in S. E. Bon and R. Jones (eds), Sequence and Space in Pompeii, 50-72. Oxbow Monograph 77. Oxford.

Lehner, H. 1907 'Vetera. Ausgrabungen in den Jahren 1906-1907'. Bonner Jahrbücher 116, 302-43.

Lehner, H. 1912 'Vetera. Ausgrabungen in den Jahren 1910-1912'. Bonner Jahrbücher 122, 311-42.

Lehner, H. 1930 Vetera: Die Ergebnisse der Ausgrabungen des Bonner Provinzialmuseums bis 1929. Römisch-Germanische Forschungen 4. Frankfurt.

Liebenam, W. 1909 Paulys Realencyclopädie der classischen Altertumswissenschaft 6, 16751679. A. Druckmüller, Stuttgart.

Ling, R. 1997 The Insula of the Menander at Pompeii I: The structures. Clarendon Press, Oxford.

Maiuri, A. 1933 La Casa del Menandro e il suo tesoro di argenteria. Libreria dello Stato, Rome.

Manning, W.H. 1985 Catalogue of Romano-British iron tools, fittings and weapons in the British Museum. British Museum Publications, London.

Martin-Kilcher, S. 1993 'Römische Grabfunde als Quelle zur Trachtgeschichte in zirkumalpinen Raum' in M. Struck (ed.), Römerzeitliche Gräber als Quellen zu Religion, Bevölkerungsstructur und Sozialgeschichte, 181-203. Institut für Vor- und Frühgeschichte der Johannes Gutenberg-Universität, Mainz.

Mau, A. 1899 Pompeii: its life and art (transl. by F.W. Kelsey). MacMillan and Co., London. Maxfield, V. and Dobson, M.J. (eds) 1991 Roman frontier studies 1989: Proceedings of the XVth international congress of Roman frontier studies. University of Exeter, Exeter. 
McKay, A.G. 1977 Houses, villas and palaces in the Roman world. Thames and Hudson (reprint), Southampton.

McKendrick, N., Brewer, J. and Plumb, J.H. 1982 The birth of a consumer society: The commercialization of eighteenth-century England. Europa Publications Ltd., London.

Nandris, J. 1981 'Aspects of Dacian economy and highland zone exploitation'. Dacia XXV, 231-54.

Painter, K.S. 2001 The Insula of the Menander at Pompeii IV: The silver treasure. Clarendon Press, Oxford.

Palágyi, S. 1986 'Über Pferdegeschirr- und Jochrekonstrucktionen von Inota' in C. Unz (ed) Studien zu den Militärgrenzen Roms III, 13. Internationaler Limeskongress, Aalen 1983, 389-97. Forschungen und Berichte zur Vor- und Frühgeschichte im Baden-Württemberg Konrad Theiss, Stuttgart.

Phang, S.E. 2001 The marriage of Roman soldiers (13 BC-AD 235): Law and family in the imperial army. Brill, Leiden.

Phang, S.E. 2002 'The timing of marriage in the Roman army' in P. Freeman, J. Bennett, Z. Fiema and B. Hoffmann (eds), Limes XIII, Proceedings of the XVIIIth international congress of Roman frontier studies held in Amman, Jordan (September 2000), 873-78. BAR International Series 1084. Oxford.

Polybius 'Excursion on the Roman camp' in M.C.J. Miller and J.C. De Voto (transl. and eds 1994), Polybius and Pseudo-Hyginus: The fortification of the Roman camp, 1-44. Ares Publisher, Chicago.

Pseudo-Hyginus 'De munitionibus castrorum' in M.C.J. Miller and J.C. De Voto (transl. and eds 1994), Polybius and Pseudo-Hyginus: The Fortification of the Roman Camp, 59-102. Ares Publisher, Chicago.

Riha, E. 1979 Die römischen Fibeln aus Augst und Kaiser Augst. Forschungen in Augst Band 3. Römermuseum Augst, Augst.

Riha, E. 1990 Der römische Schmuck aus Augst und Kaiser. Forschungen in Augst Band 10. Römermuseum Augst, Augst.

Riha, E. 1994 Die römischen Fibeln aus Augst und Kaiser: die Neufunde seit 1975.

Forschungen in Augst Band 18. Römermuseum Augst, Augst.

Robinson, H.R. 1975 The armour of imperial Rome. Lionel Leventhal, London.

Roxan, M.M. 1991 'Women on the frontiers' in V. Maxfield and M.J. Dobson (eds), Roman frontier studies 1989: Proceedings of the XVth international congress of Roman frontier studies, 462-67. University of Exeter, Exeter.

Schiffer, M.B. 1985 'Is there a Pompeii premise?' Journal of Anthropological Research 41, 1841.

Schiffer, M.B. 1987 Formation processes of the archaeological record. University of New Mexico, Albuquerque.

Shennan, S. 1988 Quantifying Archaeology. Edinburgh University Press, Edinburgh.

Smith, R. 1972 'The army reforms of Septimius Severus'. Historia 23, 481-500.

Sommers, C.S. 1991 'Life beyond the ditches: Housing and planning of the military vici in upper Germany and Raetia' in V. A. Maxwell and M. J. Dobson (eds), Roman frontier studies 
1989: Proceedings of the XVth international congress of Roman frontier studies, 472-76. University of Exeter, Exeter

Southern, P. and Dixon, K.R. 1996 The late Roman army. Yale University Press, New Haven.

Speidel, M.A. 1996 Die römischen Schreibtafel von Vindonissa. Veröffentlichungen der Gesellschaft Pro Vindonissa Band XII, Baden-Dättwil.

Speidel, M.A. 1999 'Stadt- und Lagerleben' in H. von Hesberg (ed.), Das Militär als Kulturträger in römischer Zeit, 75-85. Schriften des Archäologischen Instituts der Universität zu Köln, Köln.

Swan, V. 2003 'Gauls in the army of Britain: some ceramic indicators'. Paper presented at the XIXth international congress of Roman frontier studies (Pécs Sept. 2003, conference details online at http://limesxix.btk.pte.hu/).

Tacitus Annals (transl. J. Jackson, 1962). Loeb Classical Library. William Heineman and Harvard University Press, London and Cambridge, Mass.

Tacitus Histories (transl. C.H. Moore, 1975). Loeb Classical Library. William Heineman and Harvard University Press, London and Cambridge, Mass.

Tassinari, S. 1993 Il vasellame bronzeo di Pompei. Soprintendenza archeologica di Pompei cataloghi 5. L'Erma di Bretschneider, Rome.

Ter Braak, C.J.F. 1999 Canoco for Windows. Microcomputer Power, New York.

Treggiari, S. 1976 'Jobs for women'. American Journal of Ancient History 1, 76-104.

Trigger, B.G. 1993 A history of archaeological thought. Cambridge University Press, Cambridge.

Ulbert, G. 1969 Das fruhrömische Kastell Rheingönheim. Römisch-Germanisch Commission, Limesforschungen 9, Berlin.

Unz, C. (ed). 1986 Studien zu den Militärgrenzen Roms III: 13. Internationalen

Limeskongress, Aalen 1983. Konrad Thiess, Stuttgart.

Unz, C. and Deschler-Erb, E. 1997 Katalog der Militaria aus Vindonissa: Militärische Funde, Pferdegeschirr und Jochteile bis 1976. Gesellschaft Pro Vindonissa, Brugg.

Van Driel-Murray, C. 1986 'Shoes in perspective' in C. Unz (ed.), Studien zu den Militärgrenzen Roms III: 13. Internationaler Limeskongress, Aalen 1983, 139-45. Konrad

Thiess, Stuttgart.

Van Driel-Murray, C. (ed.) 1989 Roman military equipment: The source of evidence.

Proceedings of the fifth Roman military equipment conference. BAR International Series 476, Oxford.

Van Driel-Murray, C. 1994 'A question of gender in a military context'. Helinium 34.2, 34262.

Van Driel-Murray, C. 1995 'Gender in question' in P. Rush (ed.), Theoretical Roman archaeology: second conference proceedings. Worldwide Archaeology Series 14, 3-21. Avebury.

Van Driel-Murray, C. 1997 'Women in forts?' Jahrbuch der Gesellschaft Pro Vindonissa, 5561.

Van Driel-Murray, C. 2003 'Ethnic soldiers: The experience of the lower Rhine tribes' in T. Grünewald and Sandra Seibel (eds), Kontinuität and Diskontinuität: Germania inferior am 
Beginn und am Ende der römischen Herrschaft, 200-17. Walter de Gruyter, Berlin and New York.

Varro De lingua latina (transl. R. G. Kent, 1951). Loeb Classical Library. William Heineman Ltd and Havard University Press, London and Cambridge, Mass.

Vetters, H. and Kandler, M. (eds) 1990 Akten des 14. Internationalen Limeskongress 1986 in Carnuntum. Österreichischen Akademie des Wissenschaften, Vienna.

Von Petrikovits, H. 1975 Die Innenbauten römischer legionslager während der Prinzipatzeit. Abhandlungen der Rheinisch-Westfälischen Akademie der Wissenschaften Band 56. Westdeutscher Verlag, Weisbaden.

Wallace-Hadrill, A.F. 1994 Houses and society in Pompeii and Herculaneum. Princeton University Press, Princeton, New Jersey.

Watson, G. 1969 The Roman soldier. Thames and Hudson, London.

Webster, G. 1985 The Roman imperial army of the first and second centuries A.D. (Third Edition). A. and C. Black, London.

White, K.D. 1967 Agricultural implements of the Roman world. Cambridge University Press, Cambridge.

Wild, J.P. 1968 'Clothing in the north-west provinces of the Roman empire'. Bonner Jahrbücher 168, 166-240.

Wild, J. P. 1970a Textile manufacture in the northern Roman provinces. Cambridge University Press, Cambridge.

Wild, J.P. 1970b 'Button-and-loop fasteners in the Roman provinces'. Britannia I, 137-55.

Willis, S. 1997 'Samian: Beyond dating' in K. Meadows, C. Lemke and J. Heron (eds), TRAC 96: Proceedings of the sixth annual theoretical Roman archaeology conference, Sheffield 1996, 38-54. Oxbow Books, Oxford.

Wilmott, T. 1997 Birdoswald: Excavations of a Roman fort on Hadrian's Wall and its successor settlements: 1987-92. English Heritage Archaeological Report 14. English Heritage, London.

Woolf, G. 2004 'The present state and future scope of Roman archaeology'. American Journal of Archaeololgy 108, 417-28.

Wyke, M. 1994 'Woman in the mirror' in L. J. Archer, S. Fischler and M. Wyke (eds), Women in ancient societies. Macmillan Press, London.

Young, L. 2003 Middle-class culture in the nineteenth century: America, Australia and Britain. Palgrave MacMillan, Basingstoke and New York.

Zanier, W. 1992 Das Römische Kastell Ellingen. Römisch-Germanisch Commission, Limesforschungen Band 23. Philipp von Zabern, Mainz am Rhein.

Zanker, P. 1988 Pompeji: Stadtbilder als Spiegel von Gesellschaft und Herrschaftsform. Philipp von Zabern, Mainz am Rhein.

\section{back forward contents home}




\section{back forward contents home}

\section{Section 10: Glossary}

\section{Term}

apsidal

Augst

Augustus

BCE

Bézier 'splines' tools

born-GIS data

CAD software

Caesar

canabae

Casa del

Menandro

Cassius Dio

CE

centurion

century

cingillum

Claudius

control points
Bézier drawing

refers to a building which has an apse in one or more walls oldest Roman colony on the Rhine, established 44 - 43 BCE (Colonia Raurica), now in Switzerland. City (Augusta Raurica) developed in 2nd century $\underline{C E}$ (see Kaiseraugst)

Octavius (63 BCE - 14 CE), first Roman emperor, founder of Julio-Claudian imperial family

\section{before the Christian era}

also called Bézier curves. A mathematically precise and efficient method for drawing curves, shapes and lines using computer graphics software. Named after Pierre Bézier who discovered the mathematical formula for creating the splines

Bézier drawing tools are used to create and edit Bézier splines. Bézier drawing tools are incorporated into many computer graphics applications, for example, Adobe Illustrator, Macromedia Freehand and Corel Draw

New GIS data that is created without reference to, or derived from, other data sources

Computer Aided Drawing (CAD) software is widely used for drawing architectural and engineering plans. CAD is similar to GIS in that it uses vector-based graphics to represent graphic entities and attributes

Gaius Julius Caesar (100 - 44 BCE), became dictator in 49 BCE

term used for small village which was established outside walls of fort, usually of a legionary fortress and at same time as fortress (see also vicus) (Latin)

so-called House of the Menander (I 10,4) in Pompeii (Italian)

Roman author and Greek senator (C. 164 - after $229 \underline{\text { CE}}$ ). Author of history of Rome from foundation to 229 CE

of the Christian era

principal professional officer in the Roman army, in charge of eighty men (a century). Six centurions in each cohort (see legion)

literally 100 soldiers, later only 80 , under the command of a centurion. Smallest unit in a legion (see legion)

girdle or belt, reputedly worn by women (Latin)

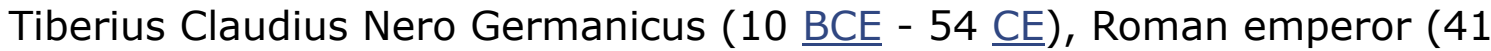
- 54 BCE)

part of Bézier 'splines' and can be modified by users to change the attributes of the spline

Correspondence multivariate statistical analysis that assesses the frequency of occurrence analysis of a set of variables in relation to another set 
cross-tab

queries

cuirass

$\mathrm{dbf}$ files

epigraphic

fibula (fibulae)

freeborn

Fürstenberg

geo-referenced data

gagat

Germanicus

GIS

GPS

Hadrian's Wall

'head-down' digitisation

'head-up' digitisation

Herodian

immunes

insula

Insula del

Menandro

intaglio

Juvenal

Kaiseraugst
Microsoft Access term describing a method of summarizing large amounts of data using a variety of calculations on data in database tables

body armour consisting of breast-plate and back-plate, usually buckled together and reaching to waist

database file format used in DBase IV, a popular database in the 1980s that is still widely used for data exchange

pertaining to epigraphy - collective term for inscriptions and term for the study of inscriptions

brooch or clasp (Latin)

not born into slavery and born to freeborn Roman citizen parents

hill to north-east of Vetera I

data that establishes the relationship between $X Y$ co-ordinates on a planar map and known real-world co-ordinates

jet (German)

Nero Claudius Drusus Germanicus (born 16/15 BCE), adopted by the emperor Tiberius ( $4 \underline{\mathrm{CE}}$ ), hence adopted grandson of Augustus, served as commander-in-chief in Gaul and Germany from 13 CE

Geographical Information Systems (GIS) is a computer system capable of assembling, storing, manipulating, and displaying geographicallyreferenced information in a relational database

Geographic Positioning Systems (GPS) is a technology that enables users to accurately locate their geographic position, typically from information transmitted by orbiting satellites and received by hand-held GPS devices

$3 \mathrm{~m}$ wide wall and forward ditch, built across northern England, from near Newcastle on east to Willowford on west, during the reign of the Roman emperior, Hadrian (possibly c. 117 - $119 \underline{\text { CE})}$

GIS term referring to a method of data capture that involves the conversion of data in analogue form, such as maps and plans, into a digital form that is directly readable by a computer. 'Head-down' digitization refers to an operator moving a cursor, or puck, over a printed work on a digitising table

as 'head-down', but 'head-up' digitization refers the digitization of scanned maps that are imported in a computer and digitised, or traced, by an operator using a computer mouse, or tablet

Roman author of 3rd century $\underline{\mathrm{CE}}$, born in eastern empire, wrote history of Roman empire during period 180 - 238 CE

soldiers with special tasks, e.g. craftsmen, who were excused from routine duties (Latin)

city block (Latin)

city block in Pompeii which includes the Casa del Menandro (Latin)

stone with a design incised into it (Italian)

Roman satirist, born between 60 - $70 \underline{\mathrm{CE}}$ and writing some time between C. $98-138 \underline{\mathrm{CE}}$

Roman military fort established on Rhine in 3rd century $\underline{C E}$, after destruction of city of Augst 
Kragenfibeln

Late La Tène

legacy data

legatus legionis

legion

lorica

segmentata

milites gregarii

multivariate

analyses

New

Archaeologists

normalised related tables

Nz function

OCR

ODBC driver

OLE DB

provider

oppidum

(oppida)

Ostia

Polybius

polygon

praefectus

(praefecti) collared brooches (German)

Late phase of La Tène (c. 100 BCE - 100 CE). La Tène is name given to Celtic period (c. 450 BCE - C. 100 CE), taken from site, La Tène, near the Neuenburger Lake in the western part of Switzerland

data from obsolete information systems

Commander of a legion (Latin)

military unit of some 6,000 soldiers under the command of a legate (see legatus legionis). Divided into ten cohorts each of six centuries (see century)

name, invented during Renaissance, for Roman armour composed of bands of iron fastened together with buckles and strips of leather (Latin)

ordinary soldiers or privates, legionaries (Latin)

statistical analyses that use two or more variables (e.g. a number of measurements on a pot) to assess for similarities and differences (e.g. between pots) and groups the objects accordingly (see Shennan 1988, 241-291)

practitioners, mainly American, of New Archaeology, introduced in the 1960s and popularised by Lewis Binford. Goals of New Archaeology are to 'explain the similiarities and differences in cultural behaviour' (see Trigger 1993, 289-328)

a relational database term referring to a series of steps followed to obtain a database design that allows for consistent storage and efficient access of data. These steps reduce data redundancy and the chances of data becoming inconsistent

Visual Basic function in Access, used to replace null values in tables and queries with a zero, zero length string or other value

Optical Character Recognition (OCR) is computer software designed to translate images of printed text (usually captured by a scanner) into machine-editable text

Open Database Connectivity (ODBC) is a standard software protocol for connecting to relational database management systems. In addition to the ODBC software, a separate module or driver is needed for each database to be accessed

OLE is an abbreviation of "Object Linking and Embedding", a proprietary Microsoft technology used to link its software products to database and other software applications

town, or collection of dwellings (Latin)

harbour town of the ancient city of Rome which flourished in 2 nd and 3 rd centuries $\underline{\mathrm{CE}}$

Greek historian (c. 200 - 118 BCE) who wrote on Rome's rise to dominate the Mediterranean region

GIS term describing a feature used to represent areas. A polygon is defined by the lines that make up its boundary and a point inside its boundary for identification

literally prefect or superintendent, leader of the cohorts, usually of aristocratic status (Latin) 
praetorium

principia

Pseudo-Hyginus

puck

relational

databases

sacellum

Scole

Septimius

Severus

'shape' files

SQL

strigil

stylus (styli)

taberna

(tabernae)

Tacitus

terra sigillata

tetrarchs

TIFF

tribune

unguentarium

(unguentaria)

valetudinarium

Varus senatorial class

camp superintendent's residence, near the principia (Latin)

staff building usually placed at the centre of the fort, with offices and weaponry rooms. Opposite entrance was an assembly area and court room (Latin)

Unknown Roman author, whose essay De munitionibus castrorum (camp fortifications), has survived

GIS term referring to a hand-held device used in association with a digitising table for accurately digitising maps, plans and aerial photographs

databases that feature a relational data model that permits the designer to create a consistent logical model of the information to be stored. Data is processed and retrieved using SQL statements. Microsoft Access is the most commonly used relational database management system

sanctuary (Latin)

village in Norfolk, England

highest social class, members eligible to be selected to senate

Lucius Septimius Severus, Roman emperor (193 - 211 CE)

GIS term referring to the file format used to exchange data for ArcView or ArcGIS. The filename extension is named .shp

Structured Query Language (SQL) is the standard computer language used with relational databases

bronze or iron instrument with a curved blade, for scraping the sweat and dirt from the skin after exercise or in bath

pointed instrument used as a pen (Latin)

place of business, shop, office or stall (Latin)

P(?). Cornelius Tacitus, Roman historian, born c. $56 \underline{\mathrm{CE}}$

literally 'stamped clay', refers to type of red burnished Roman pottery that often had a maker's stamp in the base (Italian)

Four emperors who ruled together - Diocletian, Maximian, Galerian and Constantius (293 - $324 \underline{\text { CE})}$

Tagged Image File Format (TIFF) is a commonly used raster or bitmap graphics file format. A bitmap file represents images as a collection of pixels (dots)

one of six officer's beneath the commanding officer of a legion, or aristocratic status

term invented by archaeologists for small bottle, thought to have contained unguents (Latin)

sick room or hospital (Latin)

Publius Quintilius Varus ( 46 - $9 \underline{\mathrm{CE}}$ ), Roman general whose three legions were utterly defeated by Germans in the Teutoberg Forest, east of the Rhine (near modern Kalkriese) in 9 CE. Led to withdrawal of Roman army from east bank of Rhine

vector graphics describes the use of geometrical primitives such as points, lines, curves, 
and polygons to represent images in computer graphics software

vertices

GIS term describing one of a set of ordered $X Y$ co-ordinates that constitute a line

via principalis

vicus (vici)

Vindolanda

Vindonissa

XY coordinates

main street running across centre of camp, in front of principia (Latin)

term used for small village which was often established outside walls of fort, usually at same time as fort (see also canabae) (Latin)

Roman fort on Hadrian's Wall ( c. 85 - $130 \underline{\underline{C E}}$ )

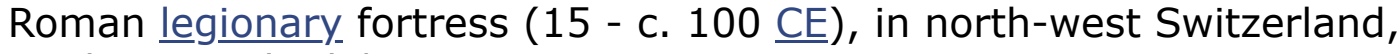
modern Windisch/Brugg

GIS term describing a two-dimensional, planar co-ordinate system in which $X$ measures horizontal distance and $Y$ measures vertical distance. An XY co-ordinate defines each point on the plane. Relative measures of distance, area, and direction are constant throughout the co-ordinate plane

\section{back forward contents home}

(C) Internet Archaeology URL: http://intarch.ac.uk/journal/issue17/4/glossary.html

Last updated: Mon Apr 42005 